\title{
Parental psychological control and adolescent problem behaviors: The role of depressive symptoms
}

\author{
Katelyn F. Romm
}

Follow this and additional works at: https://researchrepository.wvu.edu/etd

\section{Recommended Citation}

Romm, Katelyn F., "Parental psychological control and adolescent problem behaviors: The role of depressive symptoms" (2017). Graduate Theses, Dissertations, and Problem Reports. 6529.

https://researchrepository.wvu.edu/etd/6529

This Thesis is protected by copyright and/or related rights. It has been brought to you by the The Research Repository @ WVU with permission from the rights-holder(s). You are free to use this Thesis in any way that is permitted by the copyright and related rights legislation that applies to your use. For other uses you must obtain permission from the rights-holder(s) directly, unless additional rights are indicated by a Creative Commons license in the record and/ or on the work itself. This Thesis has been accepted for inclusion in WVU Graduate Theses, Dissertations, and Problem Reports collection by an authorized administrator of The Research Repository @ WVU. For more information, please contact researchrepository@mail.wvu.edu. 
Parental Psychological Control and Adolescent Problem Behaviors: The Role of Depressive Symptoms

\author{
Katelyn F. Romm, M.S. \\ Thesis submitted to the \\ Eberly College of Arts and Sciences \\ at West Virginia University \\ in partial fulfillment of the requirements \\ for the degree of \\ Master of Science \\ in \\ Psychology \\ Aaron Metzger, Ph.D., Chair \\ Amy Gentzler, Ph.D. \\ Cheryl McNeil, Ph.D. \\ Department of Psychology \\ Morgantown, West Virginia \\ 2016
}

Keywords: parental psychological control, depressive symptoms, adolescent problem behaviors

Copyright 2016 Katelyn Romm 


\begin{abstract}
Parental Psychological Control and Adolescent Problem Behaviors: The Role of Depressive

Symptoms

The current study examined the role of depressive symptoms as both a process variable (mediator), as well as a risk factor (moderator) for the association between psychological control and adolescent health-risk behaviors. Participants included 161 adolescents $\left(M_{\text {age }}=14.42, \mathrm{SD}=\right.$ $1.73 ; 80.7 \%$ Caucasian; $59.6 \%$ female) living in a University city in a Mid-Atlantic state. Participants completed survey questionnaires about parental psychological control, eating behaviors, cyber behaviors, substance use, and depressive symptoms. Results indicated that psychological control had significant indirect and direct effects on under-eating behaviors, as well as significant indirect effects on risky cyber behaviors and substance use. Additionally, psychological control was found to be associated positively with risky cyber behaviors and substance use for adolescents with greater depressive symptoms, but not adolescents with fewer depressive symptoms. The findings provide support for the indirect associations between psychological control and adolescent problem behaviors through adolescent depressive symptoms, as well as the role of depressive symptoms as a risk factor for the associations between psychological control and problem behaviors.
\end{abstract}




\section{ACKNOWLEDGEMENTS}

I would like to thank Dr. Aaron Metzger, my academic advisor and thesis chair for his guidance and support throughout this project. I would also like to thank Dr. Amy Gentzler and Dr. Cheryl McNeil for the time and helpful feedback they have provided. Additionally, I would like to thank my fellow lab members, Lauren Alvis and Rebecca Olson for their continued support. Lastly, my family members and friends have been an incredible source of support throughout this process. 


\section{TABLE OF CONTENTS}

Page

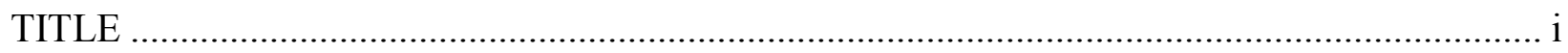

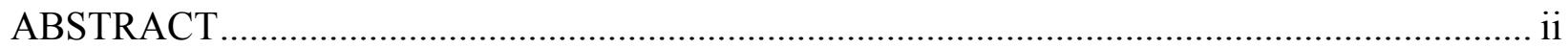

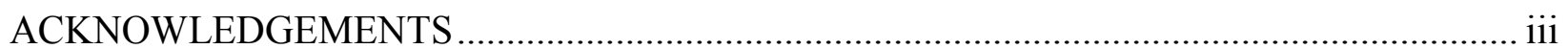

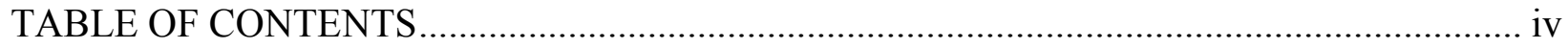

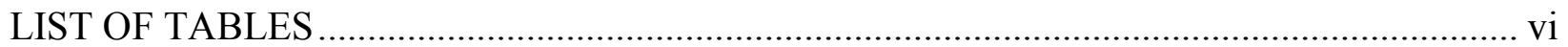

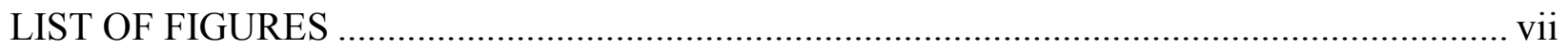

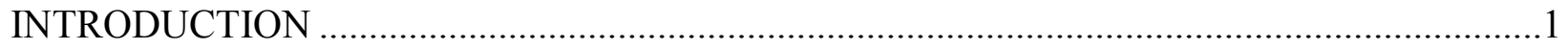

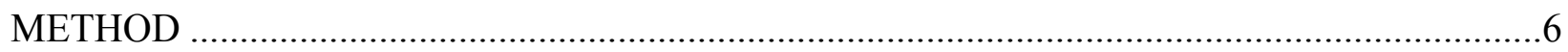

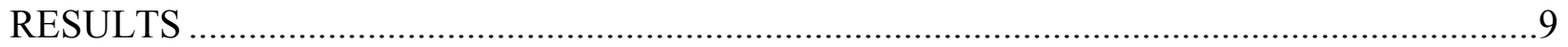

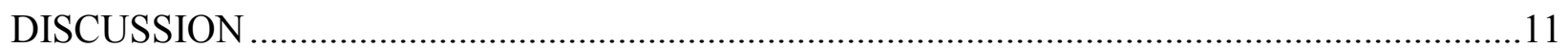

LIMITATIONS AND FUTURE DIRECTIONS ............................................................ 15

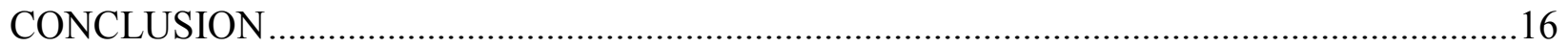

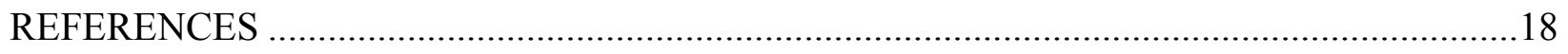

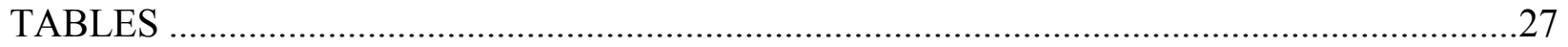

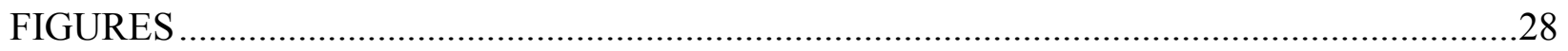

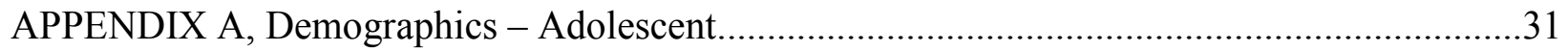

APPENDIX B, Parental Psychological Control Scale, Youth Self-Report ................................33

APPENDIX C, Dutch Eating Behavior Questionnaire ........................................................34

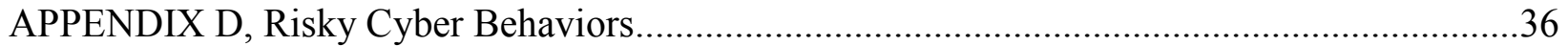

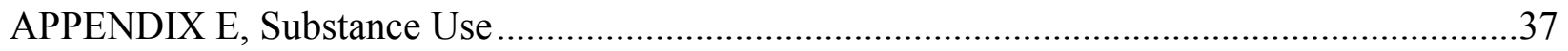

APPENDIX F, Center for Epidemiological Studies - Depression (CES-D) ..............................38 
APPENDIX G, Extended Literature Review and Methods .........................................................

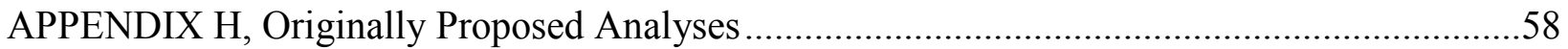

APPENDIX I, Psychological Control and Family Rules as Predictors .........................................64

APPENDIX J, Discrepancies between Perceived and Desired Decision-Making Autonomy as a

Mediator

APPENDIX K, Discrepancies between Perceived and Desired Decision-Making Autonomy as a

Moderator .68

APPENDIX L, Principal Components Analysis of Parental Psychological Control. .69 


\section{LIST OF TABLES}

Table 1

Descriptive Statistics and Correlations for Key Study Variables 


\section{LIST OF FIGURES}

Figure 1

The associations between psychological control and adolescent problematic outcomes

Figure 2

The indirect effects of psychological control through depressive symptoms

Figure 3 ...... 30

Psychological control predicting problem behaviors moderated by depressive symptoms 
Parental Psychological Control and Adolescent Problem Behaviors: The Role of Depressive Symptoms

The role of parenting on the psychological development of children and adolescents has been examined by researchers across numerous fields. The parent-child relationship has been viewed as both salient and volatile during adolescence, as adolescents experience numerous developmental changes, including a push for greater levels of autonomy and independence, leading to transformations in the parent-child relationship (Collins \& Steinberg, 2006; Steinberg, 2001). While a blend of both parental support and behavioral control is ideal for adolescent development (Barber \& Xia, 2013; Baumrind, 1971), some forms of parental control, including psychological control, are associated with poor developmental outcomes during adolescence (Barber, 1996; Finkenauer, Engels, \& Baumeister, 2005; Silk, Morris, Kanaya, \& Steinberg, 2003; Soenens, Vansteenkiste, Luyten, Duriez, \& Goossens, 2005). Behavioral control focuses on the regulation of the adolescent's behavioral world, with higher levels associated with greater youth safety, adjustment, and self-esteem (Crouter, MacDermid, McHale, \& Perry-Jenkins, 1990; Dishion \& Loeber, 1985; Peterson, Ewigman, \& Kivlahan, 1993). Parental psychological control, on the other hand, refers to the manipulation of the adolescent's psychological world through tactics such as guilt induction, love withdrawal, and conditional approval to pressure the adolescent to feel, think, and behave in ways that are consistent with the parents' own feelings, thoughts, and behaviors (Barber, 1996; Schaefer, 1965). Because it is emotionally manipulative in nature, psychological control has a negative impact on adolescents' psychological well-being and is associated with greater depressive symptoms (Soenens, Vansteenkiste, \& Luyten, 2010). Psychological control has also been consistently linked to numerous unhealthy and problematic behaviors during adolescence, including both over- (Snoek, Engels, Janssens, \& van Strien, 
2007) and under-eating behaviors (Bruch, 1985; Minuchin, Rosman, \& Baker, 1978), risky cyber activities (Li, Li, \& Newman, 2013), and illicit substance use (Galambos, Barker, \& Almeida, 2003). Given that adolescents with greater depressive symptoms often engage in higher levels of problem behaviors as a means of coping with their internalizing symptoms (Perle et al., 2013), it is possible that the negative effects of parental psychological control on adolescent problem behaviors may be mediated or explained by adolescent depressive symptoms. Alternatively, the deleterious effects of psychological control may be exacerbated for youth who are already experiencing greater levels of depressive symptoms. The current study examined adolescent depressive symptoms as both a process variable (mediator), as well as a risk factor (moderator) for the association between psychological control and four adolescent problem behaviors, including over-eating behaviors, under-eating behaviors, risky cyber behaviors, and substance use.

Psychological control has consistently been linked to numerous internalizing problems during adolescence, including lower levels of self-esteem and higher levels of depression and anxiety (Barber, 1996; Barber, Olsen, \& Shagle, 1994; Soenens et al., 2005). Previous research has posited that the emotionally manipulative nature of psychological control is especially responsible for these negative effects (Barber, Maughan, \& Olsen, 2005). Psychologically controlling parents lack the empathic capacities necessary to properly respond to their adolescent's physical, emotional, and psychological needs (Barber et al., 2005). This intrusive parenting often interferes with the adolescent's autonomy development and is therefore typically associated with greater dependence on parents, social isolation, and depressive symptoms (Barber \& Xia, 2013; Soenens et al., 2010). In line with this idea, psychological control has been found to be associated with depressive symptoms over and above the influence of parental 
behavioral control and parental warmth in both cross-sectional and longitudinal studies (Barber, 1996; Barber et al., 1994; Conger, Conger, \& Scaramella, 1997; Gray \& Steinberg, 1999; Herman, Dornbusch, Herron, \& Herting, 1997; Soucy \& Larose, 2000).

Depressive symptoms are also predictive of a wide range of problem behaviors during adolescence (Perle et al., 2013; Pesola et al., 2015; Skinner, Haines, Austin, \& Field, 2012; Tokunaga \& Rains, 2010). Depressive symptoms experienced during early adolescence have been linked to higher levels of alcohol consumption later in adolescence, such that adolescents with greater depressive symptoms at baseline exhibited higher levels of alcohol use when assessed five years later (Pesola et al., 2015). Depressive symptoms have also been identified as a risk factor that predispose adolescents to engage in problematic Internet use, such as cyberbullying, talking to strangers, and posting inappropriate photos and/or messages, over and above the influence of adolescent anxiety and loneliness (Tokunaga \& Rains, 2010). Adolescent depressive symptoms have been found to be longitudinally predictive of problematic eating behaviors, as well. Specifically, adolescents with greater depressive symptoms engaged in higher levels of both over-eating behaviors, including emotional and external eating (Skinner et al., 2012), as well as under-eating behaviors (e.g., a drive for thinness and body dissatisfaction; Soenens et al., 2008). Depressed youth have been found to be particularly vulnerable to deviant peer affiliations, placing them at greater risk for engagement in substance use (Fontaine, 2006; Miller-Johnson, Lochman, Coie, Terry, \& Hyman, 1998). Alternatively, youth high in depressive symptoms have been theorized to engage in health-risk behaviors, including over-eating behaviors, risky cyber behaviors, and illicit substance use as a way of either coping directly with their depressive symptoms (Faith et al., 1997; Hutchinson \& Rapee, 2007; Perle et al., 2013) or reducing the frustration of social rejection (Berkowitz, 1989; Davis, 2001). It has also been 
suggested that adolescents with greater depressive symptoms engage in under-eating behaviors in an attempt to reduce negative affect and regain control over appearance (Hutchinson \& Rapee, 2007; Koenig \& Wasserman, 1995).

The above pattern of research findings hint at the possibility that increases in depressive symptoms may explicate the links between psychological control and adolescents' engagement in problematic and health-risk behaviors. Adolescents who experience the intrusive nature of parental psychological control are often susceptible to greater parental dependence and social isolation, placing them at greater risk for depressive symptoms (Barber, 1996; Barber, Olsen, \& Shagle, 1994; Soenens et al., 2005). Furthermore, adolescents with greater depressive symptoms often engage in health-risk behaviors as a means of either directly coping with their depressive symptoms or with the social rejection associated with depressive symptoms (Berkowitz, 1989; Davis, 2001; Faith et al., 1997; Hutchinson \& Rapee, 2007; Perle et al., 2013). That is, psychologically controlled youth may experience greater depressive symptoms, which may in turn be associated with higher levels of problem behaviors, including over-eating behaviors, under-eating behaviors, risky cyber behaviors, and substance use. The current study will shed light upon depressive symptoms as a potential psychological mechanism accounting for the association between parental psychological control and adolescent health-risk behaviors. A greater understanding of such explanatory mechanisms will aid practitioners in targeting specific factors for youth experiencing negative parenting behaviors.

Alternatively, the effects of psychological control may be amplified by adolescent depressive symptoms. Belsky (2005) argued that children with higher levels of negative emotionality are more sensitive to parental influences, placing them at greater risk for experiencing problematic outcomes in the face of negative parenting. Consistent with this idea, 
children with a difficult temperament or higher levels of fearfulness and irritability experienced greater adjustment problems in response to poor parenting compared to children with an easy temperament or lower levels of fearfulness and irritability (Lengua, 2008; Sanson, Oberklaid, Pedlow, \& Prior, 1991). It has been suggested that children with greater levels of internalizing symptoms, including anxiety and depressive symptoms, may be more adversely affected by parental rejection because they tend to internalize the rejection and criticism (Gruner, Muris, \& Merckelbach, 1999). However, little research has examined whether adolescent depressive symptoms increase youth susceptibility to the negative influences of parental psychological control. Psychological control often involves both criticism and rejection through the use of conditional approval and love withdrawal (Barber, 1996), so it is likely that adolescents with greater depressive symptoms will be more sensitive to these negative parenting practices, placing them at greater risk for the problem behaviors associated with psychological control.

The first aim of the current study was to examine whether adolescent depressive symptoms helped to explicate the association between parental psychological control and adolescent problem behaviors. It was hypothesized that psychological control would be indirectly associated with adolescents' over-eating behaviors, under-eating behaviors, risky cyber behaviors, and substance use through adolescents' depressive symptoms. The second aim of the current study was to examine whether the association between parental psychological control and adolescent problem behaviors varied as a function of adolescents' depressive symptoms. It was hypothesized that associations between parental psychological control and problem behaviors would be stronger for adolescents with higher levels of depressive symptoms. Adolescents' perception of parental psychological control, internalizing symptoms, and engagement in problem behaviors has been found to vary based upon demographic factors 
(Pettit, Laird, Dodge, Bates, \& Criss, 2001; Scaramella, Conger, \& Simons, 1999; van der Ende \& Verhulst, 2005), as well as parenting behaviors (Steinberg, 2001). Therefore, structural models controlled for adolescent age and gender, as well as family rules and parental warmth.

\section{Method}

\section{Participants}

Participants were drawn from a study of adolescents living in a University city in a MidAtlantic state. Participants were 161 adolescents (96 women, 65 men; $M_{a g e}=14.42, S D=1.73$, range $=12-18$ ) recruited from various organizations in which they were involved, including Boy's and Girl's club, church youth groups, and youth sport organizations. A local medical clinic and three local high-schools were also involved with participant recruitment. The medical clinic mailed parent information letters and recruitment flyers to the parents of adolescents. Furthermore, graduate students and undergraduate research assistants recruited participants in classrooms, as well as at school and community-related events. Each participating adolescent was required to recruit at least one adult primary caregiver, including any biological parent, stepparent, legal guardian, aunt, uncle, or grandparent. Most adolescents reported that they identified as Caucasian/White (81\%) and received either mostly A's or some A's and some B's in school $(73 \%)$.

\section{Procedure}

The majority of the family visits took place in participants' homes. However, some additional family visits took place at the research lab and in community-group locations (e.g. public library, church). Caregivers gave informed consent for themselves and their adolescent before participating, while adolescents gave informed assent before participating. After giving informed consent and assent, all participants received payment for participating: \$25 for each 
participating parent and $\$ 50$ for participating adolescents. The adolescent was then asked to complete survey questionnaires about parental psychological control, depressive symptoms, eating behaviors, cyber behaviors, and substance use in a separate room.

\section{Measures}

Psychological Control Scale-Youth Self-Report. To assess parental psychological control, adolescents completed the Psychological Control Scale-Youth Self-Report by Barber (1996). Participants were instructed to rate the extent to which each item is descriptive of their parents. The scale included 16 items, such as "will avoid looking at me when I have disappointed them" and the participant was asked to rate each item on a 5-point Likert-type scale from 1 (Never) to 5 (Always). Mean scores were computed by averaging responses to each of the 16 items $(\alpha=.89)$.

Center for Epidemiological Studies - Depression (CES-D). Depressive symptoms were measured using the 20-item Center for Epidemiological Studies Depression inventory (CES-D; Radloff, 1977). Participants were asked to rate the frequency of depressive symptoms experienced within the past week on a Likert-type scale from 0 (rarely or none of the time) to 3 (most or all of the time). Sample items included "During the past week, I was bothered by things that usually don't bother me" and "During the past week, I thought my life had been a failure." Mean scores were calculated for each adolescent $(\alpha=.76)$.

Problematic eating behaviors. The Dutch Eating Behavior Scale (van Strien, Frijters, Bergers, \& Defares, 1986) was used to measure restrained, external, and emotional eating behaviors. Participant responses were measured on a 5-point Likert-type scale $(1=$ Never $)$ to $(5$ $=$ Very Often). Higher scores on each subscale (restrained, external, and emotional eating) were associated with higher levels of problematic eating behaviors. Participants' scores on the external 
and emotional eating subscales were combined in an over-eating behavior scale. Participants' scores on the restrained eating subscale were used to measure under-eating behavior. Sample items included "When you have put on weight, do you eat less than you usually do?" and "Do you have a desire to eat when you have nothing to do?" Mean scores were calculated for the over-eating behavior scale $(\alpha=.93)$ and the under-eating behavior scale $(\alpha=.90)$ with higher scores indicating higher levels of problematic eating behaviors.

Risky cyber behaviors. Adolescents' risky Internet and cell-phone behaviors were measured using an 8-item self-report measure. Participants were asked to rate how often in the last 30 days they engaged in risky Internet and cell-phone behaviors $(1=0$ days, $2=1$ day, $3=$ 2-3 days, 4 = 4-6 days, $5=7-10$ days, $6=11+$ days). Sample items included "How often in the last 30 days have you posted photos on Facebook involving alcohol and drug use?" and "How often in the last 30 days have you added friends on Facebook whom you have never met offline?" Mean scores were calculated for each adolescent with higher scores indicating greater engagement in risky cyber behaviors $(\alpha=.62)$.

Illicit substance use. Adolescent substance use was measured using an 8-item self-report scale asking participants to rate how often in the last three months they have engaged in alcohol behaviors. Participants were asked to record their responses on a Likert-type scale from 1 (Never) to 4 (Often). Sample items included "In the last 3 months, how often have you drank alcohol?" and "In the last 3 months, how often have you drank so much you got sick?" In addition, participants' past substance use was measured using three items from a larger Adolescent Delinquency measure. Participants were asked to rate how often in the past 30 days they engaged in substance use behaviors on a Likert-type scale from 1 (Never) to 4 (Often). Sample items included "In the past 30 days, how often have you smoked marijuana?" and "In 
the past 30 days, how often have you used prescription medications not meant for you?" Mean scores were calculated with higher scores indicating higher levels of substance use $(\alpha=.87)$.

\section{Planned Analyses}

Data were analyzed using structural equation models (SEM) in SPSS Amos 24. Significant paths were interpreted upon achieving an adequate fit (Kline, 2005, CMIN/DF < $2.00, \mathrm{CFI}>.90, \mathrm{RMSEA}<.08)$. In all analyses, nonsignificant pathways were trimmed to increase parsimony. To assess the first hypothesis, a path model examined the direct associations between parental psychological control and adolescent problem behaviors. Next, a model was run with depressive symptoms included as a mediator between psychological control and youth problem outcomes. Bootstrapped standard errors were used to determine significance of indirect paths (Kline, 2005). The second hypothesis was examined using multi-group models to explore whether associations between parental psychological control and adolescent problem behaviors varied as a function of adolescent depressive symptoms. The fit of an unconstrained model that freely estimated structural paths for adolescents with higher levels of depressive symptoms and adolescents with lower levels of depressive symptoms was compared to the fit of a model that constrained structural paths to be equal. Critical ratios were investigated to determine whether paths significantly differed for adolescents high vs. low in depressive symptoms.

\section{Results}

\section{Data Cleaning and Preliminary Analyses}

Analyses were performed to assess missing data, outliers, and the distribution of all continuous variables. There was one missing data point for the substance use scale and one missing data point for the CES-D inventory. Mean scores were created based on the items 
participants did complete. Results did not differ when these participants were removed from analyses. Means, standard deviations, and bivariate correlations for key study variables can be found in Table 1.

\section{Depression as a Mediator between Parental Psychological Control and Youth Problematic}

\section{Outcomes}

A structural equation model was performed with parental psychological control predicting adolescents' over-eating behaviors, under-eating behaviors, risky cyber behaviors, substance use, and depressive symptoms, while controlling for adolescent age, adolescent gender, family rules, and parental warmth (Figure 1). Variables with significant bivariate correlations were allowed to covary. Standardized regression coefficients for all direct effects are reported in Figure 1. The proposed model provided an adequate fit to the data $(\mathrm{CMIN} / \mathrm{DF}=1.99$, $\mathrm{CFI}=.93$, RMSEA $=.08$ ). Results suggested that parental psychological control was associated positively with adolescents' under-eating behaviors $(\beta=.17, \mathrm{SE}=.10, p<.05)$, risky cyber behaviors $(\beta=.20, \mathrm{SE}=.06, p<.01)$, substance use $(\beta=.19, \mathrm{SE}=.04, p<.01)$, and depressive symptoms $(\beta=.24, \mathrm{SE}=.06, p<.01)$. Parental psychological control was not associated significantly with over-eating behaviors. Examination of critical ratios indicated that these paths did not significantly differ (C.R. < 1.96).

Next, a path model examined the indirect effects of parental psychological control on adolescents' over-eating behaviors, under-eating behaviors, risky cyber behaviors, and substance use through adolescent depressive symptoms (see Figure 2). Independent variables that were significantly correlated were allowed to freely covary. Standardized regression coefficients for all direct and indirect effects can be found in Figure 2. The model provided an adequate fit to the data $(\mathrm{CMIN} / \mathrm{DF}=1.85, \mathrm{CFI}=.91, \mathrm{RMSEA}=.07)$. Results indicated that parental psychological 
control was associated positively with adolescent depressive symptoms, and adolescent depressive symptoms were associated positively with adolescents' under-eating behaviors, risky cyber behaviors, and substance use. An examination of the bootstrapped indirect effects indicated that psychological control had both significant indirect, $\beta=.10,95 \% \mathrm{CI}[.04, .18]$, and direct effects, $\beta=.17,95 \%$ CI $[.04, .31]$, on adolescents' under-eating behaviors. However, psychological control had only a significant indirect effect on adolescents' risky cyber behaviors $\beta=.09,95 \% \mathrm{CI}[.05, .16]$, and adolescents' substance use $\beta=.07,95 \% \mathrm{CI}[.03, .14]$. Psychological control did not have a significant indirect or direct effect on adolescents' overeating behaviors.

\section{Depression as a Moderator}

Multi-group analyses at low and high levels of depression indicated the model in which structural paths were allowed to freely vary provided a better fit compared to the model in which structural paths were constrained to be equal $\left(\Delta X^{2}(9)=36.38, p<.001\right.$; see Figure 3). Critical ratios indicated that parental psychological control was associated positively with risky cyber behaviors for adolescents with higher levels of depressive symptoms $(\beta=.24, p<.05$, C.R. $=$ 2.05) but not adolescents with lower levels of depressive symptoms. Additionally, parental psychological control was associated positively with substance use for adolescents with higher levels of depressive symptoms $(\beta=.19, p<.05$, C.R. $=2.48)$ but not adolescents with lower levels of depressive symptoms.

\section{Discussion}

The results of the current study provide new insights into the processes through which parental psychological control influences adolescents' problem behaviors, as well as risk factors for the negative impact of psychological control. Specifically, the findings provide support for 
the indirect associations between psychological control and adolescents' under-eating behaviors, risky cyber behaviors, and substance use through adolescent depressive symptoms. Results also indicate that youth depressive symptoms may amplify the association between psychological control and both risky cyber behaviors and illicit substance use.

Consistent with previous research and with hypotheses, adolescents with higher levels of perceived parental psychological control reported higher levels of under-eating behaviors (Bowen, 1985; Bruch, 1985; Minuchin, Rosman, \& Baker, 1978), higher levels of problematic Internet use, including cyberbullying, talking to strangers, and posting inappropriate pictures or messages (Li et al., 2013), higher levels of alcohol use and illicit substance use (Galambos et al., 2003), as well as greater depressive symptoms (Soenens et al., 2010).

Depressive symptoms were found to be a significant explanatory variable for many of the problem outcomes tested in the model. Results indicated that psychological control was both directly and indirectly associated with adolescents' under-eating behaviors. Moreover, psychological control was found to be indirectly associated with both risky cyber behaviors, as well as substance use, through adolescent depressive symptoms. Additionally, the direct paths between psychological control and both risky cyber behaviors, as well as substance use, were no longer significant when depressive symptoms were incorporated in the model. Taken together, the findings suggest that adolescent depressive symptoms are an important explanatory mechanism accounting for the association between parental psychological control and both risky cyber behaviors and substance use. Although parental psychological control was found to be indirectly associated with adolescents' under-eating behaviors through depressive symptoms, it is likely that additional mechanisms may also be contributing to this association, as psychological control remained directly linked to under-eating behaviors when depressive 
symptoms were incorporated into the model. Thus, findings indicate that one potential reason that psychological control is associated with increased risk behavior is because adolescents who are psychologically controlled experience greater levels of depressive symptoms, which, in turn, put them at increased risk of engaging in a range of problem and health risk behaviors.

Parental psychological control is theorized to increase adolescents' depressive symptoms because it involves the use of love withdrawal, guilt induction, and conditional approval in order to pressure the adolescent to think, feel, and behave in a manner consistent with the parent's own thoughts, feelings, and behaviors (Soenens et al., 2009). Adolescents strive for greater levels of autonomy and increased independence from their parents (Barber, 1996; Finkenauer et al., 2005; Soenens et al., 2005), but due to its emotionally manipulative and intrusive nature, psychological control typically interferes with this developmental task and is instead associated with adolescents' dependence upon their parents and social isolation, typically placing the adolescent at risk for depressive symptoms (Barber, 1996; Finkenauer et al., 2005; Soenens et al., 2005). The current study raises the possibility that psychologically controlled adolescents may engage in under-eating behavior, alcohol consumption, or risky internet behavior as a means of directly coping with their depressive symptoms stemming from the social isolation and inhibited autonomy that are influenced by experiencing high levels of psychological control (Berkowitz, 1989; Davis, 2001; Faith et al., 1997; Hutchinson \& Rapee, 2007; Koenig \& Wasserman, 1995; Perle et al., 2013). As much of the previous research has explored psychological control as a direct predictor of adolescent health-risk behaviors, the current findings place emphasis upon the importance of future researches to examine depressive symptoms as a mediator of psychological control. The findings also provide practitioners with a point of intervention for adolescents with psychologically controlling parents. For instance, it may be difficult for practitioners to identify 
parents' engagement in psychological control, but targeting the depressive symptoms of adolescents who are experiencing psychological control may be one way to decrease youth engagement in various health-risk behaviors.

In addition to serving as an explanatory mechanism, the current study also hints at the possibility that depressive symptoms may also be a risk factor that enhances the negative effects of psychological control, particularly for adolescent cyber behaviors and illicit substance use. Psychological control was only associated positively with risky cyber behaviors and substance use for adolescents with higher levels of depressive symptoms. These findings are consistent with previous research, which suggests that adolescents with greater depressive symptoms pay more attention to and are more susceptible to the influences of negative parenting behaviors (Belsky, 2005). Adolescents with greater depressive symptoms typically experience greater social isolation from peers, which further increases the strength of negative parenting behaviors (Rubin et al., 1990). As parental psychological control was not associated with risky cyber behaviors and substance use for adolescents with fewer depressive symptoms, the current findings also suggest that the effects of psychological control may be less deleterious for adolescents who are experiencing low levels of depressive symptomatology.

Interestingly, depressive symptoms did not exacerbate the association between parental psychological control and adolescent under-eating behaviors. It is likely that this association did not vary as a function of adolescents' depressive symptoms, as adolescents often engage in under-eating behaviors in order to regain emotional control in response to parental psychological control, which is emotionally intrusive and interferes with the adolescent's autonomy and development (Rorty et al., 2000; strong \& Huon, 1998). These findings not only highlight the role of adolescent depressive symptoms as a psychological factor that may explain the 
association between parental psychological control and certain adolescent health-risk behaviors, but the findings also suggest that adolescents with fewer depressive symptoms may fare well, despite the influence of parental psychological control on certain health-risk behaviors.

\section{Limitations and Future Directions}

The present study's findings should be interpreted in light of several limitations. First, the current study utilized a cross-sectional, correlational design, which limits the ability to make causal or directional inferences. Although the current study examined parental psychological control as a predictor of problem behaviors, it is possible that adolescents' engagement in problem behaviors influences parents' use of psychological control. Therefore, future research should examine the role of depressive symptoms as both a mediator and a moderator of the association between parental psychological control and adolescent problem behaviors using a longitudinal design to better understand the direction of the associations. An additional limitation is the use of self-report data. It is important for future studies to use multiple informant reports and observational data of parental psychological control, as well as adolescent problematic outcomes, as self-report measures are susceptible to social desirability biases, which may be of concern, as adolescents often under report their engagement in problem behaviors (Thayer \& Hutchinson, 2012). The use of a single reporter may also have increased common method variance. Furthermore, the sample was limited in terms of diversity, as most of the participants identified as white and reported receiving mostly A's and B's in school. Therefore, the current study should be replicated in more diverse samples with regards to race/ethnicity, as well as academic success, to increase the generalizability of the findings.

As parental psychological control was not directly or indirectly associated with adolescents' over-eating behaviors in the current study, future research should explore alternative 
predictors of over-eating behaviors, such as parent-child communication, parental monitoring, and parental modeling of eating behaviors. Specifically, parents who communicate openly with their adolescents about health behaviors, including over-eating behaviors have been found to have adolescents who engage in lower levels of over-eating (Topham et al., 2011), as positive parent-adolescent communication fosters adolescents' sense of autonomy, allowing them to make better health-related decisions (Grolnick, 2003; Jelalian et al., 2014). It also remains important for future researchers to explore additional mediators that may help to explain the association between parental psychological control and different types of adolescent health-risk behaviors. In addition to depressive symptoms, adolescents' emotion-regulation strategies and self-efficacy have been found to mediate the association between parental psychological control and problematic outcomes, including aggressive behaviors and academic performance (Cui, Morris, Criss, Houltberg, \& Silk, 2014; Filippello, Sorrenti, Buzzai, \& Costa, 2015). Therefore, research should begin to explore differential mediation pathways for the association between parental psychological control and adolescent health-risk behaviors in order to determine whether psychological control is indirectly associated with different types of adolescent healthrisk behaviors through different mechanisms.

\section{Conclusion}

The current study is among the first to investigate adolescent depressive symptoms as one of the underlying mechanisms explaining why parental psychological control contributes to adolescent problem behaviors, and provide support for the premise of depressive symptoms as a risk factor for the negative influences of parental psychological control. Findings urge researchers to continue to examine the mechanisms through which psychological control is associated with adolescent problem behaviors in order to determine whether psychological 
control is associated with various adolescent problem behaviors through different types of mechanisms, such as emotion regulation and self-efficacy, in addition to depressive symptoms. Finally, the results place emphasis upon the importance of accounting for characteristics of the adolescent that may place them at greater risk for the negative outcomes associated with psychological control, as adolescent depressive symptoms were found to serve as a risk factor for the negative influences of parental psychological control in the current study. 


\section{References}

Barber, B. K. (1996). Parental psychological control: Revisiting a neglected construct. Child Development, 67, 3296-3319. http://dx.doi.org/10.2307/1131780

Barber, B. K., Maughan, S. L., \& Olsen, J. A. (2005). Patterns of parenting across adolescence. New Directions for Child and Adolescent Development, 108, 5-16. http://dx.doi.org/10 $.1002 / \mathrm{cd} .124$

Barber, B. K., Olsen, J. E., \& Shagle, S. C. (1994). Associations between parental psychological and behavioral control and youth internalized and externalized behaviors. Child Development, 65, 1120-1136. http://dx.doi.org/10.2307/1131309

Barber, B. K., \& Xia, M. (2013). The centrality of control to parenting and its effects. In A. S. Morris, R. E. Larzelere, \& A. W. Harrist (Eds.), New directions for authoritative parenting (pp. 61-87). Washington, DC: American Psychological Association.

Baumrind, D. (1971). Current patterns of parental authority. Developmental Psychology, 4, 1-103. http://dx.doi.org/10.1037/h0030372

Belsky, J. (2005). Differential susceptibility to rearing influences: An evolutionary hypothesis and some evidence. In B. Ellis \& D. Bjorklund (Eds.), Origins of the social mind: Evolutionary psychology and child development (pp. 139-163). New York, NY: Guilford.

Berkowitz, L. Frustration-aggression hypothesis: Examination and reformulation. Psychological Bulletin, 106, 59-73. http://dx.doi.org/10.1037/0033-2909.106.1.59

Bruch, H. (1985). Four decades of eating disorders. In D. M. Garner \& P. E. Garfinkel (Eds.), Handbook of psychotherapy for anorexia and bulimia (pp. 7-18). New York: Guilford. 
Collins, W. A., \& Steinberg, L. (2006). Adolescent development in interpersonal context. In N. Eisenberg, W. Damon \& R M. Lerner (Eds.), Handbook of Child Psychology: Vol. 3, Social, Emotional, and Personality Development (pp. 1003-1067). Hoboken, NJ: John Wiley \& Sons.

Conger, K. J., Conger, R. D., Scaramella, L. V. (1997). Parents, siblings, psychological control, and adolescent adjustment. Journal of Adolescent Research, 12, 113-138. http://dx.doi . org/10.1177/0743554897121007

Crouter, A. C., MacDermid, S. M., McHale, S. M., \& Perry-Jenkins, M. (1990). Parental monitoring and perceptions of children's school performance and conduct in dual and single-earner families. Developmental Psychology, 26, 649-657. http://dx.doi.org/10.1037 /0012-1649.26.4.649

Cui, L., Morris, A. S., Criss, M. M., Houltberg, B. J., \& Silk, J. S. (2014). Parental psychological control and adolescent adjustment: The role of adolescent emotion regulation. Parenting: Science and Practice, 14, 47-67. http://dx.doi.org/10.1080/15295192.2014.880018

Davis, R. A. (2001). A cognitive-behavioral model of pathological Internet use (PIU). Computers in Human Behavior, 17, 187-195. http://dx.doi.org/10.1016/S0747 $-5632(00) 00041-8$

Dishion, T. J., \& Loeber, R. (1985). Adolescent marijuana and alcohol use: The role of parents and peers revisited. The American Journal of Drug and Alcohol Abuse, 11, 11 -25. http://dx.doi.org/10.3109/00952998509016846

Galambos, N. L., Barker, E. T., \& Almeida, D. M. (2003). Parents do matter: Trajectories of change in externalizing and internalizing problems in early adolescence. Child Development, 74, 578-594. http://dx.doi.org/10.1111/1467-8624.7402017 
Faith, M. S., Allison, D. B., \& Geleibter, A. (1997). Emotional eating and obesity: Theoretical considerations and practical recommendations. In S. Dalton (Ed.), Overweight and weight management: The health professional's guide to understanding and practice (pp.439 -465). Gaithersburg, MD: Aspen Press.

Filippello, P., Sorrenti, L., Buzzai, C., \& Costa, S. (2015). Perceived parental psychological control and learned helplessness: The role of school self-efficacy. School Mental Health, 7, 298-310. http://dx.doi.org/10.1007/s12310-015-9151-2

Fontaine, R. G. (2006). Evaluative behavioral judgments and instrumental antisocial behaviors in children and adolescents. Clinical Psychology Review, 26, 956-967. http://dx.doi.org/10 $.1016 /$ j.cpr.2006.07.003

Finkenauer, C., Engels, R. C. M. E., \& Baumeister, R. F. (2005). Parenting behavior and adolescent behavioural and emotional problems: The role of self-control. International Journal of Behavioral Development, 29, 58-69. http://dx.doi.org10.1080 $/ 01650250444000333$

Gray, M. R., \& Steinberg, L. (1999). Unpacking authoritative parenting: Reassessing a multidimensional construct. Journal of Marriage and Family, 61, 574-587. http://dx.doi . org $/ 10.2307 / 353561$

Grolnick, W. S. (2003). The psychology of parental control: How well-meant parenting Backfires. Mahwah, NJ: Erlbaum Publishers.

Gruner, K., Muris, P., Merckelbach, H. (1999). The relationship between anxious rearing behaviours and anxiety disorders symptomatology in normal children. Journal of Behavior Therapy and Experimental Psychiatry, 30, 24-35. http://dx.doi.org/10.1016 /S0005-7916(99)00004-X 
Herman, M. R., Dornbusch, S. M., Herron, M. C., \& Herting, J. R. (1997). The influence of family regulation, connection, and psychological autonomy on six measures of adolescent functioning. Journal of Adolescent Research, 12, 34-67. http://dx.doi.org/10.1177 /0743554897121004

Hutchinson, D. M., \& Rapee, R. M. (2009). Do friends share similar body image and eating problems? The role of social networks and peer influences in early adolescence. Behavior Research and Therapy, 45, 1557-1577. http://dx.doi.org/10.1016/j.brat.2006.11.007

Jelalian, E., Hadley, W., Sato, A., Kuhl, E., Rancourt, D., Oster, D., \& Lloyd-Richardson, E. (2014). Adolescent weight control: An intervention targeting parent communication and modeling compared with minimal parent involvement. Journal of Pediatric Psychology, 40, 202-213. http://dx.doi/org/10.1093/jpepsy/jsu082

Kline, R. B. (2005). Principles and practice of structural equation modeling (2nd ed.). New York: Guilford.

Koenig, L., \& Wasserman, E. L. (1995). Body image and dieting failure in college men and women: Examining links between depression and eating problems. Sex Roles, 32, 225 -249. http://dx.doi.org/10.1007/BF1544790

Lengua, L. J. (2008). Anxiousness, frustration, and effortful control as moderators of the relation between parenting and adjustment in middle-childhood. Temperament and Parenting in Middle-Childhood, 17, 554-577. http://dx.doi.org/10.1111/j.1467-9507.2007.00438.x

Li, X., Li, D., \& Newman, J. (2013). Parental behavioral and psychological control and Problematic internet use among Chinese adolescents: The mediating role of self-control. Cyberpsychology, Behavior, and Social Networking, 16, 442-447. http://dx.doi.org /10.1089/cyber.2012.0293 
Miller-Johnson, S., Lochman, J. E., Coie, J. D., Terry, R., \& Hyman, C. (1998). Comorbidity of conduct and depressive problems at sixth grade: Substance use outcomes across adolescence. Journal of Abnormal Child Psychology, 26, 221-232. http://dx.doi.org/10 $.1023 / \mathrm{A}: 1022676302865$

Minuchin, S., Rosman, B.L., \& Baker, L. (1978). Psychosomatic families: Anorexia nervosa in context. Cambridge, MA: Harvard University Press.

Nguyen-Rodriguez, S. T., Unger, J. B., Spruijt-Metz, D. (2009). Psychological determinants of emotional eating in adolescence. Eating Disorders, 17, 211-224. http://dx.doi.org/10 $.1080 / 10640260902848543$

Perle, J. G., Levine, A. B., Odland, A. P., Ketterer, J. L., Cannon, M. A., \& Marker, C. D. (2013). The association between internalizing symptomatology and risky behaviors. Journal of Child and Adolescent Substance Use, 22, 1-24. http://dx.doi.org/10.1080 /1067828X.2012.724289

Pesola, F., Shelton, K. H., Heron, J., Munafo, M., Hickman, M., \& van den Bree, M. B. M. (2015). The developmental relationship between depressive symptoms in adolescence and harmful drinking in emerging adulthood: The Role of Peers and Parents. Journal of Youth and Adolescence, 44, 1752-1766. http://dx.doi.org/10.1007/s10964-015-0295-z

Peterson, L., Ewigman, B., \& Kivlahan, C. (1993). Judgments regarding appropriate child supervision to prevent injury: The role of environmental risk and child age. Child Development, 64, 934-950. http://dx.doi.org/10.2307/1131228 
Pettit, G. S., Laird, R. D., Dodge, K. A., Bates, J. E., \& Criss, M. M. (2001). Antecedents and behavior-problem outcomes of parental monitoring and psychological control in early adolescence. Child Development, 72, 583-598. http://dx.doi.org/10.1111/1467-8624 .00298

Radloff, L.S. (1977). The CES-D scale: A self-report depression scale for research in the general population. Applied Psychological Measurement, 1, 385-401. http://dx.doi.org/10.1177 /014662167700100306

Rorty, M., Yager, J., Rossotto, E., Buckwalter, G. (2000). Parental intrusiveness in adolescence recalled by women with a history of bulimia nervosa and comparison women. International Journal of Eating Disorders, 28, 202-208. http://dx.doi.org/10.1002-1098 $-108 X(200009) 28: 2<202::$ AID-EAT9 $>3.0 \mathrm{CO} ; 2-\mathrm{G}$

Rubin, K. H., LeMare, L. J., \& Lollis, S. (1990). Social withdrawal in childhood: Developmental pathways to peer rejection. In S. R. Asher \& J. D. Coie (Eds.), Peer rejection in childhood (pp. 217-249). New York: Cambridge University Press.

Scaramella, L. V., Conger, R. D., Simons, R. L. (1999). Parental protective influences and gender-specific increases in adolescent internalizing and externalizing problems. Journal of Research on Adolescence, 9, 111-141. http://dx.doi.org/10.1207/s15327795jra0902_1

Schaefer, E. S. (1965). A configurational analysis of children's reports of parent behavior. Journal of Consulting Psychology, 29, 552-557. http://dx.doi.org/10.1037/h0022702

Silk, J. S., Morris, A. S., Kanaya, T., \& Steinberg, L. (2003). Psychological control and autonomy granting: Opposite ends of a continuum or distinct constructs? Journal of Research on Adolescence, 13, 113-128. http://dx.doi.org/10.1111/1532-7795.1301004 
Skinner, H. H., Haines, J., Austin, S. B., \& Field, A. E. (2012). A prospective study of overeating, binge eating, and depressive symptoms among adolescent and young adult women. Journal of Adolescent Health, 50, 478-483. http://dx.doi.org/10.1016 /j.jadohealth.2011.10.002

Snoek, H. M., Engels, R. C. M. E., Janssens, J. M. A. M., \& van Strien, T. (2007). Parental behavior and adolescents" emotional eating. Appetite, 49, 223-230. http://dx.doi.org /10.1016/j.appet.2007.02.004

Soenens, B., Vansteenkiste, M., \& Luyten, P. (2010). Toward a domain-specific approach to the study of parental psychological control: Distinguishing between dependency-oriented and achievement-oriented psychological control. Journal of Personality, 78, 217-256. http://dx.doi.org/10.1111/j.1467-6494.2009.00614.x

Soenens, B., Vansteenkiste, M., Luyten, P., Duriez, B., \& Goossens, L. (2005). Maladaptive perfectionistic self-representations: The mediational link between psychological control and adjustment. Personality and Individual Differences, 38, 487-498. http://dx.doi.org /10.1016/j.paid.2004.05.008

Soenens, B., Vansteenkiste, M., Vandereycken, W., Luyten, P., Sierens, E., \& Goossens, L. (2008). Perceived parental psychological control and eating-disordered symptoms: Maladaptive perfectionism as a possible intervening variable. The Journal of Nervous and Mental Disease, 196, 144-152. http://dx.doi.org/10.1097/NMD.0b013e318162aabf

Soucy, N., \& Larose, S. (2000). Attachment and control in family and mentoring contexts as determinants of adolescent adjustment to college: Attachment and adjustment. Journal of Family Psychology, 14, 125-143. http://dx.doi.org/10.1037/0893-3200.14.1.125 
Steinberg, L. (2001). We know some things: Parent-adolescent relationships in retrospect And prospect. Journal of Research in Adolescence, 11, 1-19. http://dx.doi.org $/ 10.1111 / 1532-7795.00001$

Strong, K. G., \& Huon, G. F. (1998). An evaluation of a structural model for studies of the initiation of dieting among adolescent girls. Journal of Psychosomatic Research, 44, 315 -326. http://dx.doi.org/10.1016/S0022-3999(97)00257-2

Thayer, R., \& Hutchison, K. E. (2012). Improving accuracy of adolescents's substance use reports via Text Messaging. Addiction, 107, 1015-1016. http://dx.doi.org/10.1111/j.1360-0443 $.2011 .03768 . x$

Tokunaga, R. S., \& Rains, S. A. (2010). An evaluation of two characteristics of the relationships between problematic internet use, time spent using the internet, and psychosocial problems. Human Communication Research, 36, 512-545. http://dx.doi.org/10.1111/j $.1468-2958.2010 .01386 . x$

Topham, G. L., Hubbs-Tait, L., Rutledge, J. M., Page, M. C., Kennedy, T. S., Shriver, L. H., \& Harrist, A. W. (2011). Parenting styles, parental response to child emotion, and family emotional responsiveness are related to child emotional eating. Appetite, 56, 261-264. http://dx.doi.org/10.1016/j.appet.2011.01.007

van der Ende, J., \& Verhulst, F. C. (2005). Informant, gender, and age differences in ratings of adolescent problem behavious. European Child and Adolescent Psychiatry, 14, 117-126. http://dx.doi.org/10.1007/s00787-005-0438-y 
van Strien, T., Frijters, J.E., Bergers, G.P., \& Defares, P.B. (1986). The Dutch Eating Behavior Questionnaire (DEBQ) for assessment of restrained, emotional, and external eating behavior. International Journal of Eating Disorders, 5, 295-315. http://dx.doi.org /10.1002/1098-108X(198602)5:2<295::AID-EAT2260050209>3.0.CO;2-T 
Table 1

Descriptive Statistics and Correlations for Key Study Variables $(N=161)$

\begin{tabular}{|c|c|c|c|c|c|c|c|c|c|c|}
\hline & $M(S D)$ & Age & Rules & Warmth & P Control & Depression & Over & Under & Cyber & Substance \\
\hline Age & $14.42(1.73)$ & --- & & & & & & & & \\
\hline Rules & $3.32(0.64)$ & $-0.46^{* *}$ & --- & & & & & & & \\
\hline Warmth & $3.11(0.63)$ & $-0.32 * *$ & $0.31 * *$ & --- & & & & & & \\
\hline P Control & $2.24(0.74)$ & 0.06 & -0.12 & $-0.54 * *$ & --- & & & & & \\
\hline Depression & $0.74(0.55)$ & 0.06 & -0.01 & $-0.39 * *$ & $0.39 * *$ & --- & & & & \\
\hline Over & $2.47(0.70)$ & 0.13 & -0.13 & $-0.31 * *$ & $0.26 * *$ & $0.20 * *$ & --- & & & \\
\hline Under & $2.26(0.85)$ & 0.11 & 0.09 & $-0.28 * *$ & $0.28 * *$ & $0.36 * *$ & $0.20 *$ & --- & & \\
\hline Cyber & $1.31(0.58)$ & $0.32 * *$ & $-0.29 * *$ & $-0.25^{* *}$ & $0.23 * *$ & $0.30 * *$ & 0.12 & $0.16^{*}$ & --- & \\
\hline Substance & $1.32(0.52)$ & $0.47 * *$ & $-0.47 * *$ & $-0.26 * *$ & $0.23 * *$ & $0.25 * *$ & $0.19 *$ & $0.17 *$ & $0.52 * *$ & --- \\
\hline
\end{tabular}

Note. Some variable names have been shortened; $\mathrm{P}$ Control $=$ Psychological Control; Over $=$ Overeating; Under $=$ Undereating; Cyber $=$ Risky Cyber Behaviors; Substance $=$ Substance Use $* p<.05, * * p<.01, * * * p<.001$ 


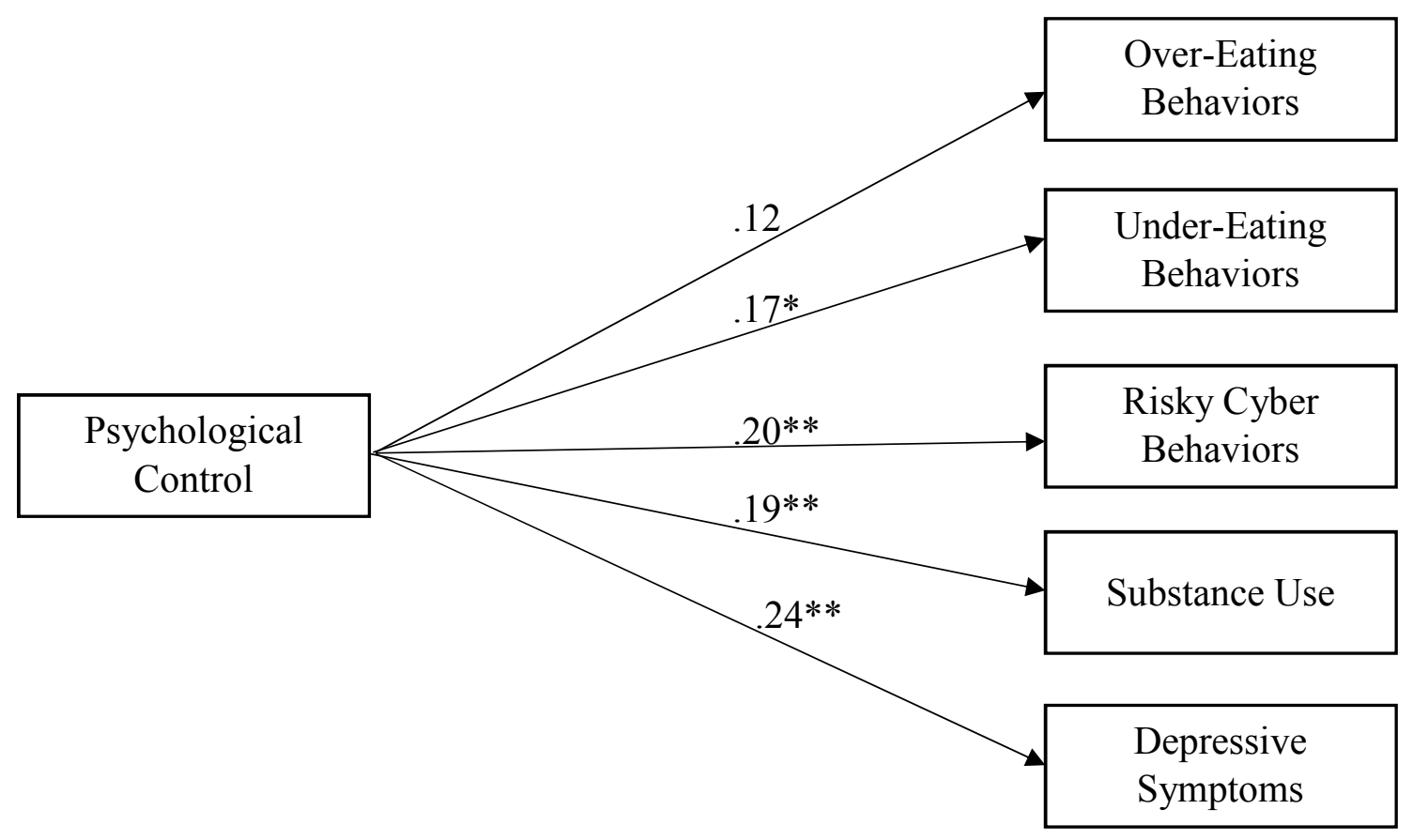

Figure 1. The associations between psychological control and adolescent problematic outcomes. All estimates are standardized coefficients.

$* p<.05, * * p<.01, * * * p<.001$ 


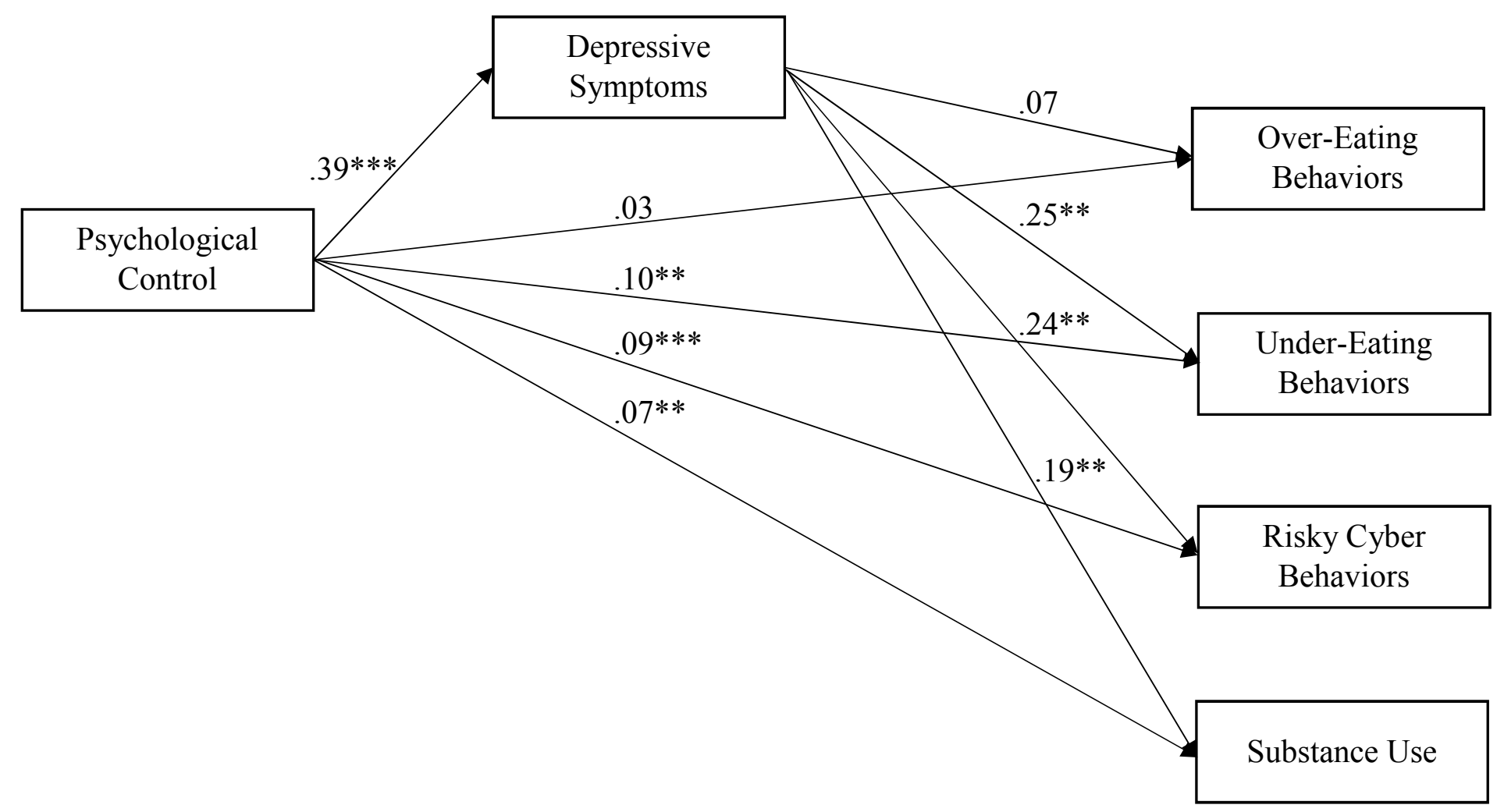

Figure 2. The indirect effects of psychological control through depressive symptoms. All estimates are standardized coefficients.

$* p<.05, * * p<.01, * * * p<.001$ 


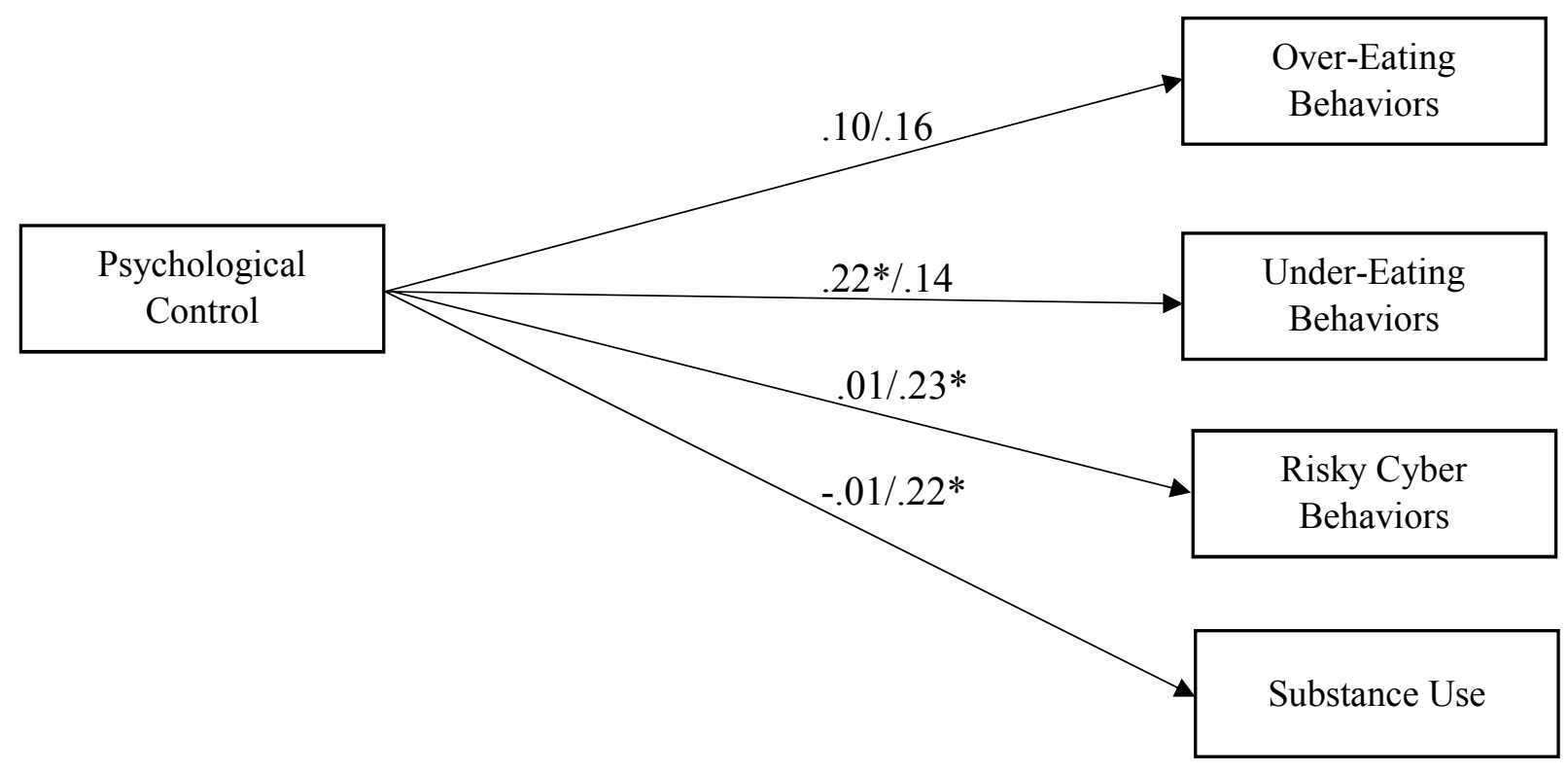

Figure 3. Psychological control predicting problem behaviors moderated by depressive symptoms. All estimates are standardized coefficients.

Note. Coefficients on the left are for adolescents with lower levels of depressive symptoms. Coefficients on the right are for adolescents with higher levels of depressive symptoms. $* p<.05, * * p<.01, * * * p<.001$ 


\section{Appendix A}

\section{Demographics - Adolescent}

\section{Demographics}

1. What gender are you?

Male Female

2. How old are you? (years) What is your birthday?

(Month/Day/Year)

3. What is your grade in school? $6^{\text {th }} 7^{\text {th }} 8^{\text {th }} 9^{\text {th }} \quad 10^{\text {th }} 11^{\text {th }} 12^{\text {th }}$

4. School grades (Please circle):

Mostly A's

Some A's some B's

Mostly B's

Some B's some C's

Mostly C's

Some C's some D's

Mostly D's or lower

5. What is your ethnicity (Please circle)?

African-American/Black Hispanic/Latino

Asian-American/Pacific Islander Native American

Caucasian/White Other (describe)

6. Who currently lives in your home (Circle all that apply)?

mother (birth or adopted) stepmother

father (birth or adopted) stepfather

brothers/sisters? (ages of siblings)

other adults (who?)

7. What is the highest level of schooling your mother (or female guardian) completed?

Completed $8^{\text {th }}$ grade

Completed high school

Completed college

Graduate degree (doctor, lawyer, $\mathrm{PhD}$ )

Don't know or unsure

At what type of JOB does your MOTHER work?
8. What is the highest level of schooling your father (or male guardian) completed?

Completed $8^{\text {th }}$ grade

Completed high school

Completed college

Graduate degree (doctor, lawyer, $\mathrm{PhD}$ )

Don't know or unsure

At what type of JOB does your FATHER work? 
17. How much education would you like to get?

I don't care if I finish high school

I want to finish high school

I want some college

I want to finish a four-year college

I want more education after college, such as a graduate or professional degree (such as a law, medical, doctorate/Ph.D., business/M.B.A.)

18. What is your ideal future career?

19. Do you participate in the free or reduced lunch program?

\&o $\quad$ Yes

20. Have you ever been diagnosed with a reading disability?

No $\quad$ Yes

21. Do you currently receive tutoring for reading?

\&o Yes 


\section{Appendix B}

\section{Parental Psychological Control Scale - Youth Self-Report}

Each of the following statements asks about your feelings about your parent(s) or guardian(s). Please circle the response that best applies.

\begin{tabular}{|l|c|c|c|c|c|}
\hline My parents... & $\begin{array}{c}\text { Never } \\
\text { True }\end{array}$ & $\begin{array}{c}\text { Sometimes } \\
\text { True }\end{array}$ & $\begin{array}{c}\text { Always } \\
\text { True }\end{array}$ \\
\hline $\begin{array}{l}\text { 1. change the subject, whenever I have something } \\
\text { to say. }\end{array}$ & 1 & 2 & 3 & 4 & 5 \\
\hline 2. finish my sentences whenever I talk. & 1 & 2 & 3 & 4 & 5 \\
\hline 3. often interrupt me. & 1 & 2 & 3 & 4 & 5 \\
\hline $\begin{array}{l}\text { 4. act like they know what I'm thinking or } \\
\text { feeling. }\end{array}$ & 1 & 2 & 3 & 4 & 5 \\
\hline $\begin{array}{l}\text { 5. would like to be able to tell me how to feel } \\
\text { or think about things all the time. }\end{array}$ & 1 & 2 & 3 & 4 & 5 \\
\hline $\begin{array}{l}\text { 6. are always trying to change how I feel or think } \\
\text { about things. }\end{array}$ & 1 & 2 & 3 & 4 & 5 \\
\hline 7. blame me for other family members' problems. & 1 & 2 & 3 & 4 & 5 \\
\hline $\begin{array}{l}\text { 8. bring up my past mistakes when they criticizes } \\
\text { me. }\end{array}$ & 1 & 2 & 3 & 4 & 5 \\
\hline $\begin{array}{l}\text { 9. tell me that I am not a loyal or good member } \\
\text { of the family. }\end{array}$ & 1 & 2 & 3 & 4 & 5 \\
\hline $\begin{array}{l}\text { 10. tell me of all the things they have done } \\
\text { for me. }\end{array}$ & 1 & 2 & 3 & 4 & 5 \\
\hline $\begin{array}{l}\text { 11. say, if I really cared about them, I would } \\
\text { not do things that cause them to worry. }\end{array}$ & 1 & 2 & 3 & 4 & 5 \\
\hline $\begin{array}{l}\text { 12. are less friendly with me, if I do not see } \\
\text { things } \\
\text { their way. }\end{array}$ & 1 & 2 & 3 & 4 & 5 \\
\hline $\begin{array}{l}\text { 13. will avoid looking at me when I have } \\
\text { disappointed them. }\end{array}$ & 1 & 2 & 3 & 4 & 5 \\
\hline $\begin{array}{l}\text { 14. if I have hurt their feelings, stop talking } \\
\text { to me until I please them again. }\end{array}$ & 1 & 2 & 3 & 4 & 5 \\
\hline 15. often changes their moods when with me. & 2 & 3 & 4 & 5 \\
\hline $\begin{array}{l}\text { 16. go back and forth between being warm and } \\
\text { critical toward me. }\end{array}$ & 1 & 3 & 5 \\
\hline
\end{tabular}




\section{Appendix C}

\section{Dutch Eating Behavior Questionnaire}

\begin{tabular}{|c|c|c|c|c|c|}
\hline Eating behavior questions & Never & Seldom & Sometimes & Often & $\begin{array}{l}\text { Very } \\
\text { often }\end{array}$ \\
\hline $\begin{array}{l}\text { 1. When you have put on weight, do you eat } \\
\text { less than you usually do? }\end{array}$ & 1 & 2 & 3 & 4 & 5 \\
\hline $\begin{array}{l}\text { 2. Do you try to eat less at mealtimes than } \\
\text { you would like to eat? }\end{array}$ & 1 & 2 & 3 & 4 & 5 \\
\hline $\begin{array}{l}\text { 3. How often do you refuse food or drinks } \\
\text { offered because you are concerned about } \\
\text { your weight? }\end{array}$ & 1 & 2 & 3 & 4 & 5 \\
\hline 4. Do you watch exactly what you eat? & 1 & 2 & 3 & 4 & 5 \\
\hline $\begin{array}{l}\text { 5. Do you deliberately eat foods that are } \\
\text { slimming? }\end{array}$ & 1 & 2 & 3 & 4 & 5 \\
\hline $\begin{array}{l}\text { 6. When you have eaten too much, do you eat } \\
\text { less than usual the following day? }\end{array}$ & 1 & 2 & 3 & 4 & 5 \\
\hline $\begin{array}{l}\text { 7. Do you deliberately eat less in order not to } \\
\text { become heavier? }\end{array}$ & 1 & 2 & 3 & 4 & 5 \\
\hline $\begin{array}{l}\text { 8. How often do you try not to eat between } \\
\text { meals because you are watching your } \\
\text { weight? }\end{array}$ & 1 & 2 & 3 & 4 & 5 \\
\hline $\begin{array}{l}\text { 9. How often in the evenings do you try not } \\
\text { to eat because you are watching your } \\
\text { weight? }\end{array}$ & 1 & 2 & 3 & 4 & 5 \\
\hline $\begin{array}{l}\text { 10. Do you take into account your weight with } \\
\text { what you eat? }\end{array}$ & 1 & 2 & 3 & 4 & 5 \\
\hline $\begin{array}{l}\text { 11. Do you have the desire to eat when you are } \\
\text { irritated? }\end{array}$ & 1 & 2 & 3 & 4 & 5 \\
\hline $\begin{array}{l}\text { 12. Do you have a desire to eat when you have } \\
\text { nothing to do? }\end{array}$ & 1 & 2 & 3 & 4 & 5 \\
\hline $\begin{array}{l}\text { 13. Do you have a desire to eat when you are } \\
\text { depressed or discouraged? }\end{array}$ & 1 & 2 & 3 & 4 & 5 \\
\hline $\begin{array}{l}\text { 14. Do you have a desire to eat when you are } \\
\text { feeling lonely? }\end{array}$ & 1 & 2 & 3 & 4 & 5 \\
\hline $\begin{array}{l}\text { 15. Do you have a desire to eat when } \\
\text { somebody lets you down? }\end{array}$ & 1 & 2 & 3 & 4 & 5 \\
\hline
\end{tabular}




\begin{tabular}{|c|c|c|c|c|c|}
\hline $\begin{array}{l}\text { 16. Do you have a desire to eat when you are } \\
\text { angry or upset? }\end{array}$ & 1 & 2 & 3 & 4 & 5 \\
\hline $\begin{array}{l}\text { 17. Do you have a desire to eat when you are } \\
\text { expecting something unpleasant to } \\
\text { happen? }\end{array}$ & 1 & 2 & 3 & 4 & 5 \\
\hline $\begin{array}{l}\text { 18. Do you get the desire to eat when you are } \\
\text { anxious, worried or tense? }\end{array}$ & 1 & 2 & 3 & 4 & 5 \\
\hline $\begin{array}{l}\text { 19. Do you have a desire to eat when things } \\
\text { are going against you or when things have } \\
\text { gone wrong? }\end{array}$ & 1 & 2 & 3 & 4 & 5 \\
\hline $\begin{array}{l}\text { 20. Do you have a desire to eat when you are } \\
\text { frightened? }\end{array}$ & 1 & 2 & 3 & 4 & 5 \\
\hline $\begin{array}{l}\text { 21. Do you have a desire to eat when you are } \\
\text { disappointed? }\end{array}$ & 1 & 2 & 3 & 4 & 5 \\
\hline $\begin{array}{l}\text { 22. Do you have a desire to eat when you are } \\
\text { emotionally upset? }\end{array}$ & 1 & 2 & 3 & 4 & 5 \\
\hline $\begin{array}{l}\text { 23. Do you have a desire to eat when you are } \\
\text { bored or restless? }\end{array}$ & 1 & 2 & 3 & 4 & 5 \\
\hline $\begin{array}{l}\text { 24. If food tastes good to you, do you eat more } \\
\text { than usual? }\end{array}$ & 1 & 2 & 3 & 4 & 5 \\
\hline $\begin{array}{l}\text { 25. If food smells and looks good, do you eat } \\
\text { more than usual? }\end{array}$ & 1 & 2 & 3 & 4 & 5 \\
\hline $\begin{array}{l}\text { 26. If you see or smell something delicious, do } \\
\text { you have a desire to eat it? }\end{array}$ & 1 & 2 & 3 & 4 & 5 \\
\hline $\begin{array}{l}\text { 27. If you have something delicious to eat, do } \\
\text { you eat it right away? }\end{array}$ & 1 & 2 & 3 & 4 & 5 \\
\hline $\begin{array}{l}\text { 28. If you walk past a convenience store or fast } \\
\text { food restaurant do you have the desire to } \\
\text { buy something delicious? }\end{array}$ & 1 & 2 & 3 & 4 & 5 \\
\hline $\begin{array}{l}\text { 29. If you walk past a snack bar or a café, do } \\
\text { you have the desire to buy something } \\
\text { delicious? }\end{array}$ & 1 & 2 & 3 & 4 & 5 \\
\hline $\begin{array}{l}\text { 30. If you see others eating, do you have the } \\
\text { desire to eat? }\end{array}$ & 1 & 2 & 3 & 4 & 5 \\
\hline 31. Can you resist eating delicious foods? & 1 & 2 & 3 & 4 & 5 \\
\hline $\begin{array}{l}\text { 32. Do you eat more than usual, when you see } \\
\text { others eating? }\end{array}$ & 1 & 2 & 3 & 4 & 5 \\
\hline $\begin{array}{l}\text { 33. When preparing a meal are you inclined to } \\
\text { eat something? }\end{array}$ & 1 & 2 & 3 & 4 & 5 \\
\hline
\end{tabular}




\section{Appendix D}

\section{Risky Cyber Behaviors}

\begin{tabular}{|c|c|c|c|c|c|c|}
\hline How often in the last 30 days... & $\begin{array}{c}0 \\
\text { times }\end{array}$ & $\begin{array}{c}1 \\
\text { time }\end{array}$ & $\begin{array}{c}2-3 \\
\text { times }\end{array}$ & $\begin{array}{c}4-6 \\
\text { times }\end{array}$ & $\begin{array}{l}7-10 \\
\text { times }\end{array}$ & $\begin{array}{c}11+ \\
\text { times }\end{array}$ \\
\hline $\begin{array}{l}\text { 1. You have posted photos on Facebook } \\
\text { involving alcohol and drug use }\end{array}$ & $\begin{array}{c}0 \\
\text { times }\end{array}$ & $\begin{array}{c}1 \\
\text { time }\end{array}$ & $\begin{array}{l}2-3 \\
\text { times }\end{array}$ & $\begin{array}{c}4-6 \\
\text { times }\end{array}$ & $\begin{array}{l}\text { 7-10 } \\
\text { times }\end{array}$ & $\begin{array}{c}11+ \\
\text { times }\end{array}$ \\
\hline $\begin{array}{l}\text { 2. You have posted sexually suggestive } \\
\text { photos of yourself or your friends on } \\
\text { Facebook }\end{array}$ & $\begin{array}{c}0 \\
\text { times }\end{array}$ & $\begin{array}{c}1 \\
\text { time }\end{array}$ & $\begin{array}{c}2-3 \\
\text { times }\end{array}$ & $\begin{array}{c}4-6 \\
\text { times }\end{array}$ & $\begin{array}{c}7-10 \\
\text { times }\end{array}$ & $\begin{array}{c}11+ \\
\text { times }\end{array}$ \\
\hline $\begin{array}{l}\text { 3. You have added friends on Facebook } \\
\text { whom you have never met offline. }\end{array}$ & $\begin{array}{c}0 \\
\text { times }\end{array}$ & $\begin{array}{c}1 \\
\text { time }\end{array}$ & $\begin{array}{l}2-3 \\
\text { times }\end{array}$ & $\begin{array}{l}4-6 \\
\text { times }\end{array}$ & $\begin{array}{l}7-10 \\
\text { times }\end{array}$ & $\begin{array}{c}11+ \\
\text { times }\end{array}$ \\
\hline 4. Your parents looked at your profile page & $\begin{array}{c}0 \\
\text { times }\end{array}$ & $\begin{array}{c}1 \\
\text { time }\end{array}$ & $\begin{array}{l}2-3 \\
\text { times }\end{array}$ & $\begin{array}{l}4-6 \\
\text { times }\end{array}$ & $\begin{array}{l}7-10 \\
\text { times }\end{array}$ & $\begin{array}{c}11+ \\
\text { times }\end{array}$ \\
\hline $\begin{array}{l}\text { 5. Your parents have talked to you about any } \\
\text { potential problems related to online } \\
\text { communications }\end{array}$ & $\begin{array}{c}0 \\
\text { times }\end{array}$ & $\begin{array}{c}1 \\
\text { time }\end{array}$ & $\begin{array}{c}2-3 \\
\text { times }\end{array}$ & $\begin{array}{c}4-6 \\
\text { times }\end{array}$ & $\begin{array}{c}7-10 \\
\text { times }\end{array}$ & $\begin{array}{c}11+ \\
\text { times }\end{array}$ \\
\hline 6. You have texted/sexted sexual photos & $\begin{array}{c}0 \\
\text { times }\end{array}$ & $\begin{array}{c}1 \\
\text { time }\end{array}$ & $\begin{array}{l}2-3 \\
\text { times }\end{array}$ & $\begin{array}{c}4-6 \\
\text { times }\end{array}$ & $\begin{array}{c}7-10 \\
\text { times }\end{array}$ & $\begin{array}{c}11+ \\
\text { times }\end{array}$ \\
\hline 7. You have texted/sexted sexual messages & $\begin{array}{c}0 \\
\text { times }\end{array}$ & $\begin{array}{c}1 \\
\text { time }\end{array}$ & $\begin{array}{c}2-3 \\
\text { times }\end{array}$ & $\begin{array}{c}4-6 \\
\text { times }\end{array}$ & $\begin{array}{c}\text { 7-10 } \\
\text { times }\end{array}$ & $\begin{array}{c}11+ \\
\text { times }\end{array}$ \\
\hline 8.You have texted mean or hurtful messages & $\begin{array}{c}0 \\
\text { times }\end{array}$ & $\begin{array}{c}1 \\
\text { time }\end{array}$ & $\begin{array}{c}2-3 \\
\text { times }\end{array}$ & $\begin{array}{c}4-6 \\
\text { times }\end{array}$ & $\begin{array}{c}7-10 \\
\text { times }\end{array}$ & $\begin{array}{c}11+ \\
\text { times }\end{array}$ \\
\hline
\end{tabular}




\section{Appendix E}

\section{Substance Use}

\begin{tabular}{|c|c|c|c|c|c|c|}
\hline In the last 3 months, how often have you... & Never & Rarely & Son & times & Often & $\begin{array}{l}\text { How } \\
\text { many } \\
\text { times }\end{array}$ \\
\hline 1. Drank alcohol? & 1 & 2 & & 3 & 4 & \\
\hline 2. Attended a party where alcohol was served? & 1 & 2 & & 3 & 4 & \\
\hline 3. Been drunk? & 1 & 2 & & 3 & 4 & \\
\hline 4. Drank so much you got sick? & 1 & 2 & & 3 & 4 & \\
\hline 5. Been offered alcohol by a friend? & 1 & 2 & & 3 & 4 & \\
\hline 6. Refused alcohol that was offered by a friend? & 1 & 2 & & 3 & 4 & \\
\hline 7. Accepted alcohol that was offered by a friend? & 1 & 2 & & 3 & 4 & \\
\hline 8. Hung around with kids who drink alcohol? & 1 & 2 & & 3 & 4 & \\
\hline \multicolumn{3}{|l|}{ In the PAST 30 DAYS, how often have you... } & Never & $\begin{array}{l}\text { Once } \\
\text { or } \\
\text { twice }\end{array}$ & $\begin{array}{c}\text { A } \\
\text { few } \\
\text { times }\end{array}$ & Often \\
\hline \multicolumn{3}{|l|}{ 8. Smoked cigarettes? } & 1 & 2 & 3 & 4 \\
\hline \multicolumn{3}{|c|}{ 9. Smoked marijuana? } & 1 & 2 & 3 & 4 \\
\hline \multicolumn{3}{|c|}{ 10. Used prescription medications not meant for you? } & 1 & 2 & 3 & 4 \\
\hline
\end{tabular}




\section{Appendix F}

\section{Center for Epidemiological Studies - Depression (CES-D)}

\begin{tabular}{|l|c|c|c|c|}
\hline During the past week: & $\begin{array}{c}\text { Less than } \\
1 \text { day }\end{array}$ & $\begin{array}{c}1-2 \\
\text { days }\end{array}$ & $\begin{array}{c}3-4 \\
\text { days }\end{array}$ & $\begin{array}{c}5-7 \\
\text { days }\end{array}$ \\
\hline $\begin{array}{l}\text { 1. I was bothered by things that usually don't bother } \\
\text { me }\end{array}$ & 1 & 2 & 3 & 4 \\
\hline 2. I did not feel like eating; my appetite was poor. & 1 & 2 & 3 & 4 \\
\hline $\begin{array}{l}\text { 3. I felt that I could not shake off the blues even with } \\
\text { help from my family or friends }\end{array}$ & 1 & 2 & 3 & 4 \\
\hline 4. I felt that I was just as good as other people & 1 & 2 & 3 & 4 \\
\hline $\begin{array}{l}\text { 5. I had trouble keeping my mind on what I was } \\
\text { doing }\end{array}$ & 1 & 2 & 3 & 4 \\
\hline 6. I felt depressed & 1 & 2 & 3 & 4 \\
\hline 7. I felt that everything I did was an effort & 1 & 2 & 3 & 4 \\
\hline 8. I felt hopeful about the future & 1 & 2 & 3 & 4 \\
\hline 9. I thought my life had been a failure & 1 & 2 & 3 & 4 \\
\hline 10. I felt tearful & 1 & 2 & 3 & 4 \\
\hline 11. My sleep was restless & 1 & 2 & 3 & 4 \\
\hline 12. I was happy & 1 & 2 & 3 & 4 \\
\hline 13. I talked less than usual & 1 & 2 & 3 & 4 \\
\hline 14. I felt lonely & 1 & 2 & 3 & 4 \\
\hline 15. People were unfriendly & 1 & 2 & 3 & 4 \\
\hline 16. I enjoyed life & 1 & 2 & 3 & 4 \\
\hline 17. I had crying spells & 1 & 2 & 3 & 4 \\
\hline 18. I felt sad & 1 & 2 & 3 & 4 \\
\hline 19. I felt that people disliked me & 1 & 2 & 3 & 4 \\
\hline 20. I could not get going & 1 & 2 & 4 \\
\hline
\end{tabular}




\section{Appendix G}

\section{Extended Literature Review and Methods}

Parental Psychological Control and Adolescent Outcomes: The Role of Decision-Making Autonomy

The role of parenting on the psychological development of children and adolescents has been examined by researchers across numerous fields. The parent-child relationship has been viewed as both salient and volatile during adolescence, as adolescents experience numerous developmental changes, including a push for greater levels of autonomy and independence, leading to transformations in the parent-child relationship (Steinberg, 2001). Researchers have recently begun to place increased emphasis upon the role of parental psychological control on adolescents' psychological outcomes and problem behaviors (Barber \& Harmon, 2002; Steinberg, 1990). Psychological control is associated with manipulative and intrusive parenting involving guilt induction, love withdrawal, and conditional approval and is associated with problematic outcomes throughout adolescence (Barber, 1996; Silk, Morris, Kanaya, \& Steingerg, 2003). However, little previous research explored mechanisms, which might explicate this association.

Developmental theory suggests that adolescents' level of autonomy may mediate the association between parental psychological control and adolescent problem behaviors. Adolescents' active attempts to gain more autonomy, which include increasing self-regulation, self-motivation, and independence, constitute a healthy and normative change that accompanies shifts in the ways teenagers think about themselves in relation to their parents (McElhaney, Allen, Stephenson, \& Hare, 2009; Zimmer-Gembeck \& Collins, 2003). However, parents may upset this delicate balance by engaging in high levels of psychological control (Barber, 1996; 
Hauser et al., 1984; Steinberg, 1990). Further, measures of autonomy have consistently been linked to various problem behaviors during adolescence, including both internalizing and externalizing problems, such that adolescents with an inhibited sense of autonomy express higher levels of problem behaviors (Barber \& Olsen, 1997). In addition to their perceived decisionmaking autonomy, adolescents' desired level of decision-making autonomy, defined as the amount of decision-making autonomy the adolescent believes they should have over various activities and behaviors, may impact their engagement in problem behaviors. Adolescents who receive lower levels of decision-making autonomy than they believe they should have reported higher levels of adjustment problems, compared to those adolescents who do not desire as much decision-making autonomy (Holmbeck \& O’Donnell, 1991).

Although researchers have provided evidence for associations between parental psychological control and adolescent autonomy, as well as adolescent autonomy and problem behaviors, there has not been any empirical work that has tested autonomy as a potential mediator of the association between psychological control and adolescent outcomes. Therefore, the present study explores the role of adolescents' perceived decision-making autonomy on the association between parental psychological control and adolescents' over-eating behaviors, under-eating behaviors, risky cyber behaviors, substance use, and depressive symptoms. Furthermore, it has been suggested that adolescents who desire higher levels of decision-making autonomy than they are granted will likely experience higher levels of problem behaviors compared to those adolescents with lower levels of desired decision-making autonomy (Holmbeck \& O’Donnell, 1991). Therefore, the present study also explored the role of adolescents' desired decision-making autonomy on the association between parental psychological control and adolescents' problem behaviors. 


\section{Parenting and Adolescent Developmental Outcomes}

An important aspect of parenting that has implications for the psychological well-being of adolescents is that of perceived parental control (Barber \& Xia, 2013). Much of the research that has examined the influence of parental control on adolescent adjustment has primarily focused on behavioral control, which involves parental monitoring, rules, and regulatory behaviors (Barber \& Xia, 2013; Baumrind, 1971). More recently, researchers have begun to conceptualize parental control as multidimensional and have emphasized a need to distinguish among two different types of control: behavioral control and psychological control (Barber, 1996). Appropriate levels of behavioral control are associated positively with youth safety, adjustment, and self-esteem during childhood and adolescence (Crouter, MacDermid, McHale, \& Perry-Jenkins, 1990; Dishion \& Loeber, 1985; Peterson, Ewigman, \& Kivlahan, 1993). Extremely low levels of parental behavioral control are associated with several negative outcomes, including higher levels of delinquent behavior and both externalizing and internalizing problems (Barber, Olsen, \& Shagle, 1994; Dishion \& MacMahon, 1998; Kerr \& Stattin, 2000).

Unlike behavioral control, parental psychological control involves manipulative and intrusive parenting through tactics such as guilt induction, love withdrawal, and conditional approval (Barber, 1996). While behavioral control typically targets the adolescent's behavior, psychological control often targets the wrongfulness of the adolescent as a person (Barber, 1996). Furthermore, researchers have suggested that parents who exhibit higher levels of psychological control tend to do so in order to pressure their adolescents to feel, think, and behave in ways that are consistent with the parents' own feelings, thoughts, and behaviors (Soenens, Vansteenkiste, \& Niemiec, 2009). While behavioral control is associated with positive outcomes, psychological control is associated with only negative outcomes during childhood and 
adolescence (Grolnick, 2003; Soenens et al., 2009). Specifically, children and adolescents with psychologically controlling parents exhibit lower levels of self-esteem, an inhibited sense of autonomy, and higher levels of depression, delinquency, and externalizing problems (Barber, 1996; Finkenauer, Engels, \& Baumeister, 2005; Soenens, Vansteenkiste, Luyten, Duriez, \& Goossens, 2004). Parental psychological control may be especially harmful during adolescence, as adolescents seek more independence from their parents and become more autonomous individuals (Vansteenkiste, Zhou, Lens, \& Soenens et al., 2005). It has been suggested that adolescents with lower levels of autonomy engage in higher levels of problem behavior as a way to protest against parental psychological control in order to claim their autonomy and independence, particularly in late adolescence (Allen, Hauser, O’Connor, \& Bell, 2002).

\section{Parental Psychological Control and Problem Behaviors}

Although researchers have extensively examined the association between parental psychological control and adolescents' problem behaviors, the extant research has not examined separate categories of problem behaviors, simultaneously. The role of parental psychological control on problem behaviors during adolescence has examined problem behaviors, such as delinquency, substance use, and aggressive behavior in separate studies (Barber, 1996; Cui, Morris, Criss, Houltberg, \& Silk, 2014). However, it is likely that parental psychological control influences problem behaviors differently depending on the perceived riskiness of the behavior. For instance, the influences of parental psychological control may vary across different problematic outcomes, such as over-eating behaviors, under-eating behaviors, risky cyber behaviors, illicit substance use, and depressive symptoms.

Parental psychological control has been found to be associated with numerous problematic outcomes during adolescence, including over-eating behaviors, under-eating 
behaviors, risky cyber behaviors, and illicit substance use (Galambos, Barker, \& Almeida, 2003; Li, Li, \& Newman, 2013; Reilly, Stey, \& Lapsley, 2015; Snoek, Engels, Janssens, \& van Strien, 2007). However, the influence of parental psychological control may vary based on the domain of the behavior (Smetana \& Daddis, 2002). Parental psychological control may be more strongly associated with behaviors that are considered to be prudential, such as illicit substance use than behaviors that are more multifaceted, such as cyber behaviors and eating behaviors. With regards to eating behaviors, parenting style likely influences the development of eating disturbances among adolescents, as psychological control has been found to be associated with problematic eating behaviors, including both restrained eating and emotional eating, such that adolescents with higher levels of perceived parental psychological control report higher levels of both restrained eating and emotional eating (Bowen, 1985; Bruch, 1985; Minuchin, Rosman, \& Baker, 1978; Reilly et al., 2015; Snoek et al., 2007).

Although parental behavioral control has been found to be consistently associated with cyber behaviors during adolescence, there has been far less research examining the role of parental psychological control on risky cyber behaviors. Problematic Internet use includes such behaviors as cyberbullying, talking to strangers, and posting inappropriate photos and/or messages. Parental behavioral control predicts reduced levels of problematic Internet use. Specifically, adolescents with parents who had greater rules about Internet use and used greater Internet-management strategies displayed lower levels of problematic Internet use (Alexander, Kang, \& Kim, 2006). In a study examining the differential roles of behavioral control and psychological control on problematic Internet use, adolescents with higher levels of parental behavioral control exhibited lower levels of problematic Internet use, while adolescents with higher levels of parental psychological control exhibited higher levels of problematic Internet use 
(Li et al., 2013). Since parental psychological control has been found to frustrate the satisfaction of competence, relatedness, and autonomy, it is suggested that psychological control triggers adolescents to attempt to satisfy these psychological needs through the use of the Internet (Li et al., 2013).

In addition to problematic eating behaviors and risky cyber behaviors, adolescents' perceived level of parental psychological control has been found to be associated with both alcohol use and illicit substance use during adolescence (Galambos et al., 2003). For instance, Galambos et al. (2003) found that adolescents with parents who engaged in higher levels of psychological control reported higher levels of problem behaviors, including school misconduct, substance use, antisocial behavior, and disobedience to parents compared to adolescents with parents who engage in lower levels of psychological control.

Parental psychological control has also been consistently linked with adolescents' depression (Elliot \& Thrash, 2004; Hunter, Barber, \& Stolz, 2014). Several psychosocial variables, including self-esteem, maladaptive perfectionism, and emotion regulation, have been found to mediate the association between parental psychological control and depression (Hunter et al., 2014; Soenens et al., 2005). However, the extant research has not yet investigated potential mediators for the association between psychological control and various types of problematic outcomes simultaneously. Developmental theory and previous research suggests that perceived decision-making autonomy may mediate not only the association between parental psychological control and over-eating behaviors, under-eating behaviors, risky cyber behaviors, and substance use, but that it may also explain the association between parental psychological control and depressive symptoms. For instance, adolescents with lower levels of perceived autonomy have 
been found to experience higher levels of depressed affect (Allen, Hauser, Eickholt, Bell, \& O’Connor, 1994).

Although parental psychological control has been found to be associated with a wide array of problematic outcomes, including over-eating behaviors, under-eating behaviors, risky cyber behaviors, substance use, delinquency, antisocial behaviors, and depression, researchers have not yet examined the role of psychological control on problematic outcomes simultaneously. Examining the influence of parental psychological control on different types of problematic outcomes within a single study may provide a better understanding concerning the relative negative impact of psychological control for different types of problematic outcomes during adolescence. For instance, although adolescents typically recognize the potential harm involved in problematic eating behaviors and risky cyber behaviors, adolescents typically view these problem behaviors as less harmful and problematic than other types of problem behaviors, such as substance use (Nucci \& Smetana, 1996; Smetana, 2011; Weber, Blais, \& Betz, 2002). Thus, adolescents may view various types of eating behaviors as personal and up for them to decide rather than focusing on the potential harm that could be associated with eating behaviors (Nucci \& Smetana, 1996). With regards to cyber use, researchers have found that adolescents often view Internet use as a means socialization and connection with friends, rather than focusing on the potential harm of risky cyber behaviors (Weber et al., 2002). Additionally, research has suggested that adolescents typically report substance use as involving high levels of harm, as well as a threat to personal safety and well-being (Smetana, 2011). Adolescents report parental psychological control as more legitimate over behaviors that they perceive as risky and involving higher levels of potential harm, such as substance use (Smetana \& Daddis, 2002). Therefore, the 
influence of psychological control may be differentially associated with various problematic outcomes depending upon the perceived level of risk and harm associated with the behavior. Autonomy and Adolescent Development

As adolescents strive to become autonomous individuals, it is important for them to maintain connections with parents while they work on establishing autonomy (Allen, Hauser, O’Connor, Bell, \& Eickholt, 1996). Adolescents who are able to successfully achieve this balance of feeling autonomy in their interactions with parents while still experiencing an emotional connection to parents typically experience positive outcomes throughout adolescence and later in life (Grotevant \& Cooper, 1985; Lamborn \& Steinberg, 1993; Noom, Dekovic, \& Meeus, 1999). Rather than completely individuating themselves from parents as theorists once suggested, researchers now explain adolescent autonomy development as a gradual process occurring throughout adolescence within warm and supportive relationships (Collins \& Steinberg, 2006; Feldman \& Wood, 1994).

Theorists have identified three dimensions of autonomy that develop throughout adolescence: emotional autonomy, value autonomy, and behavioral autonomy (Douvan \& Adelson, 1966). Emotional autonomy involves feeling independent from parents, value autonomy involves developing one's own set of values and beliefs, and behavioral autonomy involves the ability to make independent decisions and self-regulate behavior. When studying behavioral autonomy, researchers typically examine the level of the adolescent's independent decision-making within the family (Maccoby, 1984). Particular emphasis has been placed upon behavioral autonomy when studying the role of parenting. Additionally, behavioral autonomy is especially salient for adolescent development, as it is typically granted gradually throughout adolescence. Specifically, adolescents generally report increased levels of behavioral autonomy 
across adolescence, as family decision-making moves from complete parent-unilateral decisionmaking during early adolescence towards adolescent-unilateral decision-making in late adolescence (Daddis \& Smetana, 2005; Smetana, Campione-Barr, \& Daddis, 2004).

\section{Perceived Decision-Making Autonomy as a Mediator between Psychological Control and Youth Outcomes}

Although adolescent autonomy has been identified as healthy and normative, emphasis has been placed upon the role of parenting in promoting or upsetting this developmental process (McElhaney et al., 2009). Historically, it was argued that adolescents must become entirely independent from their parents and experience complete emotional separation in order to achieve autonomy (Blos, 1967; Freud, 1969). More recent researchers have suggested that it is beneficial for adolescents to maintain strong relationships with their parents as they gradually gain autonomy (Collins \& Steinberg, 2006; Smetana, Campione-Barr, \& Metzger, 2006; Steinberg, 2001). Achieving a balance between independence and closeness with parents is seen as essential for adolescents who are striving for autonomy (Hauser et al., 1984). However, not all parents encourage adolescents to function autonomously, and some may even discourage this process, upsetting adolescents' ability to balance independence and closeness. One way parents may upset this balance is by engaging in high levels of psychological control, which involves active attempts on the part of the parents to control the adolescent's psychological world (Barber, 1996; Hauser et al., 1984; Steinberg, 1990). Such behavior inhibits the adolescent's push for autonomy by undermining any thoughts, feelings, and behaviors that are inconsistent or unaligned with the thoughts and wishes of parents (Barber, 1996).

Parents' use of psychological control may undermine adolescents' attempts at identifying themselves as independent decision-makers (Barber \& Harmon, 2002). For instance, parents who 
exhibit high levels of psychological control often use guilt induction, love withdrawal, and conditional approval when adolescents make decisions that are not consistent with the parent's preferences, which often makes the adolescent feel incapable of being autonomous (Barber \& Harmon, 2002). Therefore, parental psychological control may be especially harmful for adolescents' behavioral autonomy, as psychological control undermines adolescents' attempts at identifying themselves as independent decision-makers (Barber \& Harmon, 2002).

Similar to psychological control, adolescent autonomy development is associated with and predictive of a range of adolescent outcomes. For instance, lower levels of adolescent perceived decision-making autonomy are associated with lower levels of self-esteem and higher levels of depression, delinquency, and externalizing problems (Barber \& Olsen, 1997). Although adolescents seek opportunities for increased independent decision-making as they get older, higher levels of perceived decision-making autonomy in early adolescence are not optimal. Youth-alone decision-making in early adolescence is associated with lower academic effort, lower academic performance, greater deviance, and poorer psychosocial development (Dornbusch, Ritter, Mont-Reynaud, \& Chen, 1990; Lamborn, Dornbusch, \& Steinberg, 1996; Smetana et al., 2004). In contrast, parent-alone decision-making has also been found to be associated with problematic outcomes for older adolescents. In a longitudinal study examining family decision-making among high school adolescents, researchers found that greater parentunilateral decision making was associated with lower psychosocial adjustment in late adolescence (Lamborn et al., 1996). Similarly, greater perceived autonomy during earlier adolescence has been linked with poorer adjustment, while increased perceived autonomy was associated with lower levels of depression and higher levels of self-worth in late adolescence (Smetana et al., 2004). Therefore, granting adolescents too much autonomy early in adolescence 
often leads to poorer adjustment. Instead, joint decision-making is typically viewed as optimal for middle adolescents, as it has been found to be associated with higher levels of psychosocial adjustment compared to parent-unilateral or youth-unilateral decision making (Dornbusch et al., 1990; Lamborn et al., 1996). Even though adolescents often desire higher levels of autonomy, it remains important for parents to gradually increase their adolescent's autonomy, rather than providing adolescents with the complete decision-making power adolescents often desire (Eccles et al., 1991; Smetana et al., 2004). Specifically, parents should have greater decision-making power early in adolescence, gradually providing their adolescent with greater decision-making autonomy in middle and late adolescence.

In sum, parental psychological control has been found to be associated with increased levels of problematic outcomes during adolescence in both cross-sectional and longitudinal studies (Barber \& Olsen, 1997; Pettit, Laird, Dodge, Bates, \& Criss, 2001; Rogers, Buchanan, \& Winchel, 2003). Research has also provided support for a direct link between parental psychological control and inhibited levels of perceived decision-making autonomy during adolescence (Barber, 1996). In addition, inhibited autonomy development is associated with several problematic outcomes, including higher levels of depression, anxiety, delinquency, and externalizing problems, as well as lower levels of self-esteem (Barber \& Olsen, 1997; Kobak, Sudler, \& Gamble, 1991). Because parental psychological control has been found to be associated with adolescent perceived decision-making autonomy, and adolescent perceived decision-making autonomy has been found to be associated with adolescent problematic outcomes, perceived decision-making autonomy may mediate the association between parental psychological control and adolescent problem behaviors. However, given that the effects of behavioral control differ for early vs. late adolescents, adolescent behavioral autonomy may also 
differentially mediate the association between psychological control and problematic outcomes for older compared to younger adolescents.

\section{Adolescent Desired Autonomy Beliefs as a Moderator}

Although perceived decision-making autonomy plays an important role in adolescent adjustment, researchers have also placed emphasis upon the importance of adolescents' desired decision-making autonomy, or the amount of decision-making autonomy the adolescent believes they should have. Holmbeck and O'Donnell (1991) discovered that adolescents typically desired more autonomy than they were granted emphasizing the importance of the need for further examination of both actual and desired decision-making autonomy. When adolescents desire higher levels of decision-making autonomy than they are actually granted, they will likely experience adjustment problems compared to adolescents who do not believe they should be granted more decision-making autonomy (Holmbeck \& O’Donnell, 1991). Specifically, adolescents' satisfaction with autonomy has been found to be associated with higher levels of academic achievement and self-competence, as well as lower levels of problem behavior, suggesting that adolescents who receive the amount of autonomy they desire experience more positive outcomes compared to those adolescents who report discrepancies between their desired decision-making autonomy and their perceived decision-making autonomy (Holmbeck \& O'Donnell, 1991). As parental psychological control is associated with an inhibited sense of perceived decision-making autonomy during adolescence, parental psychological control may be especially harmful for those adolescents who desire higher levels of decision-making autonomy (Barber, 1996). 


\section{Statement of the Problem}

During adolescence, individuals begin to strive for greater levels of autonomy and independence, which is typically associated with transformations in the parent-child relationship (Steinberg, 2001). Developmental theorists have suggested that adolescence represents a time in which adolescents and their parents must balance adolescents' expanding independence with warm and supportive connections established during childhood in order for the adolescent to achieve a healthy sense of autonomy (Hauser et al., 1984). Although this balance between independence and closeness with the parent is perceived as ideal for autonomy development, certain parenting behaviors, such as parental psychological control, may interfere with this balance (Barber, 1996; Hauser et al., 1984; Steinberg, 1990). Psychological control is associated with numerous problematic outcomes during adolescence, including higher levels of both internalizing and externalizing problems (Barber, 1996; Finkenauer et al., 2005, Soenens et al., 2004).

The current study builds upon previous research by examining the role of parental psychological control on different types of problematic outcomes, including over-eating behaviors, under-eating behaviors, risky cyber behaviors, substance use, and depressive symptoms. These findings will expand upon the previous literature that has suggested that adolescents typically view parental psychological control as less legitimate over problem behaviors that they view as less harmful, such as problematic eating behaviors and risky cyber use, compared to problem behaviors that they view as involving greater levels of harm, such as substance use (Smetana \& Daddis, 2002).

Although parental psychological control has been linked to both internalizing and externalizing problems during adolescence, less research has explored potential explanatory 
mechanisms. Parental psychological control interferes with the normal and healthy process of autonomy development and leads to lower adolescent perceived decision-making autonomy (McElhaney et al., 2009). In addition, an inhibited sense of perceived autonomy during adolescence is associated with several problematic outcomes, including depression and anxiety, delinquency, aggressive behaviors, and substance use (Barber \& Olsen, 1997). Therefore, the mediating role of perceived decision-making autonomy on the association between parental psychological control and adolescents' problematic outcomes will be examined in the current study.

Additionally, researchers have suggested that lower levels of perceived decision-making autonomy are especially harmful for older adolescents compared to younger adolescents. Specifically, higher levels of perceived decision-making autonomy in late adolescence are associated with higher levels of psychosocial adjustment. However, in earlier adolescence, higher levels of perceived decision-making autonomy are associated with lower levels of psychosocial adjustment. Therefore, the current study will explore the moderating role of age on the association between parental psychological control and problem behaviors during adolescence mediated by perceived decision-making autonomy.

Adolescents who desire higher levels of decision-making autonomy than they are granted typically report higher levels of problem behaviors than adolescents who desire lower levels of decision-making autonomy (Holmbeck \& O’Donnell, 1991). As parental psychological control has been found to be associated with an inhibited sense of perceived decision-making autonomy during adolescence, it is likely that the association between parental psychological control and problem behaviors will be stronger for those adolescents who desire higher levels of decisionmaking autonomy than those adolescents who do not desire higher levels of decision-making 
autonomy (Barber \& Harmon, 2002). In order to examine these potential differences, adolescents' desired level of decision-making autonomy will be explored as a moderator on the association between parental psychological control and adolescent problematic outcomes in the current study.

\section{Method}

\section{Participants}

Participants were drawn from a study of adolescents living in a University city in a MidAtlantic state. Participants were 161 adolescents (96 women, 65 men; $M_{a g e}=14.42, S D=1.73$, range $=12-18$ ) recruited from various organizations in which they were involved, including Boy's and Girl's club, church youth groups, and youth sport organizations. Additionally, a local medical clinic and three local high-schools were involved with participant recruitment. The medical clinic mailed parent information letters and recruitment flyers to the parents of adolescents. Furthermore, graduate students and undergraduate research assistants recruited participants in classrooms, as well as at school and community-related events. Each participating adolescent was required to recruit at least one adult primary caregiver, including any biological parent, stepparent, legal guardian, aunt, uncle, or grandparent. As research has shown that children's report of parenting behaviors is more closely related to child adjustment than parents' report of parenting, only adolescent data will be used in the proposed study (Gecas \& Schwalbe, 1986). Most adolescents reported that they identified as Caucasian/White (81\%) and received either mostly A's or some A's and some B's in school (73\%).

A power analysis conducted by G*Power 3.1.9.2 (Faul, Erdfelder, Buchner, \& Lang, 2009) revealed that a sample size of 85 is required to achieve a moderate effect size $\left(\mathrm{f}^{2}=.15\right)$ at $80 \%$ power. Although the power analysis only approximates the PROCESS model that will be 
used in the current study, the current sample size of 161 suggests that statistical power should be sufficient to detect meaningful interaction effects.

\section{Procedure}

The majority of the family visits took place in participants' homes. However, some additional family visits took place at the research lab and in community-group locations (e.g. public library, church). Caregivers gave informed consent for themselves and their adolescent before participating, while adolescents gave informed assent before participating. After giving informed consent and assent, all participants received payment for participating: \$25 for each participating parent and $\$ 50$ for participating adolescents. Caregivers and adolescents were then asked to participate in a video-recorded dyadic discussion task, involving several topics, such as civic engagement, food and eating habits, alcohol experimentation, and Internet and cell phone use for seven-minute time intervals. After the dyadic discussion task, the adolescent was asked to complete survey questionnaires in a separate room. The questionnaire asked adolescents to answer a series of questions about parental psychological control, decision-making control in reference to various activities, beliefs about decision-making control in reference to various activities, eating behaviors, cyber behaviors, substance use, and depression.

\section{Measures}

Psychological control scale-youth self-report. Parental psychological control was measured using the Psychological Control Scale-Youth Self-Report by Barber (1996) that participants completed (see Appendix B). Participants were instructed to rate the extent to which each item is descriptive of their parents. The scale includes 16 items, such as "will avoid looking at me when I have disappointed them" and the participant was asked to rate each item on a 5- 
point Likert-type scale from 1 (Never) to 5 (Always). Mean scores were computed by averaging responses to each of the 16 items $(\alpha=.89)$.

Parental restrictive control questionnaire - adolescent report. Adolescents answered questions about who in their family makes most of the decisions about various behaviors (see Appendix L). Behaviors included over-eating behaviors ("Who makes decisions about if I eat junk food?"), under-eating behaviors ("Who makes decisions about whether I am dieting or trying to lose weight?"), cyber behaviors ("Who makes decisions about the types of websites I visit online?"), and substance use (“Who makes decisions about if I drink too much alcohol or get drunk?”), as well as personal behaviors (“Who makes decisions about what I talk about on the phone with my friends?"), and multifaceted behaviors (“Who makes decisions about hanging out at a friend's house when no adult is home?"). Participant responses were measured on a 5-point Likert-type scale $(1=$ Child decides alone, 2 = Child decides after discussing with his/her parents, 3 = Parents and child decide together, $4=$ Parent decides after discussing with the child, 5 = Parent decides alone) (Smetana, 1995; Smetana, Crean, \& Daddis, 2002). Higher scores on this scale are associated with higher levels of parent unilateral decision-making, while lower scores are associated with higher levels of teen independent decision-making. Alpha coefficients ranged from .83 (cyber) to .90 (substance use).

The parental restrictive control questionnaire was also used to measure adolescents' desired level of decision-making autonomy. Adolescents were asked who should make decisions about eating behaviors, cyber behaviors, substance use, personal behaviors, school-related behaviors, and multifaceted behaviors. Participant responses were measured on a 5-point Likerttype scale $(1=$ Child decides alone, $2=$ Child decides after discussing with his/her parents, $3=$ Parents and child decide together, $4=$ Parent decides after discussing with the child, $5=$ Parent 
decides alone). Higher scores on this scale are associated with beliefs that parents should make the decisions, while lower scores on this scale are associated with beliefs that adolescents should make the decisions. Alpha coefficients ranged from .80 (over-eating) to .94 (substance use).

Problematic eating behaviors. The Dutch Eating Behavior Scale (van Strien et al., 1986) was used to measure restrained, external, and emotional eating behaviors (see Appendix C). Participant responses were measured on a 5-point Likert-type scale $(1=$ Never $)$ to $(5=$ Very Often). Higher scores on each subscale (restrained, external, and emotional eating) were associated with higher levels of problematic eating behaviors. Participants' scores on the external and emotional eating subscales were combined in an over-eating behavior scale $(\alpha=.93)$. Participants' scores on the restrained eating subscale were used to measure under-eating behavior $(\alpha=.90)$. Sample items included "When you have put on weight, do you eat less than you usually do?" and "Do you have a desire to eat when you have nothing to do?"

Risky cyber behaviors. Adolescents' risky Internet and cell-phone behaviors were measured using an 8 item self-report measure (see Appendix D). Participants were asked to rate how often in the last 30 days they engaged in risky Internet and cell-phone behaviors $(1=0$ days, $2=1$ day, $3=2-3$ days, $4=4-6$ days, $5=7-10$ days, $6=11+$ days $)$. Sample items included "How often in the last 30 hays have you posted photos on Facebook involving alcohol and drug use?" and "How often in the last 30 days have you added friends on Facebook whom you have never met offline?" Higher scores indicated higher levels of risky Internet and cell-phone behaviors $(\alpha=.62)$.

Illicit substance use. Adolescent substance use was measured using an 8-item self-report scale asking participants to rate how often in the last 3 months they have engaged in alcohol behaviors (see Appendix E). Participants were asked to record their responses on a Likert-type 
scale from 1 (never) to 4 (often). Sample items included "In the last 3 months, how often have you drank alcohol?" and "In the last 3 months, how often have you drank so much you got sick?" In addition, participants' past substance use was measured using three items from a larger Adolescent Delinquency measure. Participants were asked to rate how often in the past 30 days they engaged in substance use behaviors on a Likert-type scale from 1 (never) to 4 (often). Sample items included "In the past 30 days, how often have you smoked marijuana?" and "In the past 30 days, how often have you used prescription medications not meant for you?" Mean scores were calculated with higher scores indicating higher levels of substance use $(\alpha=.87)$.

Center for Epidemiological Studies - Depression (CES-D). Depressive symptoms were measured using the 20-item Center for Epidemiological Studies Depression inventory (CES-D; Radloff, 1977; see Appendix F). Participants were asked to rate the frequency of depressive symptoms experienced within the past week on a Likert-type scale from 0 (rarely or none of the time) to 3 (most or all of the time). Sample items included "During the past week, I was bothered by things that usually don't bother me" and "During the past week, I thought my life had been a failure." Mean scores were calculated for each adolescent $(\alpha=.76)$. 


\section{Appendix H}

\section{Originally Proposed Analyses}

\section{Research Question 1}

Is perceived level of parental psychological control associated with adolescents' problematic outcomes?

Hypothesis 1. Based on previous research, parental psychological control will be associated positively with adolescents' over-eating behaviors, under-eating behaviors, risky cyber behaviors, substance use, and depression (Aquilino \& Supple, 2001; Li et al., 2013; Snoek et al., 2007).

A structural equation model was performed with parental psychological control predicting adolescents' over-eating behaviors, under-eating behaviors, risky cyber behaviors, substance use, and depressive symptoms, while controlling for adolescent age, adolescent gender, family rules, and parental warmth (see Figure 1). Variables with significant bivariate correlations were allowed to covary. Standardized regression coefficients for all direct effects are reported in Figure 1. The proposed model provided an adequate fit to the data $(\mathrm{CMIN} / \mathrm{DF}=1.99$, $\mathrm{CFI}=.93, \mathrm{RMSEA}=.08)$. The hypothesis was partially supported, as results suggested that parental psychological control was associated positively with adolescents' under-eating behaviors $(\beta=.17, \mathrm{SE}=.10, p<.05)$, risky cyber behaviors $(\beta=.20, \mathrm{SE}=.06, p<.01)$, substance use $(\beta=.19, \mathrm{SE}=.04, p<.01)$, and depressive symptoms $(\beta=.24, \mathrm{SE}=.06, p<.01)$. Parental psychological control was not associated significantly with over-eating behaviors. Examination of critical ratios indicated that these paths did not significantly differ $($ C.R. $<1.96)$. 


\section{Research Question 2}

Is the association between parental psychological control and adolescent problematic outcomes mediated by adolescents' perceived level of decision-making autonomy?

Hypothesis 2. Previous research has indicated that parental psychological control is associated with an inhibited sense of perceived decision-making autonomy during adolescence (Barber, 1996). Therefore, it is hypothesized that the positive association between parental psychological control and over-eating behaviors, under-eating behaviors, risky cyber behaviors, substance use, and depressive symptoms, will be mediated by adolescents' perceived level of decision-making autonomy, such that adolescents with higher levels of perceived parental psychological control will report lower levels of perceived decision-making autonomy, which will be associated with higher levels of over-eating behaviors, under-eating behaviors, risky cyber behaviors, substance use, and depressive symptoms.

\section{Research Question 2a}

Will the association between parental psychological control and adolescent problematic outcomes mediated by perceived decision-making autonomy vary by the adolescents' age?

Hypothesis 2a. The association between parental psychological control and adolescents' over-eating behaviors, under-eating behaviors, risky cyber behaviors, substance use, and depressive symptoms, mediated by level of perceived decision-making autonomy will vary by the age of the adolescent. Previous researchers have suggested that adolescent decision making becomes more independent as adolescents get older (Daddis \& Smetana, 2005; Smetana et al., 2004). Therefore, it is hypothesized that the mediating role of perceived decision-making autonomy on the association between parental psychological control and adolescent problem behaviors will be stronger for older adolescents compared to younger adolescents. 
Path models examined the indirect effects of parental psychological control on adolescents' over-eating behaviors, under-eating behaviors, risky cyber behaviors, substance use, and depressive symptoms through adolescents' behavior-specific perceived decision-making autonomy (see Figure 4). Independent variables that were significantly correlated were allowed to freely covary. Standardized regression coefficients for all direct and indirect effects can be found in Figure 4. Each path model provided a good fit to the data: $\mathrm{CMIN} / \mathrm{DF}=1.41-2.06$; $\mathrm{CFI}=$ $.95-.98 ;$ RMSEA $=.05-.08$. An examination of the bootstrapped indirect effects indicated that psychological control had only significant direct effects on adolescents' under-eating behaviors $(\beta=.18,95 \%$ CI $[.07, .33]$; see Figure $4 b)$, risky cyber behaviors $(\beta=.18,95 \%$ CI $[.08, .30]$; see Figure $4 c)$, substance use $(\beta=.20,95 \%$ CI $[.08, .32]$; see Figure $4 d)$, and depressive symptoms $(\beta=.26,95 \%$ CI $[.14, .40]$; see Figure 4e). Psychological control did not have significant indirect or direct effects on adolescents' over-eating behaviors through decisionmaking autonomy (see Figure 4a). Multi-group results showed the unconstrained model did not provide a significantly better fit compared to the constrained model for over-eating behaviors $\left(\Delta X^{2}(9)=4.54, p=.48\right.$; see Figure 5a), under-eating behaviors $\left(\Delta X^{2}(9)=3.86, p=.92\right.$; see Figure 5b), risky cyber behaviors $\left(\Delta X^{2}(9)=8.06, p=.53\right.$; see Figure 5c), substance use $\left(\Delta X^{2}(9)=\right.$ 12.57, $p=.08$; see Figure $5 \mathrm{~d})$, and depressive symptoms $\left(\Delta X^{2}(9)=9.48, p=.22\right.$; see Figure 5e $)$ which indicated that the indirect associations between psychological control and each problematic outcome through perceived decision-making autonomy did not vary as a function of adolescents' age.

\section{Research Question 3}

Will the association between parental psychological control and adolescent problematic outcomes vary as a function of adolescents' desired level of decision-making autonomy? 
Hypothesis 3. Researchers have suggested that adolescents who desire higher levels of decision-making autonomy, but experience inhibited perceived decision-making autonomy exhibit higher levels of problem behaviors than adolescents who do not desire decision-making autonomy (Holmbeck \& O’Donnell, 1991). Since parental psychological control is associated with lower levels of perceived autonomy during adolescence, it is hypothesized that the positive association between parental psychological control and adolescents' over-eating behaviors, under-eating behaviors, risky cyber behaviors, substance use, and depressive symptoms will be stronger for those adolescents who desire higher levels of decision-making autonomy.

Multi-group analyses at low and high levels of adolescents' desired decision-making autonomy indicated that the unconstrained model did not provide a significantly better fit compared to the constrained model for over-eating behaviors $\left(\Delta X^{2}(5)=2.77, p=.74\right)$, undereating behaviors $\left(\Delta X^{2}(5)=9.17, p=.10\right)$, risky cyber behaviors $\left(\Delta X^{2}(5)=8.51, p=.13\right)$, substance use $\left(\Delta X^{2}(5)=1.89, p=.86\right)$, and depressive symptoms $\left(\Delta X^{2}(5)=5.00, p=.42\right.$; see Figure 6), which indicated that the association between psychological control and each problematic outcome did not vary by level of desired decision-making autonomy.

\section{Discussion}

Parental psychological control was not found to be indirectly associated with adolescents' problematic outcomes through perceived decision-making autonomy. This is inconsistent with hypotheses and with previous research, which has suggested that psychological control interferes with adolescents' autonomy development by undermining adolescents' thoughts, feelings, and behaviors that are inconsistent with the parents' own thoughts, feelings, and behaviors (Barber, 1996; Hare, Szwedo, Schad, \& Allen, 2014; Hauser et al., 1984, Steinberg, 1990). Adolescent autonomy development has also been found to be associated with numerous problematic 
outcomes during adolescence, including lower levels of self-esteem and higher levels of depression, delinquency, and externalizing problems (Barber \& Olsen, 1997). However, much of the previous research has placed emphasis upon the role of psychological control on adolescents' emotional autonomy, or adolescents' feelings of independence from parents while the current study examined the association between psychological control and adolescents' independent decision making (Douvan \& Adelson, 1996). As parental psychological control interferes with the adolescent's psychological world and is associated with increased psychological dependence on the parent, it is possible that emotional autonomy, rather than behavioral autonomy may explain the association between parental psychological control and adolescent problematic outcomes (Barber, 1996; Hauser et al., 1984; Steinberg, 1990).

Additionally, adolescents' desired decision-making autonomy was not found to moderate the associations between psychological control and adolescent problematic outcomes, which was inconsistent with hypotheses. Previous research has suggested that adolescents who desire higher levels of autonomy than they are actually granted experience greater adjustment problems compared to adolescents who do not believe they should be granted more autonomy (Holmbeck \& O’Donnell, 1991). Therefore, it was expected that the association between psychological control and adolescent problematic outcomes would be stronger for adolescents with higher levels of desired decision-making autonomy, as psychological control was thought to be associated with lower levels of perceived decision-making autonomy. However, it is likely that the association between psychological control and adolescent problematic outcomes did not vary by adolescents' desired decision-making autonomy in the current study, as psychological control was not found to be associated with adolescents' perceived level of decision-making autonomy. 
Therefore, future research should examine the role of adolescents' emotional autonomy on the association between parental psychological control and adolescent problematic outcomes. 


\section{Appendix I}

\section{Psychological Control and Family Rules as Predictors}

Exploratory Research Question 1: Are parental psychological control and family rules differentially associated with adolescent problematic outcomes, including over-eating behaviors, under-eating behaviors, risky cyber behaviors, substance use, and depressive symptoms? A structural equation model was performed with parental psychological control and family rules predicting adolescents' over-eating behaviors, under-eating behaviors, risky cyber behaviors, substance use, and depressive symptoms, while controlling for adolescent age, adolescent gender, and parental warmth (see Figure 7). Variables with significant bivariate correlations were allowed to covary. Standardized regression coefficients for all direct effects are reported in Figure 1. The proposed model provided an adequate fit to the data $(\mathrm{CMIN} / \mathrm{DF}=1.96, \mathrm{CFI}=.94$, RMSEA $=.08)$. Results suggested that parental psychological control was associated positively with under-eating behaviors $(\beta=.18, \mathrm{SE}=.10, p<.05)$, risky cyber behaviors $(\beta=.20, \mathrm{SE}=.06$, $p<.01)$, substance use $(\beta=.18, \mathrm{SE}=.04, p<.01)$, and depressive symptoms $(\beta=.24, \mathrm{SE}=.06$, $p<.01)$. Parental psychological control was not associated significantly with over-eating behaviors. However, family rules for over-eating behaviors were associated negatively with adolescents' over-eating behaviors $(\beta=-.15, \mathrm{SE}=.05, p<.05)$ and family rules for substance use were associated negatively with adolescents' substance use $(\beta=-.36, \mathrm{SE}=.06, p<.001)$. Family rules were not associated significantly with adolescents' under-eating behaviors, risky cyber behaviors, or depressive symptoms.

Exploratory Research Question 2: Are parental psychological control and family rules differentially associated with adolescent problematic outcomes, including over-eating behaviors, under-eating behaviors, risky cyber behaviors, substance use, and depressive symptoms through 
adolescent perceived decision-making autonomy? Path models examined the indirect effects of parental psychological control on adolescents' over-eating behaviors, under-eating behaviors, risky cyber behaviors, substance use, and depressive symptoms through adolescents' behaviorspecific perceived decision-making autonomy (see Figure 8). Independent variables that were significantly correlated were allowed to freely covary. All path models provided a good fit to the data: $\mathrm{CMIN} / \mathrm{DF}=1.36-2.12 ; \mathrm{CFI}=.95-.97 ; \mathrm{RMSEA}=.05-.08$. An examination of the bootstrapped indirect effects indicated that psychological control had only significant direct effects on adolescents' under-eating behaviors $\beta=.17,95 \% \mathrm{CI}[.06, .31]$, risky cyber behaviors $\beta=.20,95 \%$ CI $[.11, .32]$, substance use $\beta=.18,95 \%$ CI $[.05, .31]$, and depressive symptoms $\beta$ $=.26,95 \% \mathrm{CI}[.14, .40]$. Psychological control did not have significant indirect effects on any of the adolescent health-risk behaviors. Additionally, family rules had both significant indirect $\beta=$ $.09,95 \% \mathrm{CI}[-.18,-.02]$, and direct effects $\beta=-.31,95 \% \mathrm{CI}[-.47,-.12]$, on adolescents' substance use. Family rules did not have significant indirect or direct effects on adolescents' over- or under-eating behaviors, risky cyber behaviors, or depressive symptoms.

Exploratory Research Question 3: Will the association between parental psychological control and adolescent problematic outcomes, as well as family rules and problematic outcomes, vary as a function of adolescents' desired level of decision-making autonomy? Multi-group analyses at low and high levels of adolescents' desired decision-making autonomy indicated that the unconstrained model did not provide a significantly better fit compared to the constrained model for over-eating behaviors $\left(\Delta X^{2}(5)=2.77, p=.74\right)$, under-eating behaviors $\left(\Delta X^{2}(5)=9.17, p=\right.$ $.10)$, risky cyber behaviors $\left(\Delta X^{2}(5)=8.51, p=.13\right)$, substance use $\left(\Delta X^{2}(5)=1.89, p=.86\right)$, and depressive symptoms $\left(\Delta X^{2}(5)=5.00, p=.42\right)$, which indicated that the associations between 
psychological control and each problematic outcome, as well as family rules and each

problematic outcome did not vary by level of desired decision-making autonomy (see Figure 9). 


\section{Appendix J}

\section{Discrepancies between Perceived and Desired Decision-Making Autonomy as a Mediator}

Exploratory Research Question 1: Is parental psychological control indirectly associated with adolescent problematic outcomes, including over-eating behaviors, under-eating behaviors, risky cyber behaviors, substance use, and depressive symptoms through discrepancies between perceived and desired decision-making autonomy? Path models examined the indirect effects of parental psychological control on adolescents' over-eating behaviors, under-eating behaviors, risky cyber behaviors, substance use, and depressive symptoms through adolescents' behaviorspecific discrepancies between perceived and desired decision-making autonomy (see Figure 10). Independent variables that were significantly correlated were allowed to freely covary. Standardized regression coefficients for all direct and indirect effects can be found in Figure 10. Each path model provided a good fit to the data: $\mathrm{CMIN} / \mathrm{DF}=1.25-2.10 ; \mathrm{CFI}=.86-.99 ; \mathrm{RMSEA}$ $=.04-.08$. An examination of the bootstrapped indirect effects indicated that psychological control had only significant direct effects on adolescents' under-eating behaviors $(\beta=.17,95 \%$ CI $[.04, .32]$; see figure $10 \mathrm{~b})$, risky cyber behaviors $(\beta=.22,95 \% \mathrm{CI}[.11, .31]$; see Figure $10 \mathrm{c})$, substance use $(\beta=.18,95 \%$ CI $[.02, .29]$; see Figure $10 \mathrm{~d})$, and depressive symptoms $(\beta=.30$, $95 \%$ CI $[.14, .45]$; see Figure 10e). Psychological control did not have significant indirect or direct effects on adolescents' over-eating behaviors (see Figure 10a). 


\section{Appendix K}

\section{Discrepancies between Perceived and Desired Decision-Making Autonomy as a Moderator}

Exploratory Research Question 1: Will the association between parental psychological control and adolescent problematic outcomes vary as a function of the discrepancies between adolescents' perceived and desired level of decision-making autonomy? Multi-group analyses at low and high levels of adolescents' discrepancies between perceived and desired decisionmaking autonomy indicated that the unconstrained model did not provide a significantly better fit compared to the constrained model for over-eating behaviors $\left(\Delta X^{2}(5)=2.95, p=.71\right)$, undereating behaviors $\left(\Delta X^{2}(5)=5.09, p=.41\right)$, risky cyber behaviors $\left(\Delta X^{2}(5)=.77, p=.98\right)$, substance use $\left(\Delta X^{2}(5)=4.38, p=.36\right)$, and depressive symptoms $\left(\Delta X^{2}(5)=3.84, p=.57\right)$, which indicated that the associations between psychological control and each problematic outcome did not vary by adolescents' discrepancies between perceived and desired decision-making autonomy (see Figure 11). 


\section{Appendix L}

\section{Principal Components Analysis of Parental Psychological Control}

Exploratory Research Question 1: Will there be distinct dimensions of the Parental Psychological Control Scale - Youth Self-Report (Barber, 1996)? Are specific dimensions of psychological control differentially associated with adolescents' health-risk behaviors? A Principal Components Analysis (PCA) with varimax rotation was performed on the PCS-YSR. An examination of the scree-plot and eigenvalues indicated a three-component solution. The first factor, verbal intrusiveness included items assessing constraining verbal expression $(27 \%$ variance). The second factor, invalidation of feelings, contained items assessing personal attack and guilt induction (16\% variance). The third factor, love withdrawal, included items assessing love withdrawal (14\% variance). A structural model was performed with each psychologicalcontrol component predicting over- and under-eating behaviors, risky cyber behaviors, substance use, and depression, controlling for age and gender. The model provided an adequate fit to the data $(\mathrm{CMIN} / \mathrm{DF}=1.03, \mathrm{CFI}=.99, \mathrm{RMSEA}=.02)$. Results indicated that verbal intrusiveness was associated positively with under-eating behaviors $(\beta=.23, \mathrm{SE}=.08, p<.01)$, risky cyber behaviors $(\beta=.17, \mathrm{SE}=.05, p<.05)$, and depressive symptoms $(\beta=.28, \mathrm{SE}=.06, p<.001)$. Additionally, invalidation of feelings was associated positively with over-eating behaviors $(\beta=$ $.18, \mathrm{SE}=.14, p<.05)$, whereas love withdrawal was associated positively with substance use $(\beta$ $=.21, \mathrm{SE}=.03, p<.001 ;$ Figure 12). 


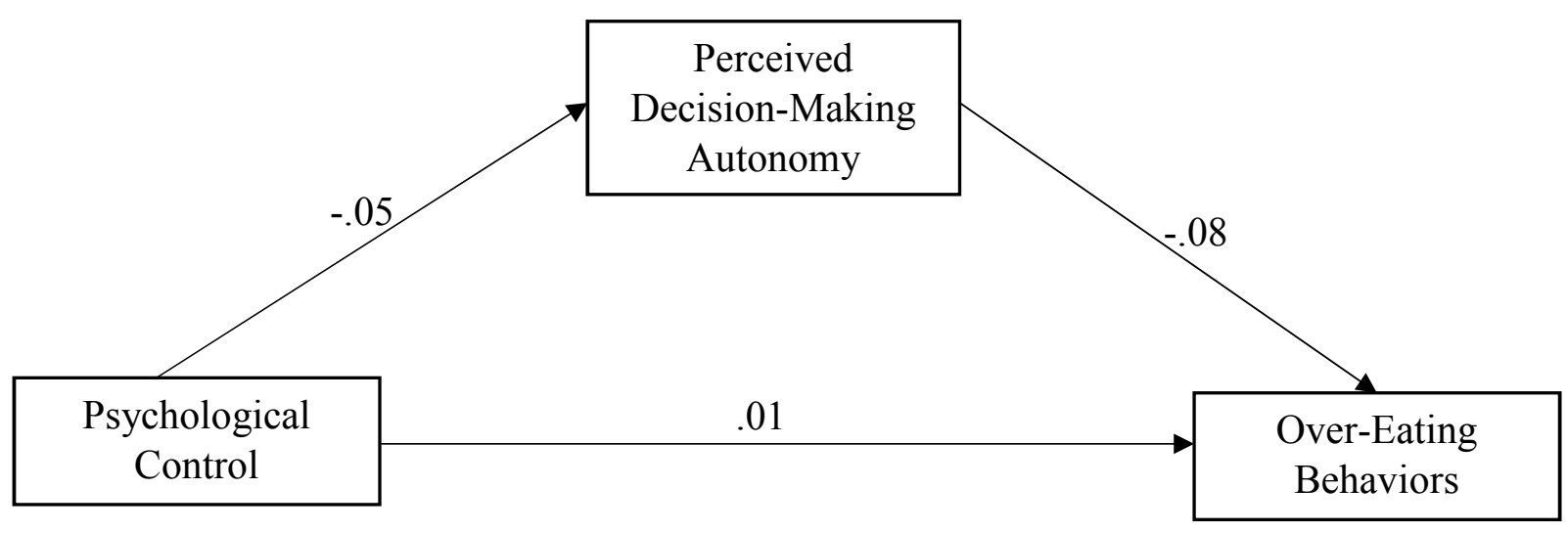

Figure 4a. The indirect effects of psychological control on over-eating behaviors through perceived decision-making autonomy. All estimates are standardized coefficients.

${ }^{*} p<.05, * * p<.01, * * * p<.001$

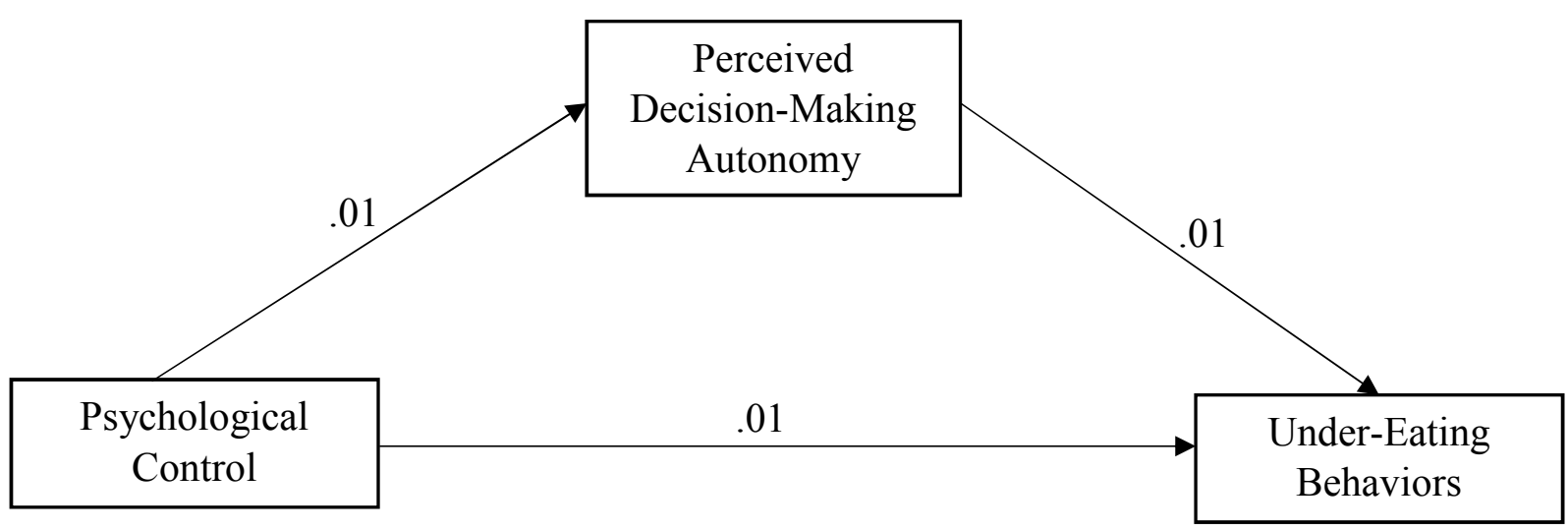

Figure $4 b$. The indirect effects of psychological control on under-eating behaviors through perceived decision-making autonomy. All estimates are standardized coefficients.

${ }^{*} p<.05, * * p<.01, * * * p<.001$ 


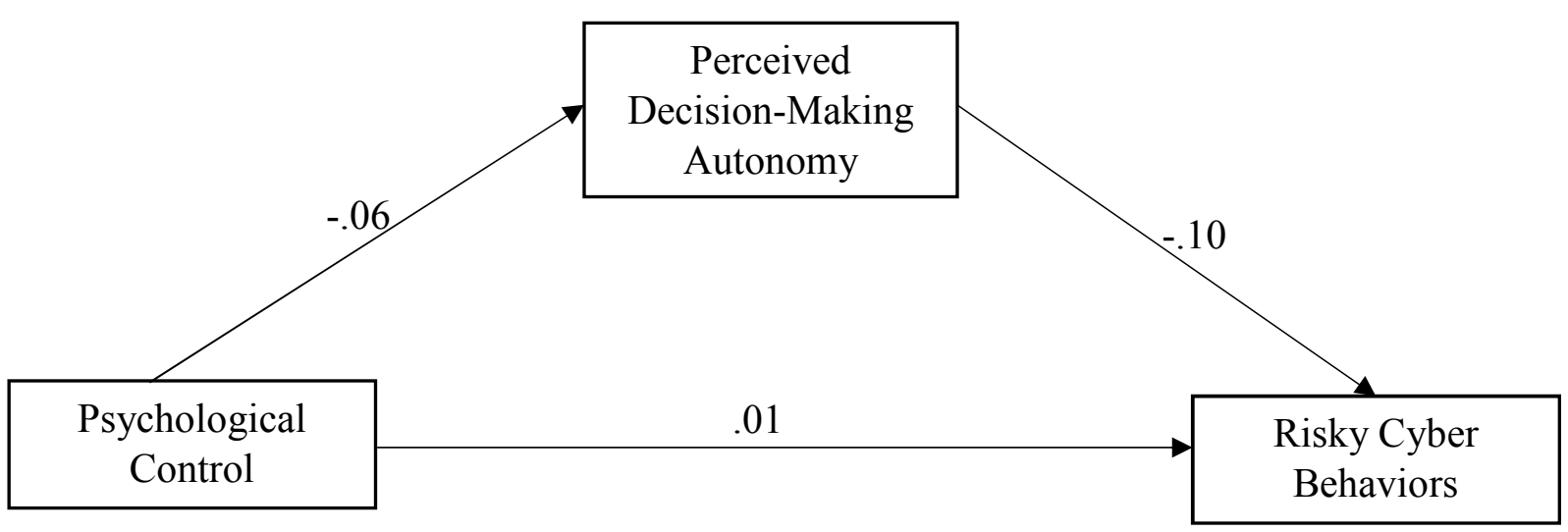

Figure $4 c$. The indirect effects of psychological control on risky cyber behaviors through perceived decision-making autonomy. All estimates are standardized coefficients. $* p<.05,{ }^{* *} p<.01,{ }^{* * *} p<.001$

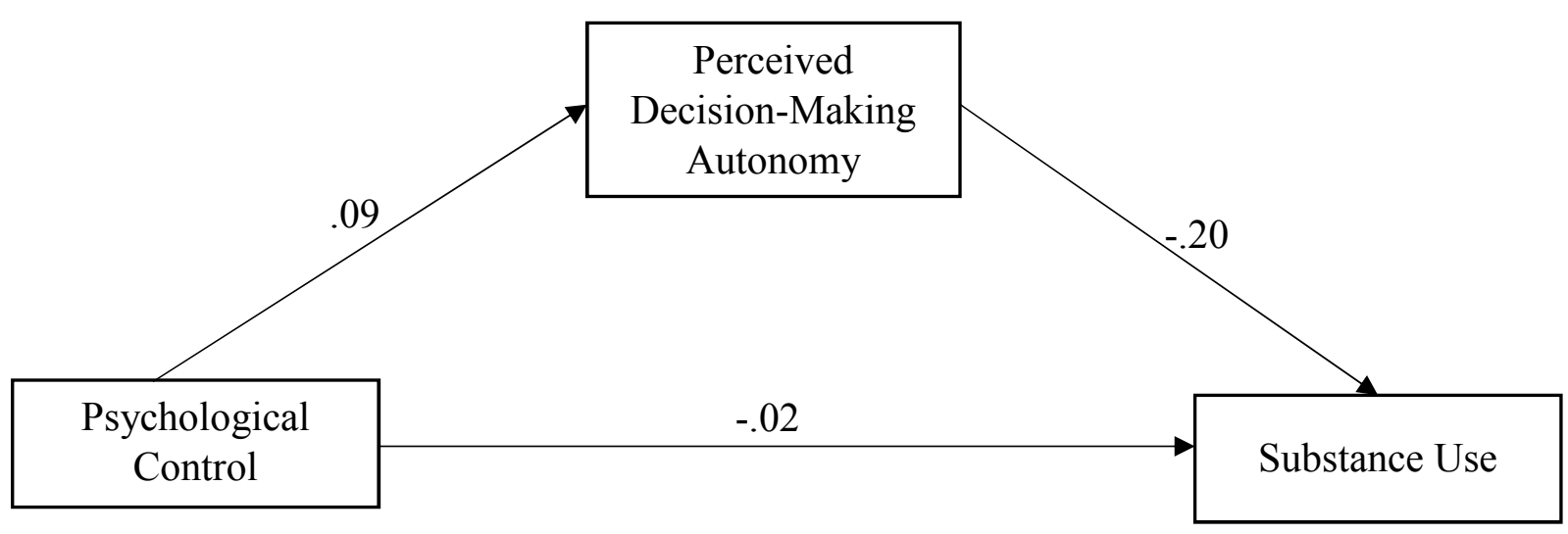

Figure $4 d$. The indirect effects of psychological control on substance use through perceived decision-making autonomy. All estimates are standardized coefficients.

$* p<.05, * * p<.01,{ }^{* * *} p<.001$ 


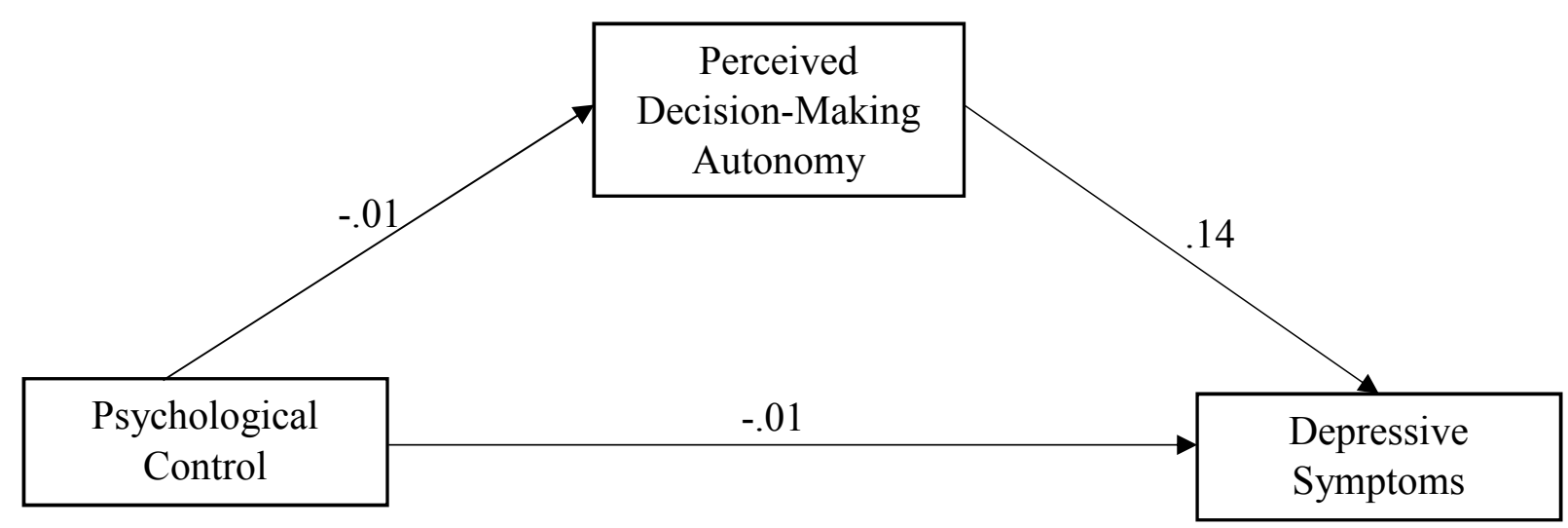

Figure 4e. The indirect effects of psychological control on depressive symptoms through perceived decision-making autonomy. All estimates are standardized coefficients.

$* p<.05,{ }^{* *} p<.01,{ }^{* * *} p<.001$ 


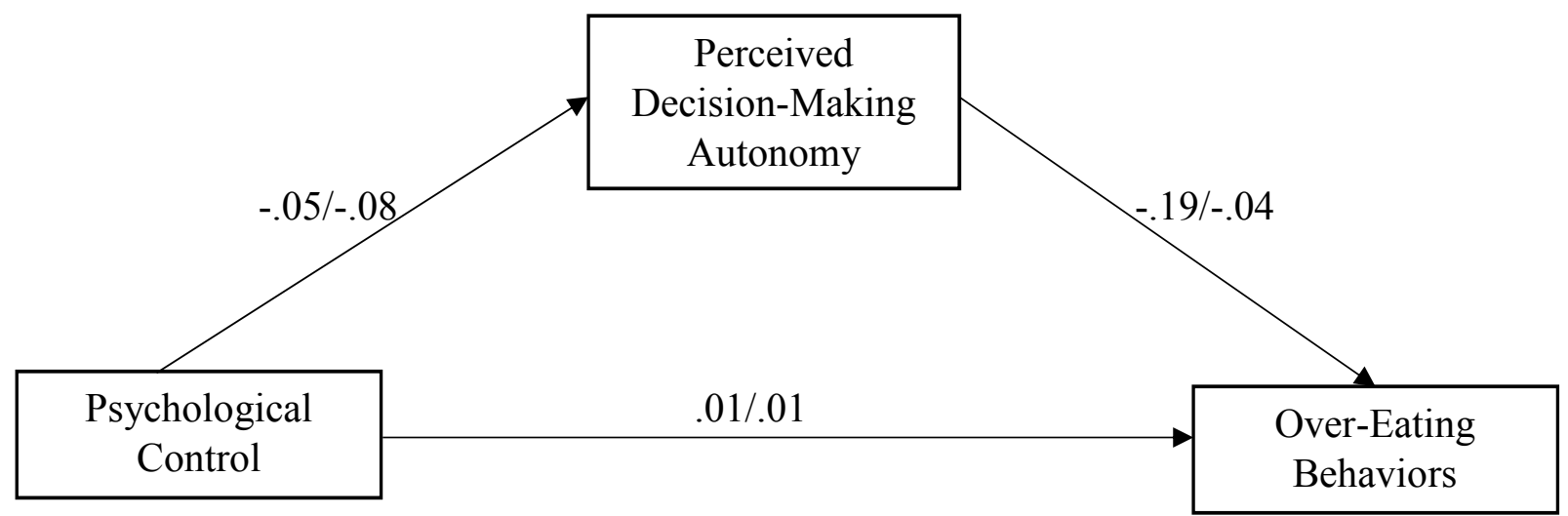

Figure 5a. The indirect effects of psychological control on over-eating behaviors through perceived decision-making autonomy moderated by age. All estimates are standardized coefficients.

Note. Coefficients on the left are for younger adolescents. Coefficients on the right are for older adolescents.

$* p<.05, * * p<.01, * * * p<.001$

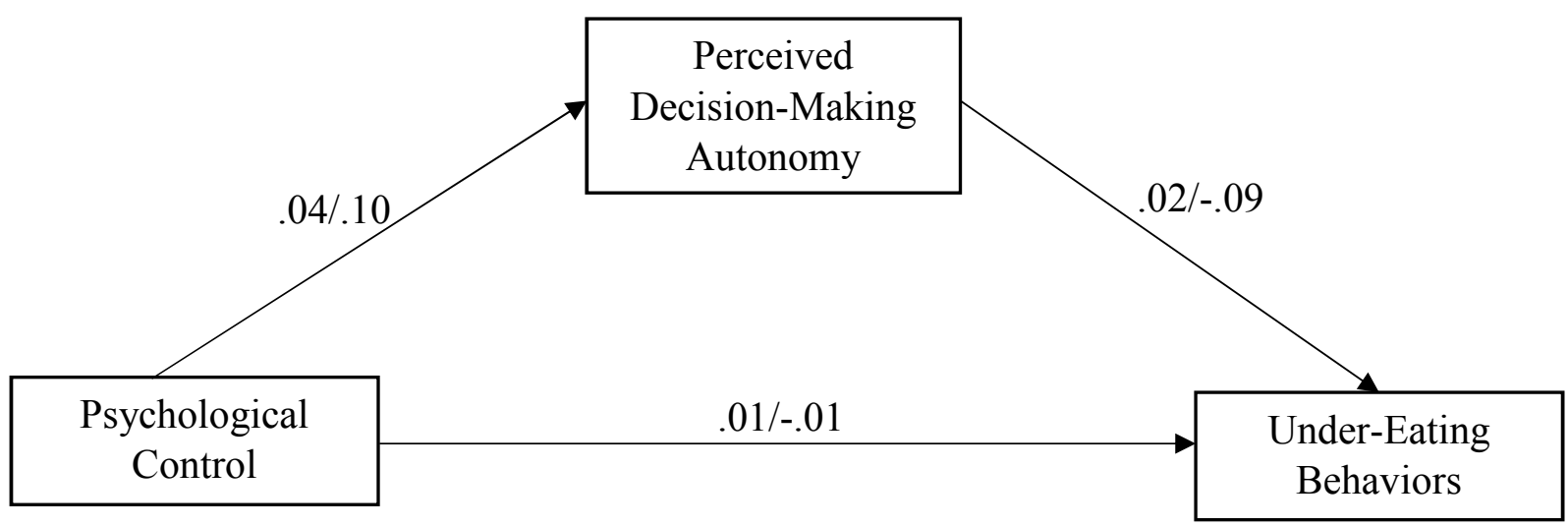

Figure $5 b$. The indirect effects of psychological control on under-eating behaviors through perceived decision-making autonomy moderated by age. All estimates are standardized coefficients.

Note. Coefficients on the left are for younger adolescents. Coefficients on the right are for older adolescents.

$* p<.05, * * p<.01, * * * p<.001$ 


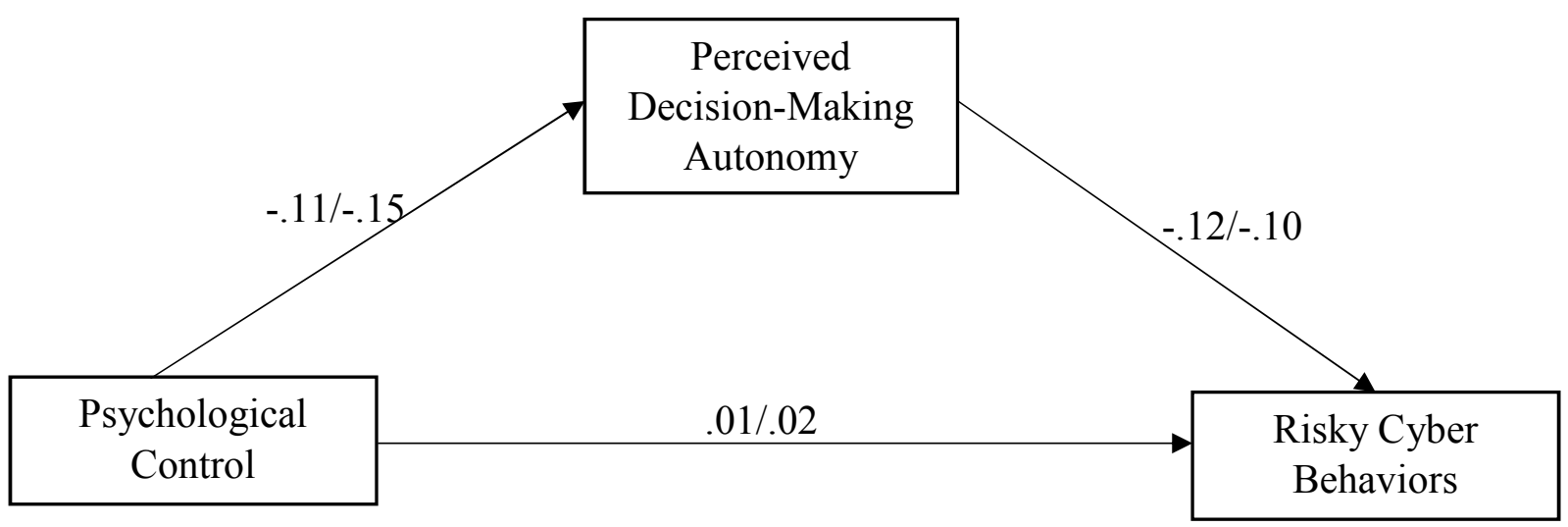

Figure 5c. The indirect effects of psychological control on risky cyber behaviors through perceived decision-making autonomy moderated by age. All estimates are standardized coefficients.

Note. Coefficients on the left are for younger adolescents. Coefficients on the right are for older adolescents.

$* p<.05, * * p<.01, * * * p<.001$

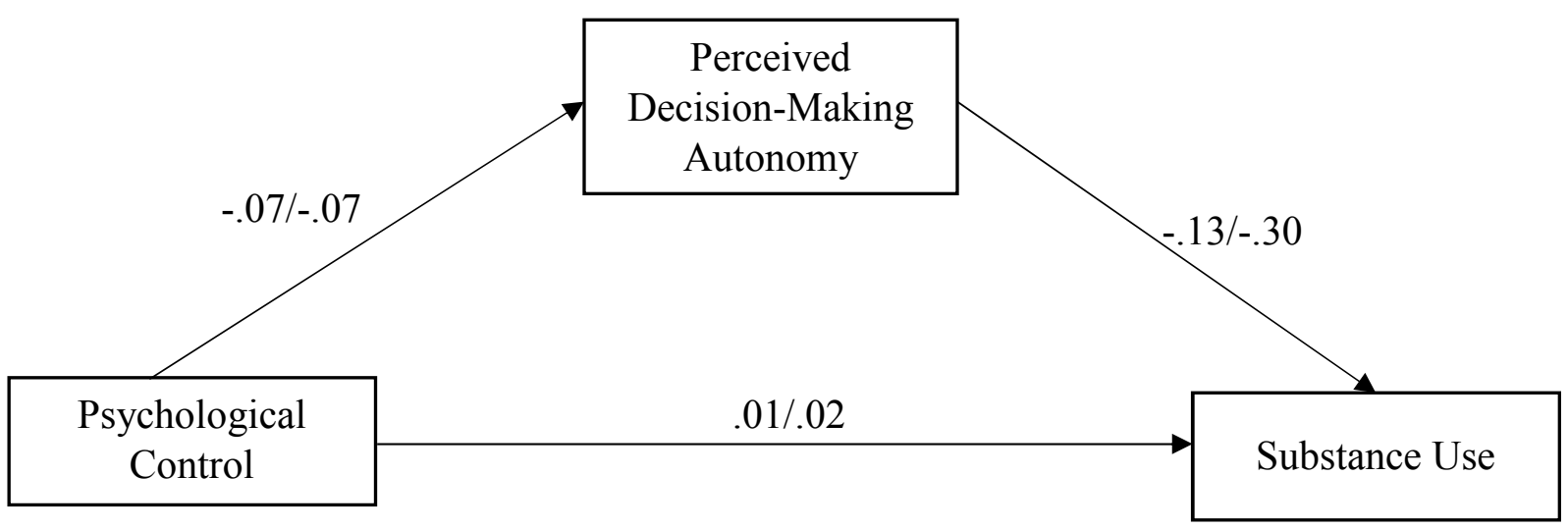

Figure $5 d$. The indirect effects of psychological control on substance use through perceived decision-making autonomy moderated by age. All estimates are standardized coefficients. Note. Coefficients on the left are for younger adolescents. Coefficients on the right are for older adolescents.

$* p<.05, * * p<.01, * * * p<.001$ 


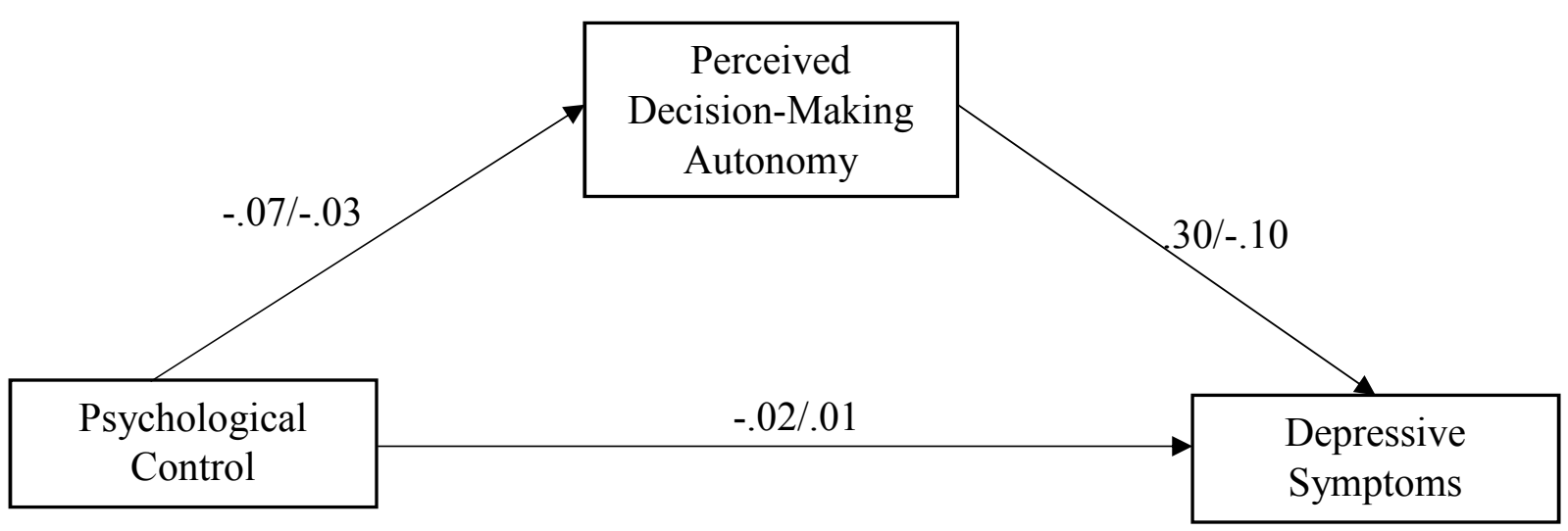

Figure 5e. The indirect effects of psychological control on depressive symptoms through perceived decision-making autonomy moderated by age. All estimates are standardized coefficients.

Note. Coefficients on the left are for younger adolescents. Coefficients on the right are for older adolescents.

${ }^{*} p<.05, * * p<.01, * * * p<.001$ 


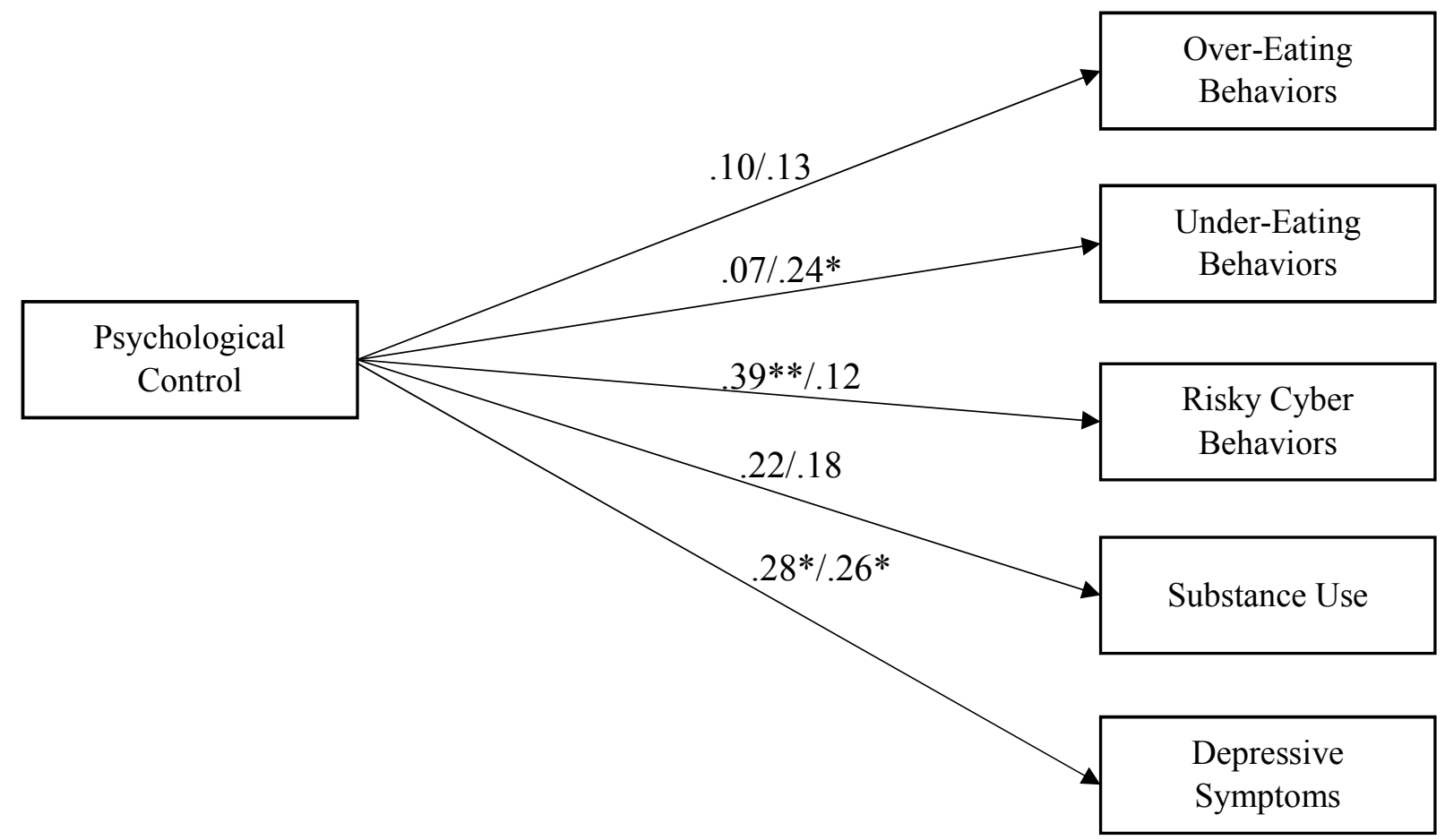

Figure 6. Psychological control predicting problem behaviors moderated by desired decisionmaking autonomy. All estimates are standardized coefficients.

Note. Coefficients on the left are for adolescents with lower levels of desired decision-making autonomy. Coefficients on the right are for adolescents with higher levels of desired decisionmaking autonomy.

${ }^{*} p<.05, * * p<.01, * * * p<.001$ 


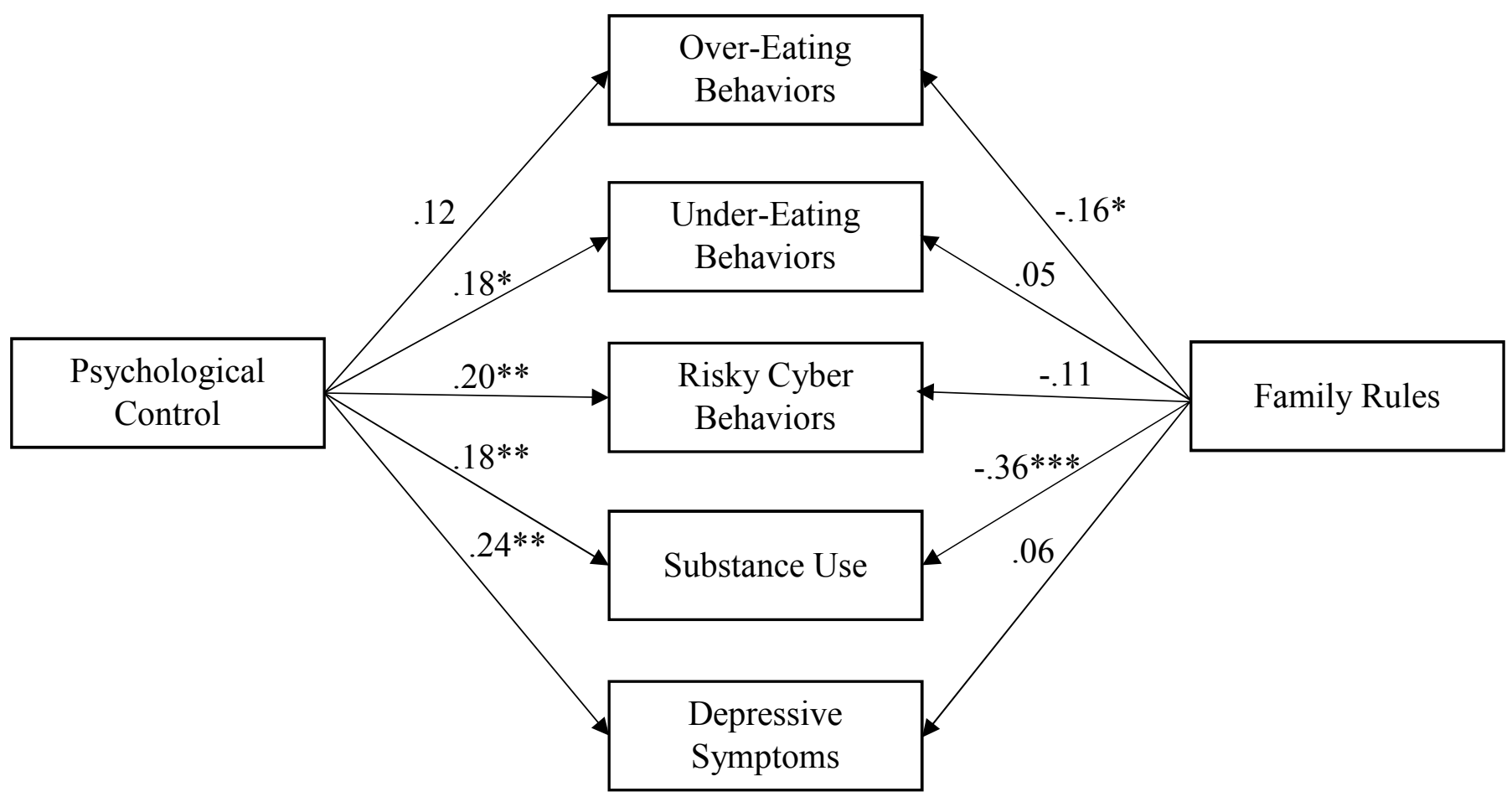

Figure 7. The associations between psychological control, family rules, and adolescent problematic outcomes. All estimates are standardized coefficients.

$* p<.05, * * p<.01, * * * p<.001$ 


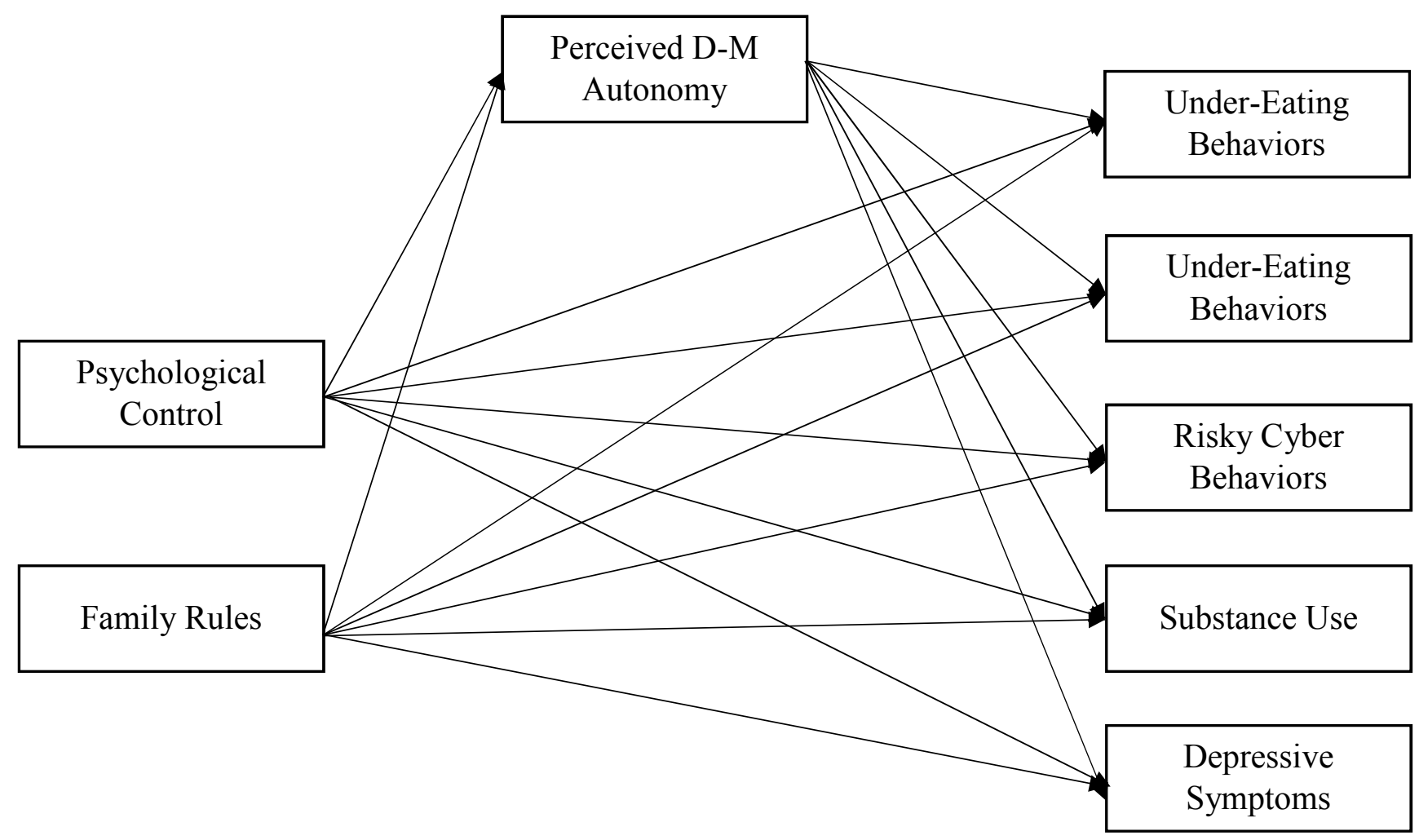

Figure 8. Conceptual model of the indirect effects of psychological control and family rules on adolescent problematic outcomes through perceived decision-making autonomy. 


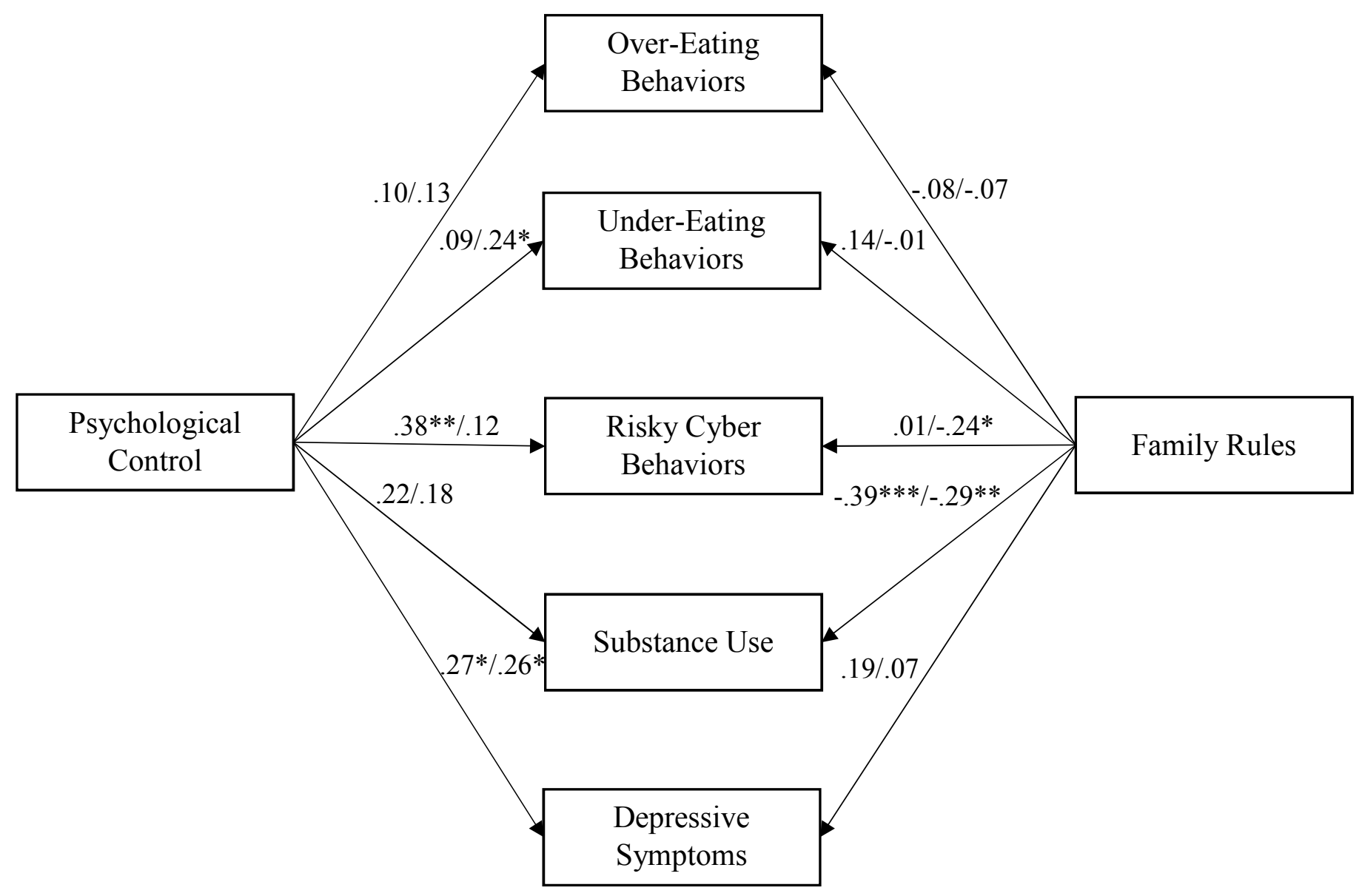

Figure 9. Psychological control and family rules predicting problem behaviors moderated by desired decision-making autonomy. All estimates are standardized coefficients.

Note. Coefficients on the left are for adolescents with lower levels of desired decision-making autonomy. Coefficients on the right are for adolescents with higher levels of desired decisionmaking autonomy.

$* p<.05, * * p<.01, * * * p<.001$ 


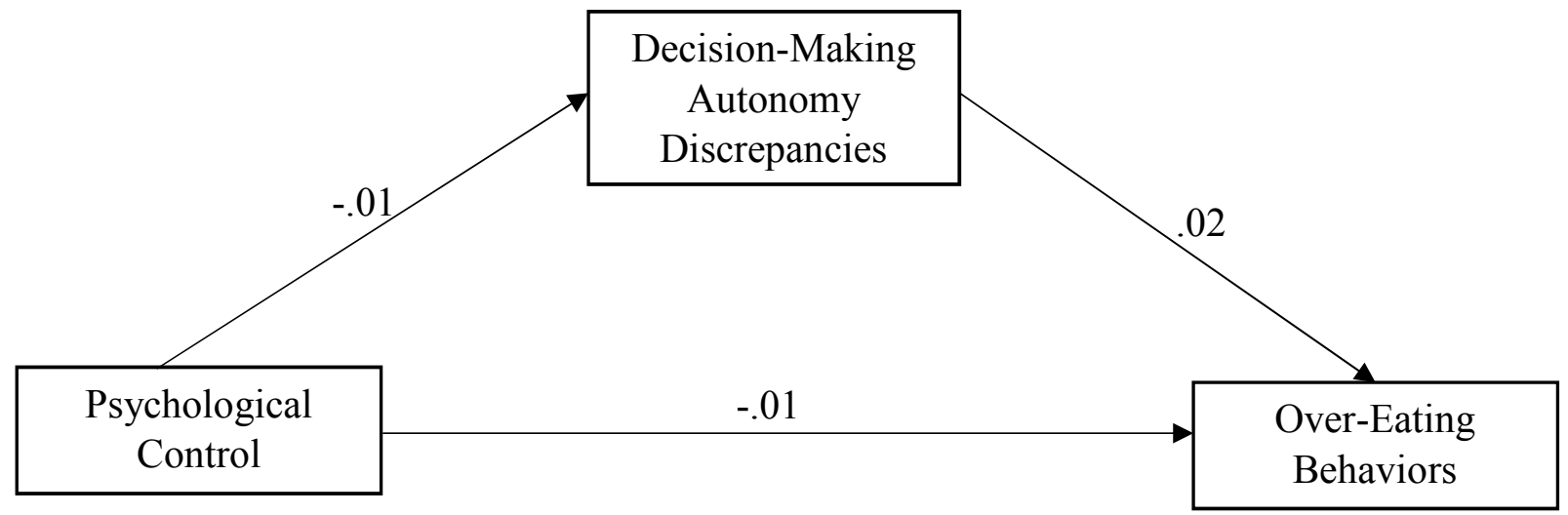

Figure 10a. The indirect effects of psychological control on over-eating behaviors through discrepancies between perceived and desired decision-making autonomy. All estimates are standardized coefficients.

$* p<.05, * * p<.01, * * * p<.001$

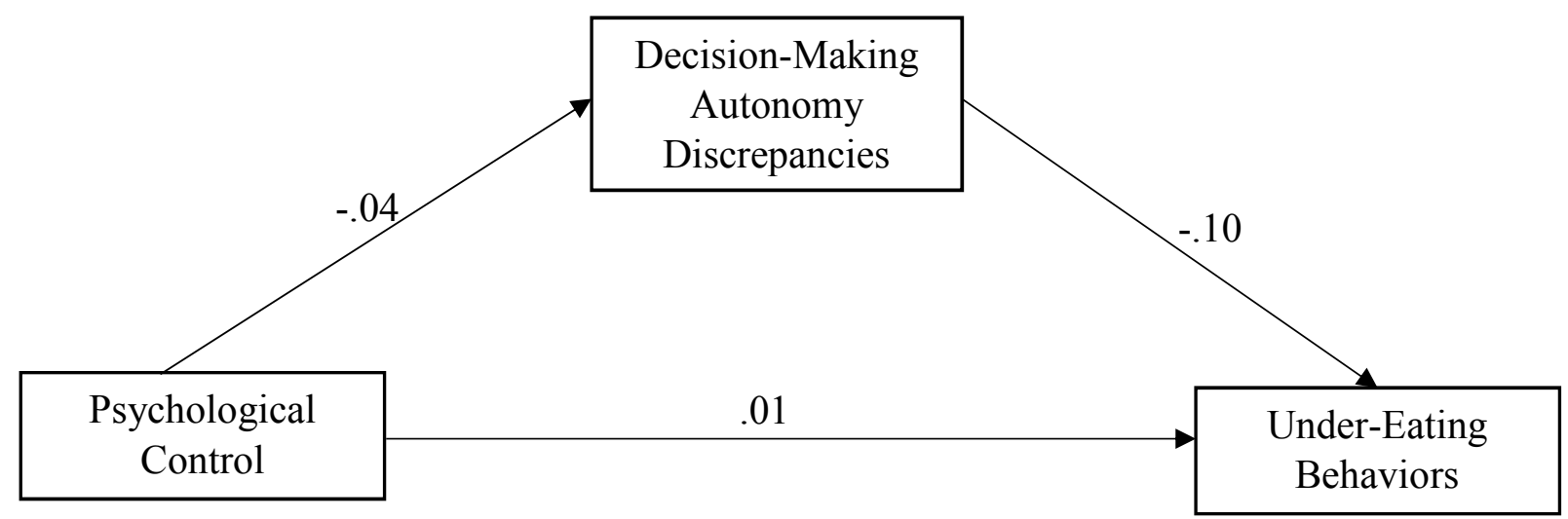

Figure 10b. The indirect effects of psychological control on under-eating behaviors through discrepancies between perceived and desired decision-making autonomy. All estimates are standardized coefficients.

$* p<.05, * * p<.01, * * * p<.001$ 


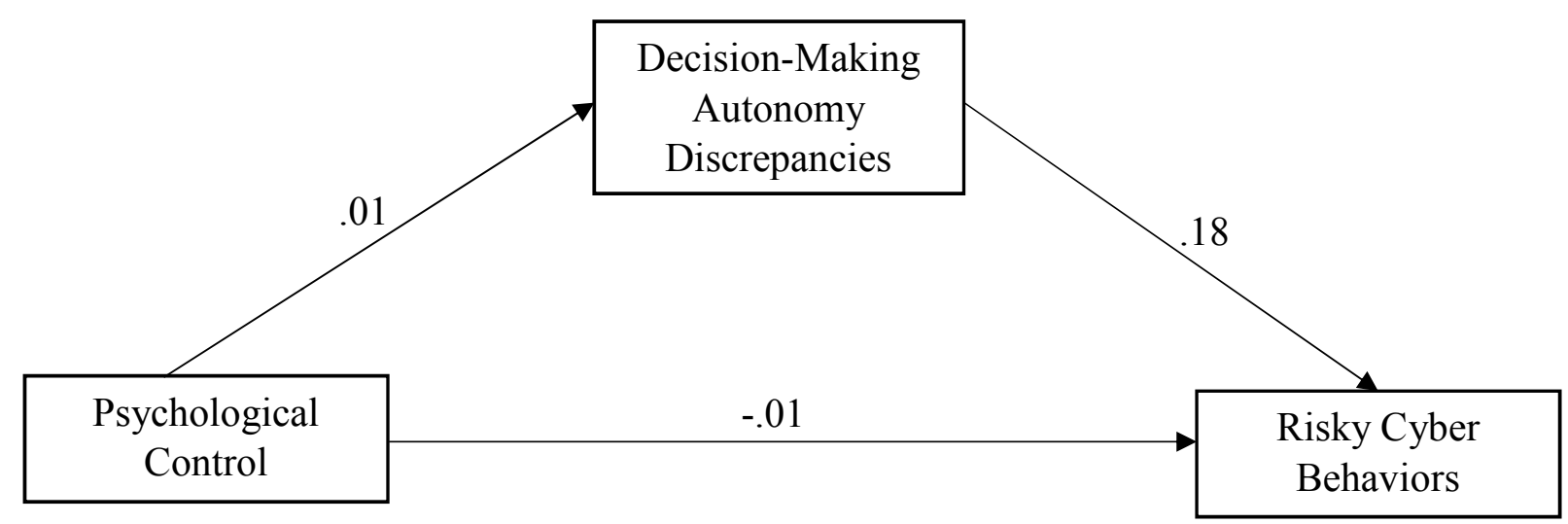

Figure 10c. The indirect effects of psychological control on risky cyber behaviors through discrepancies between perceived and desired decision-making autonomy. All estimates are standardized coefficients.

$* p<.05, * * p<.01, * * * p<.001$

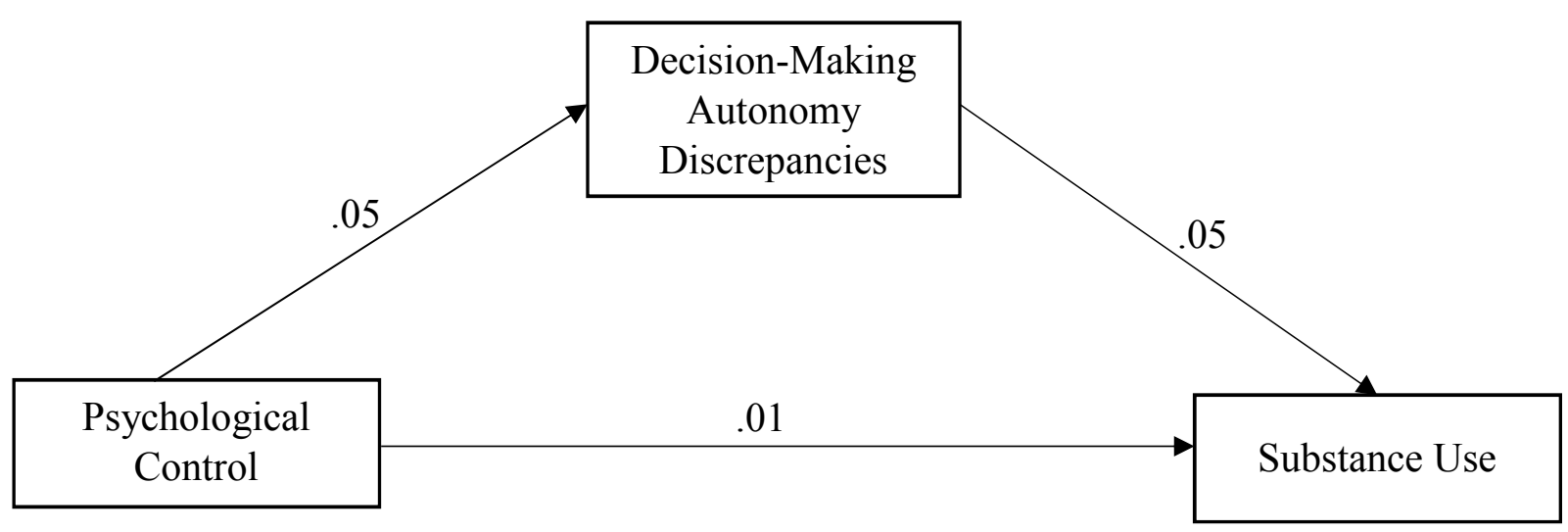

Figure 10d. The indirect effects of psychological control on substance use through discrepancies between perceived and desired decision-making autonomy. All estimates are standardized coefficients.

$* p<.05, * * p<.01, * * * p<.001$ 


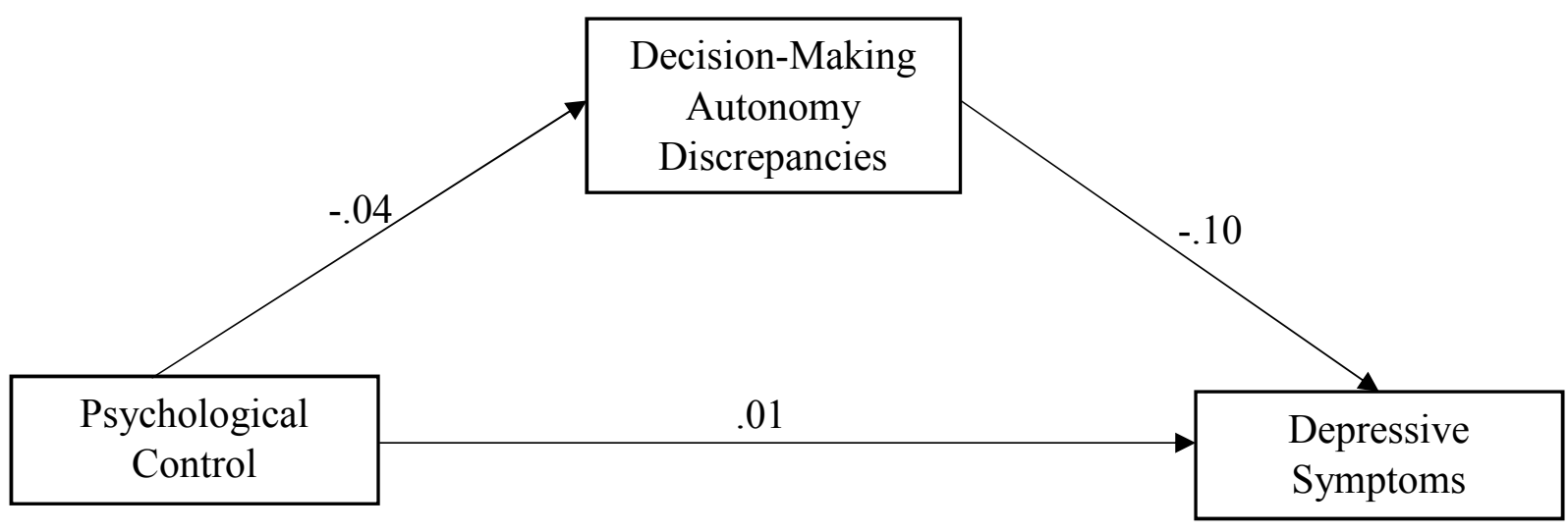

Figure 10e. The indirect effects of psychological control on depressive symptoms through discrepancies between perceived and desired decision-making autonomy. All estimates are standardized coefficients.

${ }^{*} p<.05, * * p<.01, * * * p<.001$ 


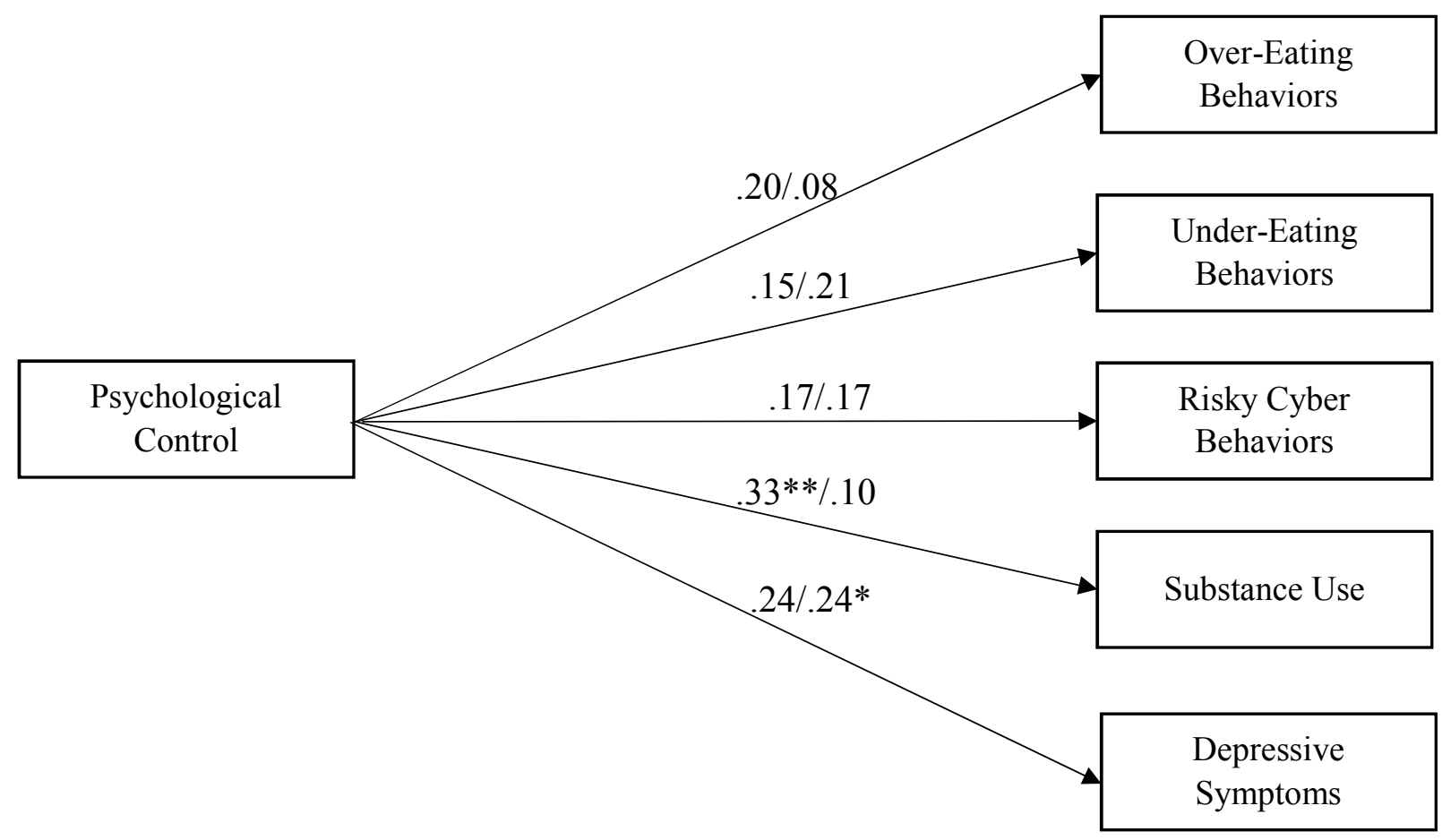

Figure 11. Psychological control predicting problem behaviors moderated by discrepancies between perceived and desired decision-making autonomy. All estimates are standardized coefficients.

Note. Coefficients on the left are for adolescents with negative discrepancies. Coefficients on the right are for adolescents with positive discrepancies.

$* p<.05, * * p<.01, * * * p<.001$ 


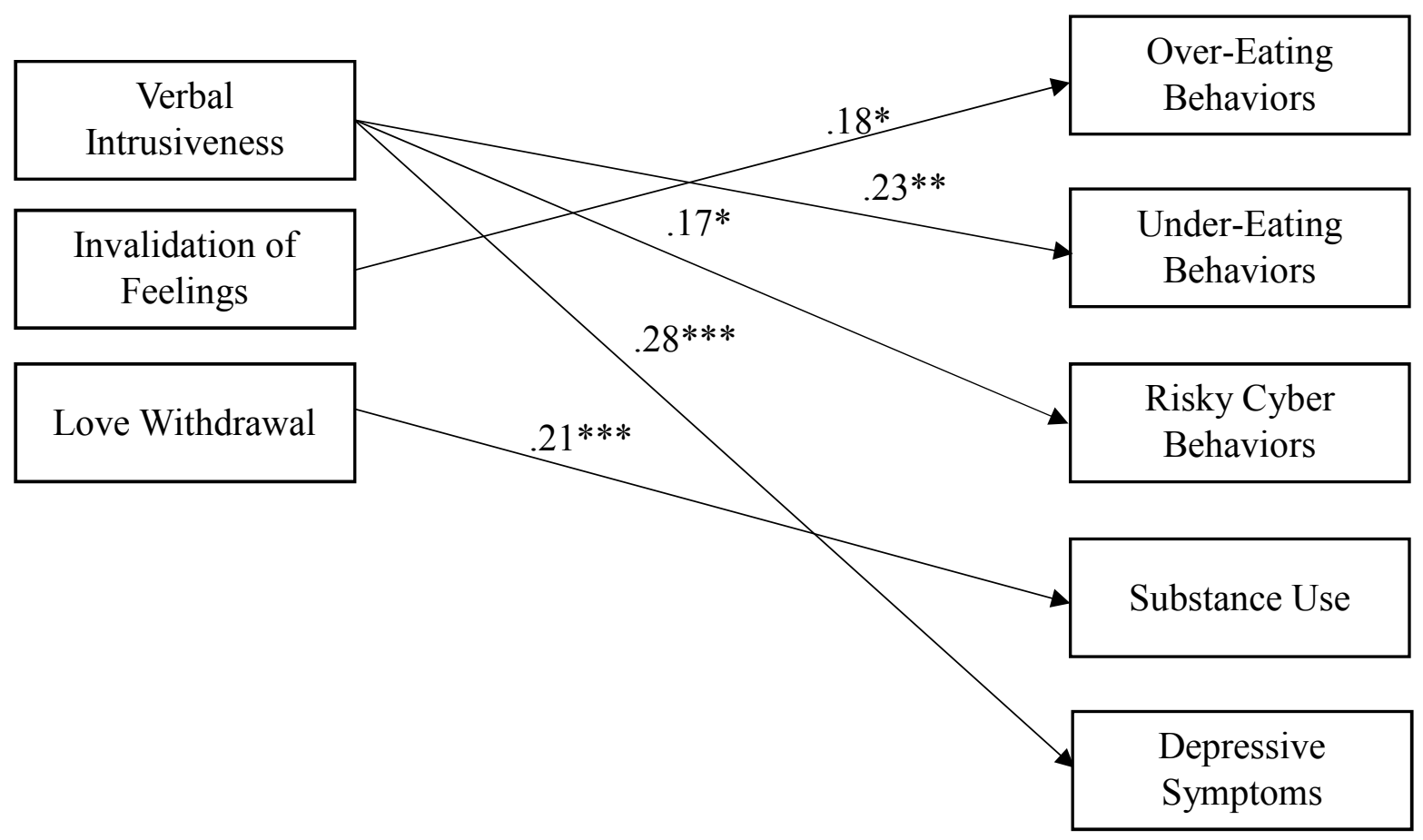

Figure 12. Structural model of the associations between components of psychological control and problematic outcomes. All estimates are standardized coefficients.

$* p<.05, * * p<.01, * * * p<.001$ 


\section{References}

Alexander, A., Kang, S., \& Kim, Y. (2006). Cyberkids: The influence of mediation and motivation on children's use of and attitudes toward the internet. In L. H. Turner \& R. L. West (Eds.), The family communication sourcebook (pp. 315-334). Thousand Oaks, CA: Sage Publications.

Allen, J. P., Hauser, S. T., Eickholt, C., Bell, K. L., \& O’Connor, T. G. (1994). Autonomy and relatedness in family interactions as predictors of expressions of negative adolescent affect. Journal of Research on Adolescence, 4, 535-552. http://dx.doi.org/10.120 /s15327797jra0404_6

Allen, J. P., Hauser, S. T., O'Connor, T. G., \& Bell, K. L. (2002). Prediction of peer-rated adult hostility from autonomy struggles in adolescent-family interactions. Development and Psychopathology, 14, 123-137. http://dx.doi.org/10.1017/S0954579402001074

Allen, J. P., Hauser, S. T., O’Connor, T. G., Bell, K. L., \& Eickholt, C. (1996). The connection of observed hostile family conflict to adolescents' developing autonomy and relatedness with parents. Development and Psychopathology, 8, 425-442. http://dx.doi.org/10.1017/S0954579400007173

Aquilino, W. S., \& Supple, A. J. (2001). Long-term effects of parenting practices during adolescence on well-being outcomes in young adulthood. Journal of Family Issues, 22, 289-308. http://dx.doi.org/10.1177/019251301022003002

Barber, B. K., \& Harmon, E. L. (2002). Violating the self: Parental psychological control and youth problem behavior. In B. K. Barber (Ed.), Intrusive parenting: How psychological control affects children and adolescents (pp. 53-96). Washington, DC: American Psychological Association. 
Barber, B. K., \& Olsen, J. A. (1997). Socialization in context: Connection, regulation, and autonomy in the family, school, and neighborhood, and with peers. Journal of Adolescent Research, 12, 287-315. http://dx.doi.org/10.1177/0743554897122008

Blos, P. (1967). The second individuation process of adolescence. Psychoanalytic Study of the Child, 22, 162-186. Retrieved from http://www.psotc.com/

Daddis, C., \& Smetana, J. (2005). Middle-class African American families' expectations for adolescents' behavioral autonomy. International Journal of Behavioral Development, 29, 371-381. http://dx.doi.org/10.1080/01650250500167053

Dishion, T. J., \& McMahon, R. J. (1998). Parental monitoring and the prevention of child and adolescent problem behavior: A conceptual and empirical formulation. Clinical Child and Family Psychology Review, 1, 61-75. http://dx.doi.org/10 $.1023 / \mathrm{A}: 1021800432380$

Dornbusch, S. M., Ritter, P. L., Mont-Reynaud, R., \& Chen, Z.-y. (1990). Family decision making and academic performance in a diverse high school population. Journal of Adolescent Research, 5, 143-160. http://dx.doi.org/10.1177/074355489052003

Douvan, E., \& Adelson, J. (1966). The adolescent experience. New York: Wiley. Eccles, J. S., Buchanan, C. M., Flanagan, C., Fuligni, A., Midgley, C., \& Yee, D. (1991). Control versus autonomy during early adolescence. Journal of Social Issues, 47, 53-68. http://dx.doi.org/10.1111/j.1540-4560.1991.tb01834.x

Elliot, A. J., \& Thrash, T. M. (2004). The intergenerational transmission of fear of failure. Personality and Social Psychology Bulletin, 30, 957-971. http://dx.doi.org/10.1177 $/ 0146167203262024$ 
Faul, F., Erdfelder, E., Lang, A.-G., \& Buchner, A. (2007). G*Power 3: A flexible statistical power analysis for the social, behavioral, and biomedical sciences. Behavior Research Methods, 39, 175-191. http://dx.doi.org/10.3758/BF03193146

Feldman, S. S., \& Wood, D. N. (1994). Parents' expectations for preadolescent sons' behavioral autonomy: A longitudinal study of correlates and outcomes. Journal of Research on Adolescence, 4, 45-70. http://dx.doi.org/10.1207/s15327795jra0401_4

Freud, A. (1969). Adolescence as a developmental disturbance. In G. Caplan \& S. Lebovici (Eds.), Adolescence (pp. 5-10). New York: Basic Books.

Galambos, N. L., Barker, E. T., \& Almeida, D. M. (2003). Parents do matter: Trajectories of change in externalizing and internalizing problems in early adolescence. Child Development, 74, 578-594. http://dx.doi.org/10.1111/1467-8624.7402017

Gecas, V., \& Schwalbe, M. L. (1986). Parental behavior and adolescent self-esteem. Journal of Marriage and the Family, 48, 37-46. http://dx.doi.org/10.2307/352226

Grotevant, H. D., \& Cooper, C. R. (1985). Patterns of interaction in family relationships and the development of identity exploration in adolescence. Child Development, 56, 415-428. http://dx.doi.org/10.111/j.1467-8624.1985.tb00116.x

Hare, A. L., Szwedo, D. E., Schad, M. M., \& Allen, J. P. (2014). Undermining adolescent autonomy with parents and peers: The enduring implications of psychologically controlling parenting. Journal of Research on Adolescence, 25, 739-752. http://dx.doi . org/10.1111/jora.12167

Hauser, S., Powers, S. I., Noam, G., Jacobson, A., Weiss, B., \& Follansbee, D. (1984). Familial contexts of adolescent ego development. Child Development, 55, 195-213. http://dx.doi .org/10.1111/j.1467-8624.1984.tb.00284.x 
Holmbeck, G. N., \& O’Donnell, K. (1991). Discrepancies between perceptions of decision making and behavioral autonomy. New Directions for Child Development, 51, 51-69. http://dx.doi.org/10.1002/cd.23219915105

Hunter, S. B., Barber, B. K., \& Stolz, H. E. (2014). Extending knowledge of parents' role in adolescent development: The mediating effect of self-esteem. Journal of Child and Family Studies. Advance online publication. http://dx.doi.org/10.1007/s10826-014-0050 $-1$

Kobak, R. R., Sudler, N., \& Gamble, W. (1991). Attachment and depressive symptoms during adolescence: A developmental pathways analysis. Development and Psychopathology, 3, 461-474. http://dx.doi.org/10.1017/S095457940000763X

Lamborn, S. D., Dornbusch, S. M., \& Steinberg, L. (1996). Ethnicity and community context as moderators of the relations between family decision making and adolescent adjustment. Child Development, 67, 283-301. http://dx.doi.org/10.1111/j.1467-8624 .1996.tb01734.x

Lamborn, S. D., \& Steinberg, L. (1993). Emotional autonomy redux: Revisiting Ryan and Lynch. Child Development, 64, 482-499. http://dx.doi.org/10.1111/j.1467-8624.1993 .tb02923.x

Maccoby, E. E. (1984). Socialization and developmental change. Child Development, 55, $317-$ 328. http://dx.doi.org/10.2307/1129945

McElhaney, K., Allen, J., Stephenson, J., \& Hare, A. (2009). Attachment and autonomy during adolescence. In R. M. Lerner, \& L. Steinberg (Eds.), Handbook of adolescent psychology, vol. 1: Individual bases of adolescent development (3rd ed., pp. 358-403). Hoboken, NJ: John Wiley. 
Noom, M. J., Dekovic, M., \& Meeus, W. H. J. (1999). Autonomy, attachment, and psychosocial adjustment during adolescence: A double-edged sword? Journal of Adolescence, 22, 771-783. http://dx.doi.org/10.1006/jado.1999.0269

Nucci, L., \& Smetana, J. G. (1996). Mothers' conceptions of young children's areas of personal freedoms. Child Development, 67, 1870-1876. http://dx.doi.org/10.1111 /j.1467-8624.1996.tb01833.x

Reilly, E. E., Stey, P., \& Lapsley, D. K. (2015). A new look at the links between perceived Parenting, socially-prescribed perfectionism, and disordered eating. Personality and Individual Differences, 88, 17-20. http://dx.doi.org/ 10.1016/j.paid.2015.08.038

Rogers, K. N., Buchanan, C. M., \& Winchell, M. E. (2003). Psychological control during early adolescence: Links to adjustment in differing parent/adolescent dyads. Journal of Early Adolescence, 23, 349-383. http://dx.doi.org/10.1177/0272431603258344

Smetana, J.G. (1995). Context, conflict, and constraint in parent-adolescent authority relationships. In M. Killen \& D. Hart (Eds.). Morality in everyday life: Developmental perspectives (pp. 225-255). Cambridge, MA: Cambridge University.

Smetana, J. G. (2011). Adolescents' social reasoning and relationships with parents: Conflicts and coordinations within and across domains. In E. Amsel \& J Smetana (Eds.), Adolescent Vulnerabilities and Opportunities: Constructivist and Developmental Perspectives (pp. 139-158). New York, NY: Cambridge University.

Smetana, J. G., Campione-Barr, N., \& Daddis, C. (2004). Longitudinal development of family decision making: Defining healthy behavioral autonomy for middle-class African American adolescents. Child Development, 75, 1418-1434. http://dx.doi.org/0009-3920 /2004/7505-0008 
Smetana, J.G., Crean, H.F., \& Daddis, C. (2002). Family processes and problem behaviors in middle-class African American Adolescents. Journal of Research on Adolescence, 12, 275-304. http://dx.doi.org/10.1111/1532-7795.00034

Smetana, J. G., Campione-Barr, N., \& Metzger, A. (2006). Adolescent development in interpersonal and societal contexts. Annual Review of Psychology, 57, 255-284. http://dx.doi.org/10.1146/annurev.psych.57.102904.190124

Smetana, J. G., \& Daddis, C. (2002). Domain-specific antecedent of parental psychological control and monitoring: The role of parenting beliefs and practices. Child Development, 73, 563-580. http://dx.doi.org/10.1111/1467-8624.00424

Soenens, B., Vansteenkiste, M., Luyten, P., Duriez, B., \& Goossens, L. (2004). Maladaptive perfectionistic self-representations: The meditational link between psychological control and adjustment. Personality and Individual Differences, 38, 487-498. http://dx.doi.org/10.1016/j.paid.2004.05.008

Soenens, B., Vansteenkiste, M., \& Niemiec, C. P. (2009). Should parental prohibition of adolescents' peer relationships be prohibited? The role of parental autonomy, support and control. Personal Relationships, 16, 507-530. http://dx.doi.org /10.1111/j.1475-6811.2009.01237.x

Steinberg, L. (1990). Autonomy, conflict, and harmony in the family relationship. In S. S. Feldman \& G. R. Elliot (Eds.), At the threshold: The developing adolescent (pp. 255-276). Cambridge, MA: Harvard University. 
Vansteenkiste, M., Zhou, M., Lens, W., \& Soenens, B. (2005). Experiences of autonomy and control among Chinese learners: Vitalizing or immobilizing? Journal of Educational Psychology, 97, 468-483. http://dx.doi.org/10.1037/0022-0663.97 .3 .468

Weber, E. U., Blais, A. R., \& Betz, N. E. (2002). A domain-specific risk-attitude scale: measuring risk perceptions and risk behaviors. Journal of Behavioral Decision Making, 15, 263-290. http://dx.doi.org/10.1002/bdm.414

Zimmer-Gembeck, M. J., \& Collins, W. A. (2003). Autonomy development during adolescence. In G. R. Adams \& M. D. Berzonsky (Eds.), Blackwell Handbook of Adolescence (pp.175-204). Oxford, UK: Blackwell. 


\section{Appendix M}

\section{Parental Restrictive Control Questionnaire}

Now, circle the number that best decides who in your family makes most of the decisions about each of the topics below, using the following scale:

1. I decide this without discussing it with my parent(s) or guardian(s).

2. I make the final decision after discussing it with my parent(s) or guardian(s).

3. My parent(s) and I make the decision together.

4. My parent(s) make the final decision after discussing it with me.

5. My parent(s) decide this without discussing it with me.

\begin{tabular}{|c|c|c|c|c|c|}
\hline & $\begin{array}{l}\text { Child } \\
\text { decides }\end{array}$ & $\begin{array}{l}\text { Mainly } \\
\text { child }\end{array}$ & $\begin{array}{l}\text { Decide } \\
\text { together }\end{array}$ & $\begin{array}{l}\text { Mainly } \\
\text { parent }\end{array}$ & $\begin{array}{l}\text { Parent } \\
\text { decides }\end{array}$ \\
\hline 1. Whether I can smoke cigarettes & 1 & 2 & 3 & 4 & 5 \\
\hline 2. When I am old enough to have sex & 1 & 2 & 3 & 4 & 5 \\
\hline 3. Whether I can do drugs & 1 & 2 & 3 & 4 & 5 \\
\hline 4. How long I am allowed to be online & 1 & 2 & 3 & 4 & 5 \\
\hline 5. What I eat while at home & 1 & 2 & 3 & 4 & 5 \\
\hline 6. What I eat while away from home & 1 & 2 & 3 & 4 & 5 \\
\hline 7. What foods are bought for meals at home & 1 & 2 & 3 & 4 & 5 \\
\hline 8. If I eat "junk food" & 1 & 2 & 3 & 4 & 5 \\
\hline 9. Who I like or have a crush on & 1 & 2 & 3 & 4 & 5 \\
\hline $\begin{array}{l}\text { 10. What I talk about on the phone with } \\
\text { friends }\end{array}$ & 1 & 2 & 3 & 4 & 5 \\
\hline 11. How I spend my own money & 1 & 2 & 3 & 4 & 5 \\
\hline $\begin{array}{l}\text { 12. Getting bad grades or not doing well on a } \\
\text { test }\end{array}$ & 1 & 2 & 3 & 4 & 5 \\
\hline $\begin{array}{l}\text { 13. The grades I get in different school } \\
\text { subjects }\end{array}$ & 1 & 2 & 3 & 4 & 5 \\
\hline $\begin{array}{l}\text { 14. Getting a good grade or score on an } \\
\text { assignment or test }\end{array}$ & 1 & 2 & 3 & 4 & 5 \\
\hline $\begin{array}{l}\text { 15. Spending time with someone my parents } \\
\text { don't like }\end{array}$ & 1 & 2 & 3 & 4 & 5 \\
\hline $\begin{array}{l}\text { 16. Hanging out at a friend's house when no } \\
\text { adult is home }\end{array}$ & 1 & 2 & 3 & 4 & 5 \\
\hline 17. If or who I am dating & 1 & 2 & 3 & 4 & 5 \\
\hline 18. If I try drinking alcohol with friends & 1 & 2 & 3 & 4 & 5 \\
\hline 19. If I drink too much alcohol or get drunk & 1 & 2 & 3 & 4 & 5 \\
\hline 20. If I attend a party where alcohol is served & 1 & 2 & 3 & 4 & 5 \\
\hline 21. The types of websites I visit online & 1 & 2 & 3 & 4 & 5 \\
\hline $\begin{array}{l}\text { 22. The types of pictures and comments I put } \\
\text { on my social networking site (FACEBOOK) }\end{array}$ & 1 & 2 & 3 & 4 & 5 \\
\hline 23. Who I talk to online & 1 & 2 & 3 & 4 & 5 \\
\hline 24. Whether I am dieting or trying to lose & 1 & 2 & 3 & 4 & 5 \\
\hline
\end{tabular}




\begin{tabular}{|l|l|l|l|l|l|}
\hline weight (stop eating when you are hungry) & & & & & \\
\hline 25. If I eat snacks between meals & 1 & 2 & 3 & 4 & 5 \\
\hline 26. Whether I continue to eat after I am full & 1 & 2 & 3 & 4 & 5 \\
\hline $\begin{array}{l}\text { 27. The types of text messages I am allowed to } \\
\text { send out on my cell phone }\end{array}$ & 1 & 2 & 3 & 4 & 5 \\
\hline
\end{tabular}

Below are listed several topics that adolescents and their parents often have to make decisions about. Who do you think should make the decision on each topic?

1.My parent(s) should be able to decide this without discussing it with me.

2. My parent(s) should be able to make the final decision about this after discussing it with me.

3. My parent(s) and I should make this decision together.

4.I should make the final decision on this after discussing it with my parent(s).

5.I should be the one to decide this without having to discuss it with my parent(s).

\begin{tabular}{|l|c|c|c|c|c|}
\hline Who SHOULD decide? & $\begin{array}{c}\text { My } \\
\text { parent } \\
\text { should } \\
\text { decide } \\
\text { without } \\
\text { me }\end{array}$ & $\begin{array}{c}\text { My } \\
\text { parent } \\
\text { should } \\
\text { decide } \\
\text { with } \\
\text { my } \\
\text { help }\end{array}$ & $\begin{array}{c}\text { We } \\
\text { should } \\
\text { decide } \\
\text { together }\end{array}$ & $\begin{array}{c}\text { I } \\
\text { should } \\
\text { decide } \\
\text { with } \\
\text { my } \\
\text { parents } \\
\text { help }\end{array}$ & $\begin{array}{c}\text { I } \\
\text { should } \\
\text { decide } \\
\text { by } \\
\text { myself }\end{array}$ \\
\hline 1. Whether I can smoke cigarettes? & 1 & 2 & 3 & 4 & 5 \\
\hline 2. When I am old enough to have sex? & 1 & 2 & 3 & 4 & 5 \\
\hline 3. Whether I can do drugs? & 1 & 2 & 3 & 4 & 5 \\
\hline 4. How long I am allowed to be online? & 1 & 2 & 3 & 4 & 5 \\
\hline 5. What I eat while at home & 1 & 2 & 3 & 4 & 5 \\
\hline 6. What I eat while away from home & 1 & 2 & 3 & 4 & 5 \\
\hline 7. What foods are bought for meals at home & 1 & 2 & 3 & 4 & 5 \\
\hline 8. If I eat "junk food" & 1 & 2 & 3 & 4 & 5 \\
\hline 9. Who teens like or have a crush on & 1 & 2 & 3 & 4 & 5 \\
\hline $\begin{array}{l}\text { 10. What teens talk about on the phone with } \\
\text { friends }\end{array}$ & 1 & 2 & 3 & 4 & 5 \\
\hline 11. How teens spend their own money & 1 & 2 & 3 & 4 & 5 \\
\hline $\begin{array}{l}\text { 12. Getting bad grades or not doing well on a } \\
\text { test }\end{array}$ & 1 & 2 & 3 & 4 & 5 \\
\hline $\begin{array}{l}\text { 13. The grades I get in different school } \\
\text { subjects }\end{array}$ & 1 & 2 & 3 & 4 & 5 \\
\hline $\begin{array}{l}\text { 14. Getting a good grade or score on an } \\
\text { assignment or test }\end{array}$ & 1 & 2 & 3 & 4 & 5 \\
\hline $\begin{array}{l}\text { 15. Spending time with someone my parents } \\
\text { don't like }\end{array}$ & 1 & 2 & 3 & 4 & 5 \\
\hline
\end{tabular}




\begin{tabular}{|l|c|c|c|c|c|}
\hline $\begin{array}{l}\text { 16. Hanging out at a friend's house when no } \\
\text { adult is home }\end{array}$ & 1 & 2 & 3 & 4 & 5 \\
\hline 17. If or who I am dating & 1 & 2 & 3 & 4 & 5 \\
\hline 18. If I try drinking alcohol with friends & 1 & 2 & 3 & 4 & 5 \\
\hline 19. If I drink too much alcohol or get drunk & 1 & 2 & 3 & 4 & 5 \\
\hline 20. If I attend a party where alcohol is served & 1 & 2 & 3 & 4 & 5 \\
\hline 21. The types of websites I visit online & 1 & 2 & 3 & 4 & 5 \\
\hline $\begin{array}{l}\text { 22. The types of pictures and comments I put } \\
\text { on my social networking site (FACEBOOK) }\end{array}$ & 1 & 2 & 3 & 4 & 5 \\
\hline 23. Who I talk to online & 1 & 2 & 3 & 4 & 5 \\
\hline $\begin{array}{l}\text { 24. Whether I am dieting or trying to lose } \\
\text { weight (stop eating when you are hungry) }\end{array}$ & 1 & 2 & 3 & 4 & 5 \\
\hline 25. If I eat snacks between meals & 1 & 2 & 3 & 4 & 5 \\
\hline 26. Whether I continue to eat after I am full & 1 & 2 & 3 & 4 & 5 \\
\hline $\begin{array}{l}\text { 27. The types of text messages I am allowed } \\
\text { to send out on my cell phone }\end{array}$ & 1 & 2 & 3 & 4 & 5 \\
\hline
\end{tabular}


